\title{
Modern Methods of Sample Preparation for GC Analysis
}

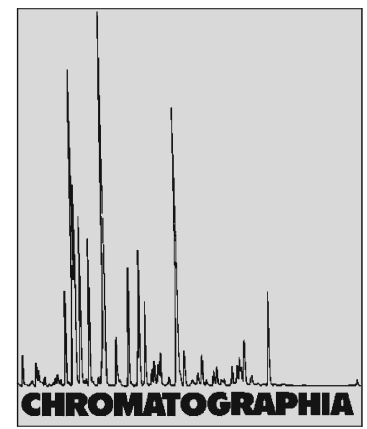

2009, 69, S33-S78

\section{Sjaak de Koning ${ }^{1, \bowtie}$, Hans-Gerd Janssen ${ }^{2,3}$, Udo A. Th. Brinkman ${ }^{4}$}

${ }^{1}$ LECO Instrumente, Department of Separation Science, Marie-Bernays-Ring 31, 41199 Mönchengladbach, Germany; E-Mail: Sjaak.dekoning@leco.de

2 Unilever Research and Development, Advanced Measurement and Imaging, P.O. Box 114, 3130 AC Vlaardingen, The Netherlands

${ }^{3}$ Van 't Hoff Institute for Molecular Sciences, University of Amsterdam, Nieuwe Achtergracht 166, 1018 WV Amsterdam, The Netherlands

${ }^{4}$ Department of Analytical Chemistry and Applied Spectroscopy, Free University, de Boelelaan 1083, 1081 HV Amsterdam, The Netherlands

\begin{abstract}
Today, a wide variety of techniques is available for the preparation of (semi-) solid, liquid and gaseous samples, prior to their instrumental analysis by means of capillary gas chromatography $(G C)$ or, increasingly, comprehensive two-dimensional GC (GC $\times G C)$. In the past two decades, a large number of 'modern' sample-preparation techniques has been introduced, which have partly superseded their 'classical' counterparts. These novel techniques include off-line and on-line (sometimes semi- or fully automated) procedures, and exhaustive extraction as well as equilibrium techniques. In order to improve overall performance, aspects such as essentially organic solvent-less approaches, large-volume injection and miniaturization receive increasing attention. In most recent applications, mass spectrometric or element-selective detection have been used. The present review discusses the advantages and disadvantages, and relative performance, of most of the modern samplepreparation techniques and cites a number of illustrative applications for each of them.
\end{abstract}

\section{Keywords}

Gas chromatography

Sample preparation

\section{Introduction}

In the past 30 years, sample preparation/pre-treatment prior to chromatographic analysis has risen from near-obscurity to the prominent place it now holds in most studies on the trace-level determination of organic micro-contaminants in real-life samples. Traditionally, sample preparation is stated to be necessary for several reasons:
- improvement of the chromatographic behaviour of the analyte(s),

- improvement of detectability of the analyte(s), or

- isolation of the analyte(s) from the matrix.

Today, the first aim has become relatively unimportant because of both the quality of column packings in gas (GC) as well as column-liquid (LC) chromatography and the essential superfluousness of derivatizing or labelling polar analytes to allow their determination by means of GC. The other two aims, viz. improved detectability and efficient separation from interfering sample constituents, are, however; as important as they were several decades ago. Over the years, it has increasingly been realized that, in many cases, sample preparation is the most time-consuming, tedious and error-prone step of the total analytical procedure. In addition, sample preparation often cannot easily be coupled on-line (or at-line) with the subsequent instrumental separation-plus-detection step, thereby making automation of sample preparation (but without sample pre-treatment; see Fig. 1 below) plus GC analysis essentially impossible. Moreover, it frequently 


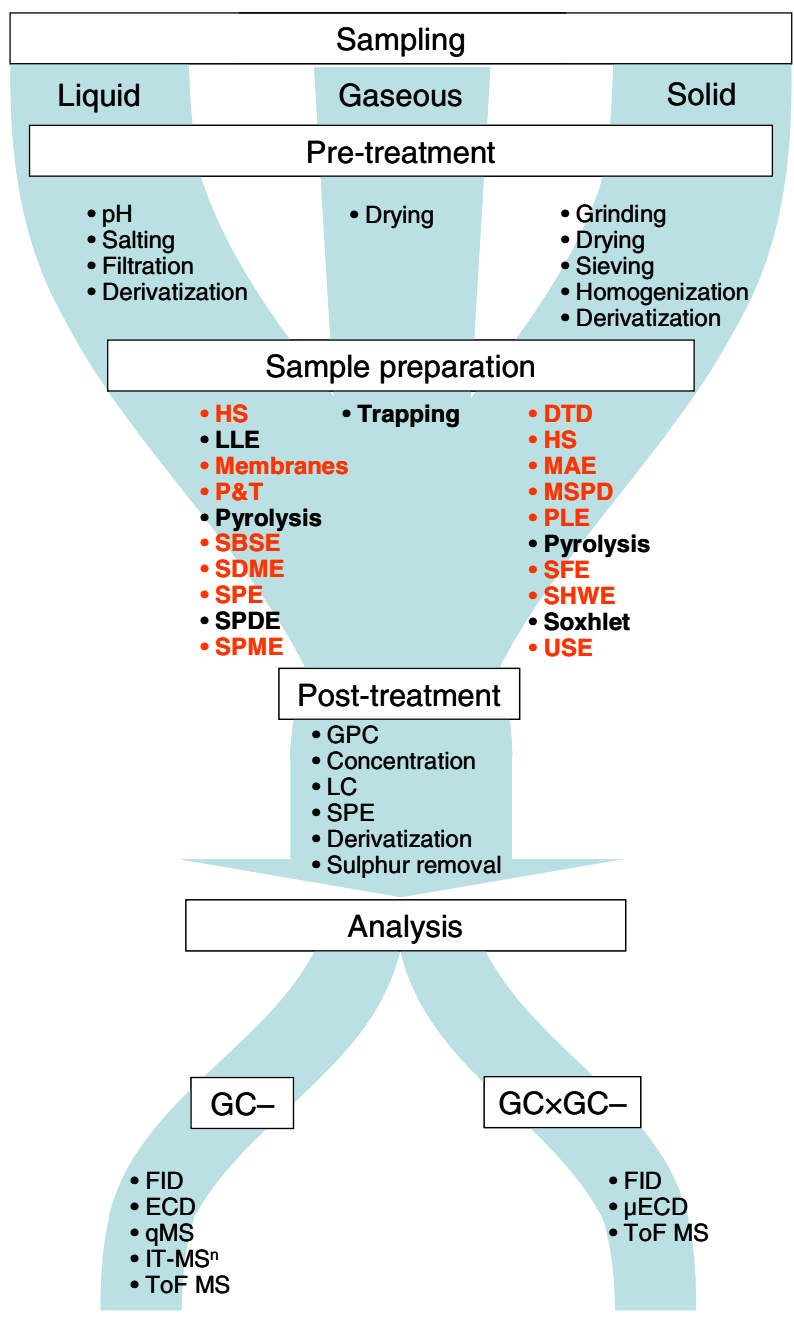

Fig. 1. Typical strategies for the GC determination of organic micro-contaminants in liquid, gaseous and solid samples. See Glossary for acronyms

adversely affects the overall performance of an analysis through effects such as loss and/or decomposition of target analytes, and introduction of extraneous contaminants. Such effects self-evidently have become more serious in recent years, with (inter)national directives and guidelines continually demanding improved performance - that is, reliable detection, identification and quantification at ever lower analyte concentrations.

Over the years, many groups of workers have attempted to improve the situation by designing new sample-preparation techniques (somewhat loosely called modern sample-preparation methods by most authors) to replace traditional methods such as Soxhlet, liquid-liquid (LLE) and ambient-pres- sure solid-liquid extraction-where one should immediately add that the former two methods are still widely used today, specifically in routine applications and, in the case of Soxhlet extraction, for reference purposes. The modern samplepreparation techniques range from highly selective methods to be used for one, or a few, target analyte(s) of special interest to wide-ranging, and usually rather nonselective procedures primarily meant for screening purposes, i.e., for target analytes as well as unknowns. Many methods can be made part of on-line (and, thus, automatable) systems, while others typically are off-line procedures. To enable their implementation, suitable sorbents, chemicals, membranes, low-dead-volume connections, cartridges, mini-columns, disks, etc., have been synthesized and/or designed and, whenever required, instrumentation and ancillary equipment was constructed and, frequently, commercialized. Over the years, a variety of applications for widely different analyte/ matrix combinations have been published to demonstrate the practicality of the various approaches. Attention has been devoted, e.g., to designing integrated analytical systems, to miniaturization and to adequately matching the samplepreparation and instrumental-analysis time. The main aims were, and still are, to increase sample throughput, improve the overall quality of the sample-preparation procedures, and decrease the required sample sizes and/or the use of organic solvents and sorbents, and the amount of waste.

One more aspect of interest should be mentioned here, that of improving detection limits. In the past ten to fifteen years, there has been an increasing, and fully justified, emphasis on the proper identification and/or identity confirmation of all analytes of interest in each sample. As a consequence, quadrupole- or ion-trap-based massspectrometric (MS) detection is the stateof-the-art approach today for a large majority of all challenging analytical procedures. The overriding importance of MS detection will readily become apparent from the many tables included in the Applications section of this review. Even element-selective detection only plays a modest role today. Its most prominent application areas are the trace-level determination of organochlorine (and -bromine) micro-contaminants by GC with electron-capture detection, and the selective screening of organo-sulphur compounds by GC with S-based chemiluminescence detection.

Today, a wide variety of analytical methods is available for the GC determination of organic micro-contaminants in sample types such as air, water and other liquid samples, soils and sediments, fish and food, and biota. A typical schematic which displays most of the more important routes is shown in Fig. 1. In the present review, we focus on the sample-preparation step-with examples primarily relating to liquid and solid samples - and, more specifically, on 
the characteristics of the modern techniques, i.e., those introduced in the past twenty or so years. These are marked in grey (electronic version in red) in the figure. All acronyms used in this figure and throughout the review are summarized in the glossary at the end of this review article. In the sub-sections, each of the separate techniques will be briefly described, and a number of selected applications, strategies and on-going developments will be given to illustrate the merits and demerits of each of these. For each technique, a number of recent reviews and/or other general reference sources will be given; in many cases, these have been used as the backbone of this chapter. Aspects such as spiking and recovery of analytes, and quantification (inclusive of validation and matrix effects) will not be discussed.

\section{Sample Preparation Methods}

\section{Pressurized Liquid and Subcritical Hot-Water Extraction}

Pressurized liquid extraction (PLE) involves extraction with solvents at elevated pressures (up to ca. $20 \mathrm{MPa}$ ) and temperatures (up to ca. $200{ }^{\circ} \mathrm{C}$ ) without their critical point being reached, to achieve rapid and efficient extraction of trace-level analytes from a (semi-) solid matrix. Since its introduction in 1995 [1], PLE, also known as accelerated solvent extraction (ASE) and pressurized fluid extraction (PFE), several reviews have been published [2-5] and the technique has been shown to have significant advantages over competing techniques such as Soxhlet, Soxtec, and microwaveassisted extraction (MAE) extraction: enhanced solubility and mass-transfer effects and the disruption of the surface equilibrium are the main beneficial causes. As a consequence, compared with Soxhlet extraction, both time and solvent consumption are dramatically reduced. Originally, the use of PLE mainly focused on the isolation of organic micro-contaminants from environmental matrices such as soil, sediment and

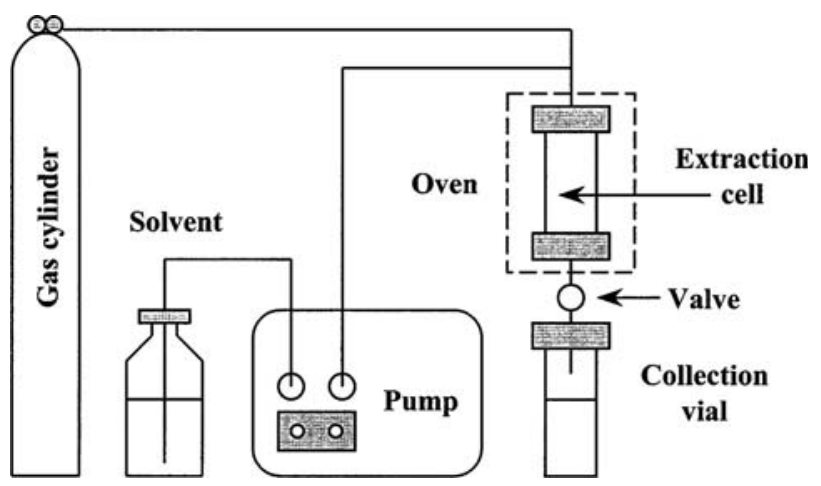

Fig. 2. Schematic representation of a PLE system [7]

sewage sludge $[1,6]$. Today, the technique is also used for the analysis of, e.g., food and biological samples. Instead of an organic solvent, pure water can also be used for extraction. In that case, the technique is usually called subcritical hot-water (SHWE) or pressurized hotwater (PHWE) extraction (see below).

The basic set-up of a PLE instrument is shown in Fig. 2. The system consists of a stainless-steel extraction cell in which the sample is placed; the programmed parameters (temperature and pressure) are kept at their specified values by electronically controlled heaters and pumps. The liquid extract is collected in a vial. The instrument used in most published studies is the ASE 200 (Dionex, Sunnyvale, CA, USA), in which up to 24 samples can be placed in a carrousel; extraction cells of $11-33 \mathrm{~mL}$ are available, and 40- and $60-\mathrm{mL}$ vials for extract collection. Recently, Dionex introduced two new systems, ASE 150 and ASE 350. The former is a single-cell system; the latter enables automated extraction of up to 24 samples. Both systems accommodate seven, 1-100-mL, extraction cells. In several studies, SFE extractors have successfully been used for PLE of a variety of samples [8, 9]. In most cases, PLE is carried out in the static mode: once the sample has been placed in the extraction cell, organic solvent is added and the cell pressurized. After heating to the required temperature, static extraction is carried out for, typically, 5-20 min. Next, the valve is opened and the solvent allowed to flow to the collection vial. Fresh solvent (some $60 \%$ of the cell volume) is added to rinse the system, with a final brief nitrogen purge to guarantee complete removal of the solvent from the system. In the dynamic mode, the solvent (in most applications, water) is continuously pumped through the extraction cell at a constant flow-rate. Dynamic PLE is usually carried out in SFE extractors or in-house constructed devices.

If samples are semi-solid, a uniform distribution over an inert support such as sand prior to packing and completely filing the cell with the mixture are recommended. Recently, Dionex introduced a chemically inert material for samples pre-treated with acids or bases, Dionium. For heterogeneous samples, grinding - frequently to $63-150 \mu \mathrm{m} \mathrm{d}_{\mathrm{p}}$ is recommended. Grinding is anyway beneficial because it will shorten the diffusion pathways and increase the surface area. Drying the sample is important since moisture may diminish the extraction efficiency, specifically when non-polar solvents are used for extraction. If more polar solvents are used to extract wet samples, the drying step becomes less crucial. Finally, filters or glass wool plugs should be inserted at both ends of the extraction cell to prevent blocking of the connective tubing by small particles.

Next to what has been said above, several parameters influencing the PLE process should be briefly discussed. Often, the same solvent as used for conventional, e.g., Soxhlet, extractions is initially tested. It is also important to take into account the compatibility with subsequent steps of the procedure such as extract clean-up or target analyte 
enrichment (actually, during enrichment, a change of solvent can often be effected). Generally speaking, the polarity of the solvent or solvent mixture should be close to that of the target compound(s). When analytes covering a wide range of polarities have to be extracted, mixtures of low- and high-polar solvents generally provide better results than single solvents. Alternatively, two extractions - one with a non-polar, and the second one with a more polar solvent - can be applied [10, 11].

In general, higher temperatures will cause an increase of the PLE efficiency due to enhanced sample wetting, better penetration of the extraction solvent, and higher diffusion and desorption rates of the analytes from the matrix to the solvent. They are therefore recommended provided there are no limitations associated with thermolabile analytes and/or matrices. To quote an example, a temperature of $100{ }^{\circ} \mathrm{C}$ is often selected as 'default value' and used for the PLE of POPs (persistent organic pollutants) from a variety of matrices with different solvents [12], while mixtures containing toluene often require temperatures close to $200{ }^{\circ} \mathrm{C}$ to provide maximum recoveries.

Pressure essentially plays no role other than to keep the extraction solvent liquid at the high temperatures used [1, 12, 13]. However, with wet samples [12] or highly adsorptive matrices [14], a high pressure can help to enhance the PLE efficiency by forcing the organic solvent into the matrix pores. This may explain why little effect of the pressure was observed during PLE of herbicides from dry soils, while in the case of moistened soils increasing the pressure from 4 to $10 \mathrm{MPa}$ was beneficial.

\section{Subcritical Hot-Water Extraction}

SHWE is a PLE-type technique based on the use of water as extraction solvent at temperatures between 100 and $374{ }^{\circ} \mathrm{C}$ (critical point of water, $374{ }^{\circ} \mathrm{C}$ and $22 \mathrm{MPa}$ ) and at pressures sufficient to keep it in the liquid state. Under these conditions, the dielectric constant of water, $\varepsilon$, i.e., its polarity, can be easily and dramatically lowered by increasing the temperature. Pure water at ambient temperature and pressure has an $\varepsilon$ of 79 , while increasing the temperature to $250{ }^{\circ} \mathrm{C}$ at a pressure of $5 \mathrm{MPa}$ effects a significant reduction to about 27 [14]. This value is similar to that of ethanol at $25{ }^{\circ} \mathrm{C}$ and 0.1 MPa and, consequently, low enough to dissolve many mediumpolarity compounds. As with PLE, increasing the temperature at moderate pressure also reduces the surface tension and viscosity of water, which results in an enhanced solubility of the analytes. Since pressure has only a limited influence on the solvent characteristics of water as long as it remains in the liquid state, one can increase the pressure to avoid the formation of steam - which is highly corrosive and can degrade the analytes - at the high temperatures used in SHWE without comprising the achieved decrease of polarity.

One should note that, since water is not a GC-compatible solvent, after SHWE the analytes in the extract must be transferred to a GC-compatible medium, e.g., by liquid-liquid extraction (LLE) [15], or by solid-phase micro extraction (SPME) or stir-bar sorptive extraction (SBSE) [16].

Applications Selected PLE and SHWE applications for the isolation of a wide range of compounds from a variety of matrices are given in Table 1. As an example of a typical PLE-based analysis, Frenich et al. [17] reported the multiresidue analysis of organochloro (OCPs) and organophosphorus pesticides (OPPs) in muscle of chicken, pork and lamb. $5 \mathrm{~g}$ of freeze-died sample were mixed with Hydromatrix and extracted by PLE using ethyl acetate as extraction solvent. After GPC clean-up followed by concentration, $10 \mu \mathrm{L}$ of the final extract were analysed by GC-QqQ-MS; LODs were in the range of $0.02-2 \mu \mathrm{g} \mathrm{kg}^{-1}$. Compared with Soxhlet extraction, PLE was found to yield improved extraction efficiency and precision. Moreover, the extraction time was shorter and the consumption of solvents much lower.

One aspect that merits attention is that, for most applications, PLE/SHWE has to be combined with a clean-up step to remove co-extracted matrix constituents such as, e.g., lipids, pigments or resins. Clean-up procedures typically are the same as used in classical procedures. Recently, several authors used matrix solid-phase dispersion (MSPD) for in situ clean-up in the extraction of trace compounds from a variety of samples: sometimes MSPD conditions (see section on MSPD below) can be selected to retain particular compounds by choosing an appropriate dispersion material/eluent combination. A novel approach for PAHs in soils and sediments is to purify the PLE extract by direct large-volume injection (LVI) in a programmed temperature vaporiser (PTV) equipped with a liner packed with an appropriate sorbent [18]. The PLE efficiencies and performance data compared well with those obtained by 6-h Soxhlet extraction and other conventional procedures [19]. As an example, Fig. 3 shows a $50-\mu \mathrm{L}$ LVIGC-MS trace obtained after miniaturized PLE of only $50 \mathrm{mg}$ of a naturally contaminated organic soil and $100 \mu \mathrm{L}$ of toluene.

As regards SHWE, Richter et al. [15] reported the determination of pesticides in soil using continuous $\operatorname{SHWE}\left(270{ }^{\circ} \mathrm{C}\right.$, 8.2 $\left.\mathrm{MPa}, 2 \mathrm{~mL} \mathrm{~min}^{-1}, 90 \mathrm{~min}\right)$. The pesticides in the aqueous extract were quantitatively transferred by LLE with dichloromethane and injected into a GC-MS system. For the 17 pesticides studied, LODs were $3-140 \mu \mathrm{g} \mathrm{kg}^{-1}$. Comparison with Soxhlet extraction showed the analytical performance to be quite similar. The main advantage of SHWE over Soxhlet extraction was the time involved in the extraction process: SHWE was some 10 times faster. Furthermore, less than $10 \mathrm{~mL}$ of solvent was used compared with $300 \mathrm{~mL}$ for Soxhlet extraction.

Several applications involving on-line coupling of SHWE with GC have been reported (e.g., [20, 21]). On-line coupling of SHWE with GC is simpler than coupling of PLE, because the aqueous solubility of the analytes decreases dramatically when the water is cooled to ambient temperature. Trapping of the extract on, e.g., a solid-phase trap is thus relatively easy. Using a somewhat different approach, Lüthje et al. [20] analysed pesticides in grapes by SHWEmicroporous membrane liquid-liquid extraction (MMLLE)-GC-MS. Grape 


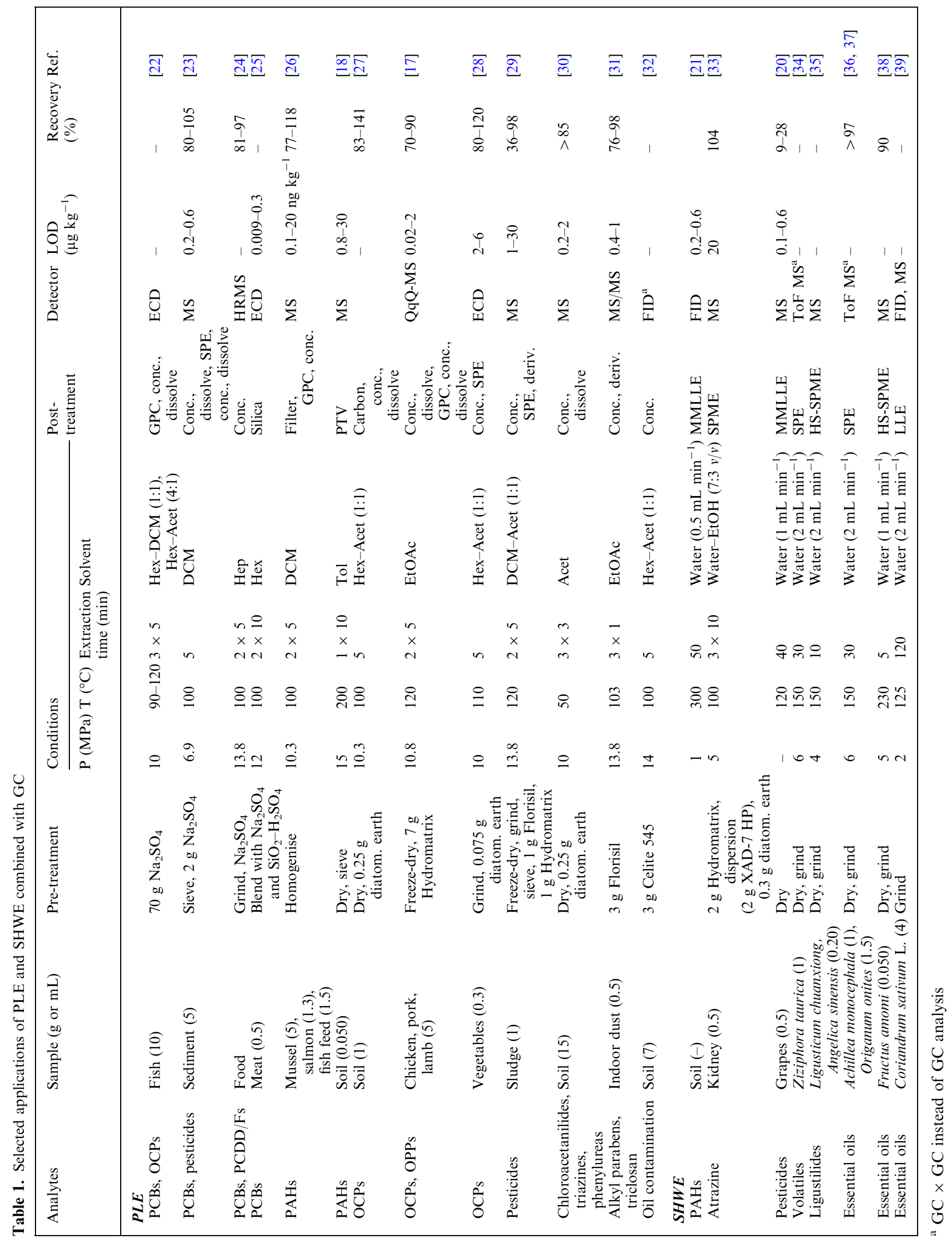




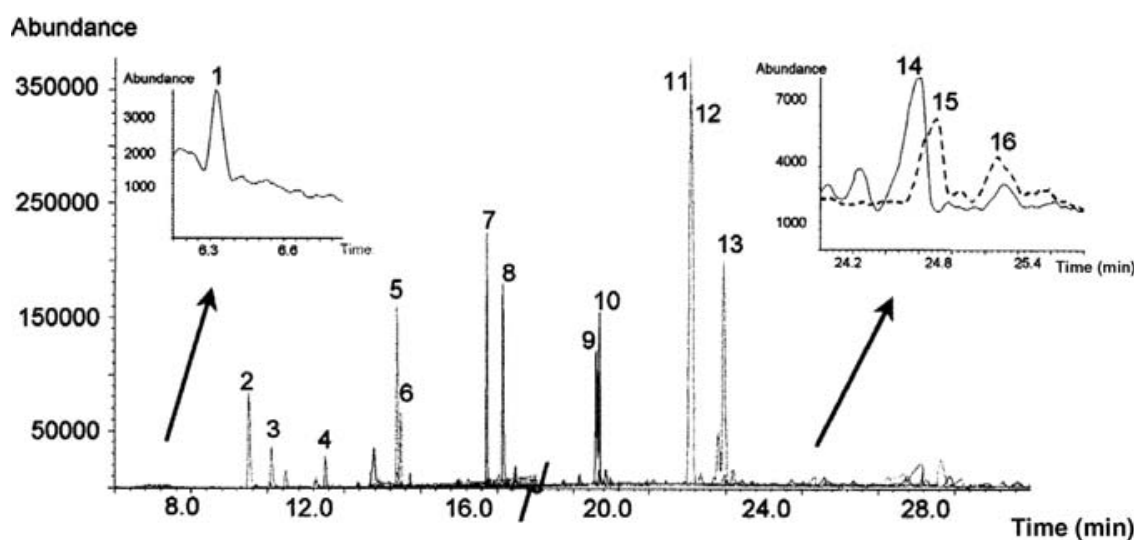

Fig. 3. 50- $\mu$ L LVI-GC-MS (SIM) of endogenous PAHs extracted from $50 \mathrm{mg}$ of an organic soil with a miniaturized PLE using $100 \mu \mathrm{L}$ of toluene at $200{ }^{\circ} \mathrm{C}$ and $15 \mathrm{MPa}$. Peak identification: $\mathbf{1}=$ Naphthalene, $m / z$ 128/102; 2 = Acenaphthylene, $m / z$ 153/152; 3 = Acenaphthene, $m / z$ 153/152; 4 = Fluorene, $m / z$ 165/166; 5 = Phenanthrene, $m / z 178 / 176 ; 6=$ Anthracene, $m / z$ 178/176; 7 = Fluoranthene, $m / z$ 202/101; 8 = Pyrene, $m / z$ 202/101; $9=$ Benzo[ $a$ ]anthracene, $m / z \quad 228 / 226 ; \quad 10=$ Chrysene, $m / z \quad 228 / 226 ; \quad 11=$ Benzo[b]fluoranthene, $m / z \quad 252 / 250 ;$ $\mathbf{1 2}=$ Benzo[k]fluoranthene, $\quad m / z \quad 252 / 250 ; \quad \mathbf{1 3}=$ Benzo[a]pyrene, $m / z \quad 252 / 250 ; \quad \mathbf{1 4}=$ Indene[1,2,3-cd]pyrene, $\quad m / z \quad 278 / 276 ; \quad \mathbf{1 5}=$ Benzo[ghi]perylene, $m / z \quad 278 / 276$; $16=$ Dibenzo[a,h]anthracene, $m / z$ 278/267. Slash in the $x$-axis indicates change in the ions monitored [18]

samples mixed with sea sand were dynamically extracted by SHWE. The extract was led to the donor side of the MMLLE unit (see section on membranes for use of MMLLE) and MMLLE extraction took place during SHWE. Next, the (static) acceptor solvent was transferred on-line to the $\mathrm{GC}$ MS system. However, the recoveries were only $9-26 \%$ due to the low efficiency of the MMLLE step; LODs were $0.1-0.6 \mu \mathrm{g} \mathrm{kg}^{-1}$.

\section{Microwave-Assisted Extraction}

Today, MAE is widely recognized as a versatile extraction technique, especially for solid samples. MAE utilizes electromagnetic radiation to desorb analytes from their matrices. The microwave region is considered to exist at frequencies of $300 \mathrm{MHz}$ to $100 \mathrm{GHz}$. Although the whole of this region is potentially available for use, all (domestic and scientific) ovens operate at $2.45 \mathrm{GHz}$ only.

The main advantages of MAE are the usually high extraction rates due to the very rapid heating and the elevated temperatures, and the ease of instrument operation. A drawback is that the heating is limited to the dielectric constant of the sample/solvent. The primary mechanisms for energy absorption in MAE are ionic conductance and rotation of dipoles. Ionic-conductance heating is due to the electrophoretic migration of ions when a microwave field is applied. The resistance of the matter to this flow will generate heat as a consequence of friction. Dipolar molecules couple electrostatically to the microwave-induced electric field and tend to align themselves with it. Since the microwave field is alternating in time, the dipoles will attempt to realign as the field reverses and so are in a constant state of oscillation at the microwave frequency. Frictional forces cause heat to be developed due to the motion of the dipoles [40].

In MAE, sample and organic solvent are subjected to radiation from a magnetron. There is a high cost differential between microwave ovens for domestic use and for MAE, which sometimes precludes the purchase of a dedicated MAE system. However, for safety reasons (explosions in the presence of an organic solvent), it is strongly recommended to use only dedicated systems. Although the application of several brands and models is reported in the literature, there is a tendency for the models of CEM (Matthews, NC, USA) and Milestone (Shelton, CT, USA).
There are two types of heating system [41] - either the sample is heated in an open glass vessel fitted with an air or water condenser [focused microwave-assisted extraction (FMAE)], or a closed sample vessel constructed in microwavetransparent material is used [pressurized microwave-assisted extraction (PMAE)]. In an open-style system, the individual sample vessels are heated sequentially. The system operates at $0-100 \%$ power increments which can be operated in stages and for different time intervals. Sample and appropriate solvent are introduced into a glass vessel which is connected to the condenser to prevent loss of volatile analytes and/or solvent. In a common closed system, up to twelve extraction vessels can be irradiated simultaneously. Safety and relevant experimental features (temperature and pressure control, in one extraction vessel) are incorporated in such systems, and extraction conditions can be varied according to either the percentage power input or by in situ measuring of the temperature and pressure in the monitoring vessel [41-43]. Figure 4 shows the schematic of a closed-vessel MAE system and of a standard as extraction vessel. The use of PMAE is preferred in the case of volatile compounds. However, after extraction one has to wait for the temperature to decrease before opening the vessel, which increases the overall extraction time. PMAE is quite similar to PLE, as the solvent is heated and pressurized in both systems, the only difference being the means of heating. Consequently, as for PLE, the number of parameters is limited, which makes application of the technique quite simple $[42,43]$. However, one should be aware that, in MAE, re-adsorption of the extracted analytes is still possible during the final cooling step, while re-adsorption is negligible in PLE where the extraction solvent is removed from the cell while still warm. With regard to the extraction efficiencies, FMAE and PMAE systems were shown to have similar performances [44, 45].

The nature of the solvent is of prime importance in MAE. Next to the fact that the solvent should efficiently solubilize the analytes and be able to desorb them from the matrix, its microwave- 
absorbing properties have to be considered. Most of the time, the solvent is chosen to absorb the microwaves without causing strong heating to avoid analyte degradation. For thermolabile compounds, the microwaves may be absorbed only by the matrix, which will result in heating the sample and release of solutes into the cold solvent [47]. This last mechanism can also be used when an absorbing material (e.g., Weflon) is added to the sample [48, 49].

Applications PAHs, PCBs, phthalate esters and pesticides are prominent classes of target analytes and sample types include soils [50, 51], sediments [52] and various types of biological matrices [53, 54]. Relevant information on a selected number of recent MAE-based applications is presented in Table 3. Post-treatment is (almost) always needed. The operating conditions have to be optimized for each analyte-matrix combination, but it is possible to give some general recommendations: temperature, 60-150 ${ }^{\circ} \mathrm{C}$; pressure, $<1.4 \mathrm{MPa}$; extraction time, 5-30 min; solvent, 5-50 mL per $0.1-25 \mathrm{~g}$ sample, with hexane-acetone being often used. MAE-relevant characteristics of this mixture and of other solvents also frequently used are presented in Table 2.

As is to be expected from the above discussion, almost all MAE applications involve off-line procedures. However, in recent years, several studies were published which use an on-line approach, which is usually combined with dynamic MAE (DMAE) [40, 52, 56]. Interfacing was based on solid-phase trapping on a copolymer sorbent with subsequent drying with nitrogen and large volume injection (LVI) to enable introduction of the whole sample extract into the GC system. Methanol was used for MAE, with a 1:4 dilution with water prior to the solid-phase trap to ensure efficient analyte retention. Figure 5 shows a schematic of the online DMAE-SPE-GC system. In one study [40], organophosphate esters were determined in air samples. The total sampling-plus-analysis time was less than $1.5 \mathrm{~h}$, analyte recoveries were over $97 \%$ and NPD-based LODs were 60$190 \mathrm{pg} \mathrm{m}^{-3}$.

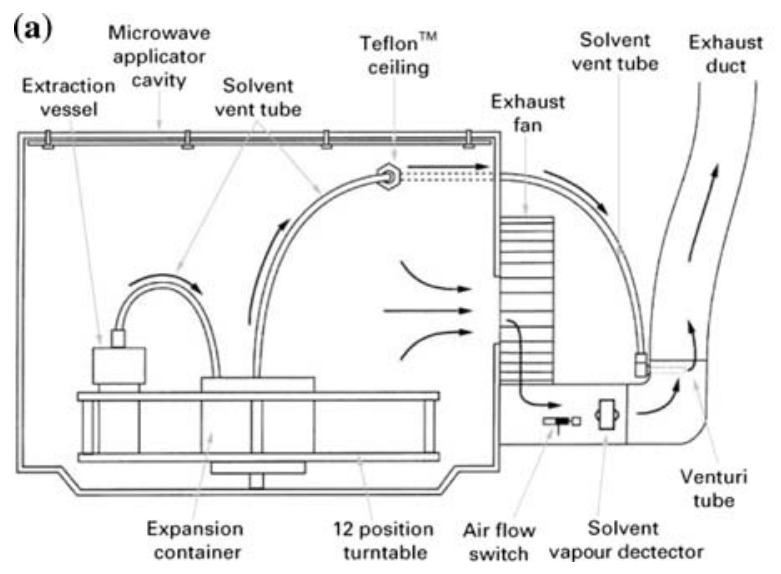

(b)

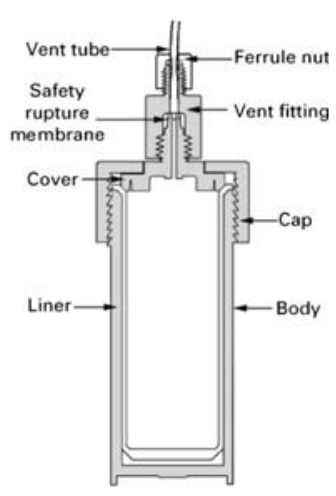

Fig. 4. Schematic of (a) a closed-vessel MAE system, and (b) a standard lined extraction vessel [46]

Table 2. MAE solvent characteristics [55]

\begin{tabular}{|lcll|}
\hline Solvent & $\begin{array}{l}\text { Dielectric } \\
\text { constant }\end{array}$ & $\begin{array}{l}\text { Boiling } \\
\text { point }\left({ }^{\circ} \mathrm{C}\right)\end{array}$ & $\begin{array}{l}\text { Closed-vessel } \\
\text { temperature }\left({ }^{\circ} \mathrm{C}\right)^{\mathrm{a}}\end{array}$ \\
\hline $\begin{array}{l}\text { Hexane } \\
\text { Hexane-acetone }\end{array}$ & 1.89 & 68.7 & - \\
Dichloromethane & - & $52.0^{\mathrm{b}}$ & 156 \\
Acetone & 8.93 & 39.8 & 140 \\
Methanol & 20.7 & 56.2 & 164 \\
Acetonitril & 32.6 & 64.7 & 151 \\
\hline
\end{tabular}

${ }^{\mathrm{a}}$ At $1.2 \mathrm{MPa}$

${ }^{\mathrm{b}}$ Experimentally determined

As regards miniaturization, Ericsson and Colmsjö [52] inserted a preheating column in front of the extraction cell in the microwave cavity. Using this configuration the authors demonstrated the feasibility of DMAE coupled on-line with SPE for the accurate determination of PAHs in a reference sediment (recoveries, 88-104\%; RSDs, 1-10\%) although only $60 \mathrm{mg}$ of sample were used. Sample preparation was complete in ca. 45 min and the final extracts, collected by back-extraction of the analytes concentrated on a $10 \mathrm{~mm} \times 2 \mathrm{~mm}$ PLRP-S SPE cartridge with $400 \mu \mathrm{L}$ of MTBE, were directly analysed by $1-\mu \mathrm{L}$ injection in a GC-PID system.

MAE was compared with Soxhlet, USE (ultrasound-assisted extraction) and SFE for the extraction of 94 compounds listed in EPA Method 8250 [57]. Freshly spiked soil samples and two reference materials were extracted using MAE (conditions: sample, $10 \mathrm{~g}$; solvent, $300 \mathrm{~mL}$ hexane-acetone, 1:1; temperature, $115^{\circ} \mathrm{C}$; extraction time, $10 \mathrm{~min}$ ), Soxhlet extraction (conditions: sample,
$10 \mathrm{~g}$; solvent, $300 \mathrm{~mL}$ hexane-acetone, 1:1; extraction time, $18 \mathrm{~h}$ ), and SFE (sample, $5 \mathrm{~g}$; solvent, $10 \% \mathrm{MeOH}-$ modified supercritical $\mathrm{CO}_{2}$; pressure, $45 \mathrm{MPa}$; temperature, $100{ }^{\circ} \mathrm{C}$; extraction time, $60 \mathrm{~min}$ ). The recoveries for MAE and Soxhlet were found to be similarthose for USE were slightly higher, and for SFE clearly lower. Precision was best with MAE and worst with Soxhlet extraction.

\section{Ultrasound-Assisted Extraction}

In ultrasound-assisted extraction (USE), acoustic vibrations with frequencies above $20 \mathrm{kHz}$ are applied to extract analytes from permeable (semi-)solid matrices. The top end of the frequency range is limited only by the ability to generate the signals; frequencies in the $\mathrm{GHz}$ range have been used in some applications. Sound waves are intrinsically different from electromagnetic waves: while the latter can pass through 


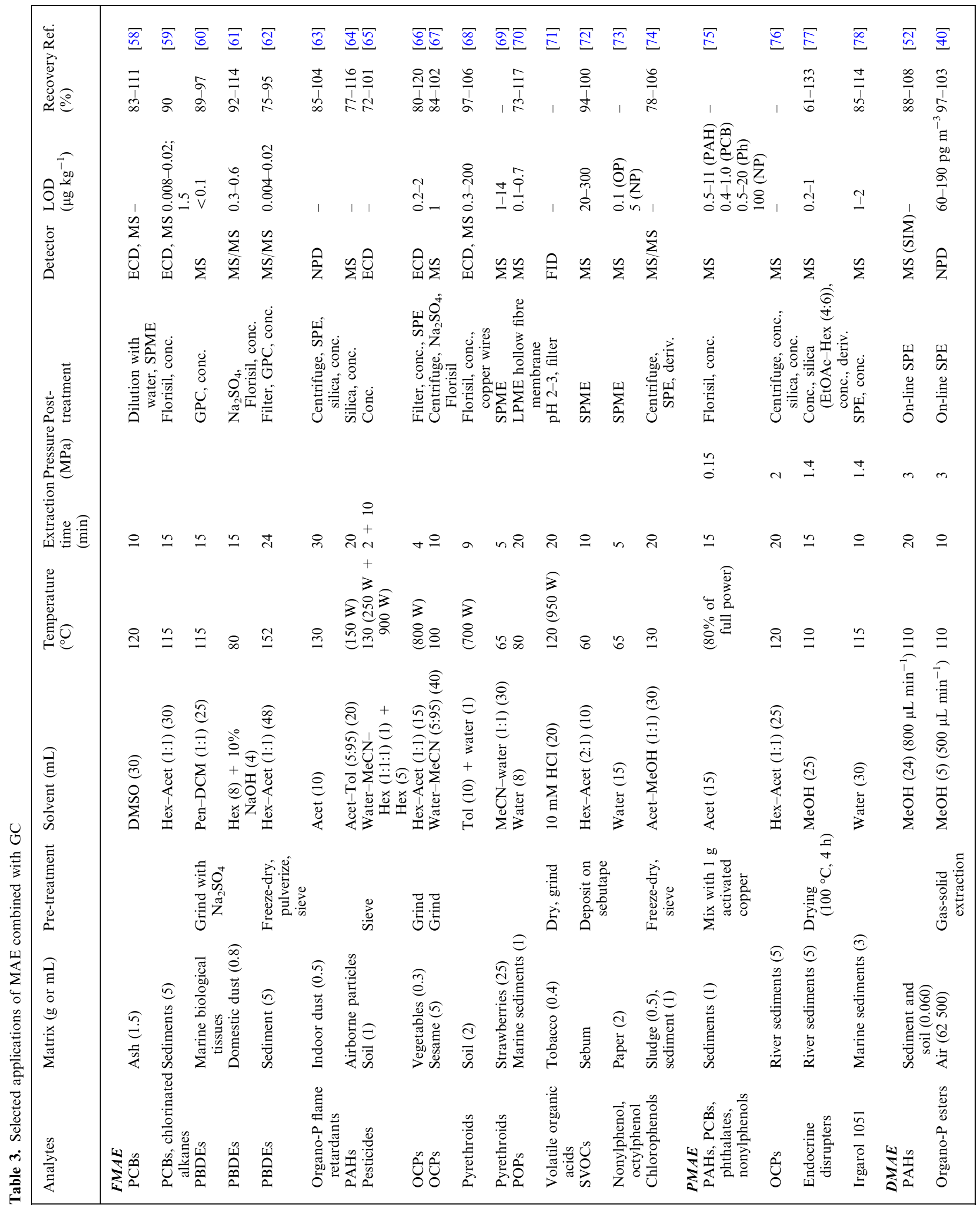


vacuum, sound waves must travel in matter, as they involve expansion and compression cycles travelling through a medium. In a liquid, the expansion cycle produces negative pressure and bubbles or cavities are formed. When a bubble can no longer efficiently absorb the energy from the ultrasound, it implodes. The whole process, known as 'cavitation', takes place within about $400 \mu \mathrm{s}$. Rapid adiabatic compression of gases in the cavities produces extremely high temperatures and pressures, estimated to be about $5,000{ }^{\circ} \mathrm{C}$ and roughly $100 \mathrm{MPa}$, respectively. The high temperatures and pressures cause the formation of free radicals and other compounds; for example, the sonication of pure water causes thermal dissociation into hydrogen atoms and $\mathrm{OH}$ radicals, the latter forming hydrogen peroxide by recombination [79].

When cavitation occurs in a liquid close to a solid surface, cavity collapse is asymmetric and produces high-speed jets of liquid. Liquid jets driving into the surface have been observed at speeds close to $400 \mathrm{~km} \mathrm{~h}^{-1}$. Such a strong impact can result in serious damage to impact zones and can produce newly exposed, highly reactive surfaces. The very high effective temperatures (which increase solubility and diffusivity) and pressures (which favour penetration and transport) at the solvent/solid matrix interface, combined with the oxidative energy of radicals created during sonolysis, result in high extractive power. Sonication times for real-life applications vary widely, i.e., from $1-10$ to 30 $120 \mathrm{~min}$ (Table 4). For excellent reviews on USE and its applications, the reader should consult references [80, 81].

There are two common devices for ultrasound application, bath and probe systems. The baths are more widely used, but have two disadvantages, which adversely affect experimental precision, viz. a lack of uniformity of the distribution of ultrasound energy (only a small fraction of the total liquid volume in the immediate vicinity of the source will experience cavitation) and a decline of power over time. The probes have the advantage over baths that they focus their energy on a localized sample zone

(a)

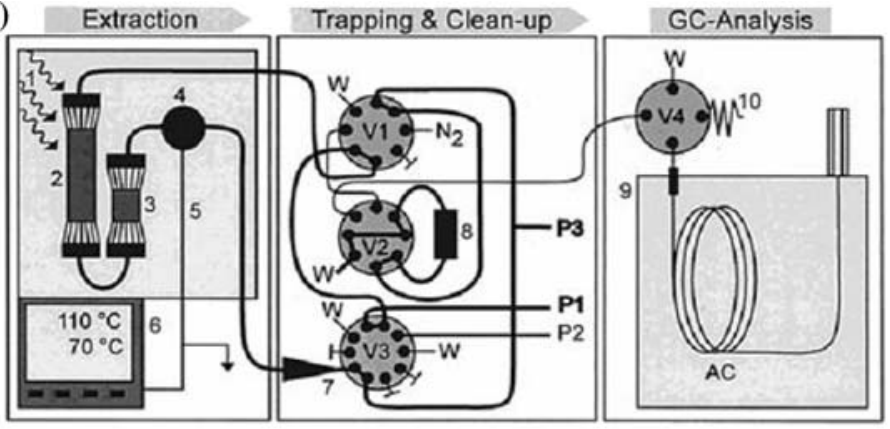

(b)

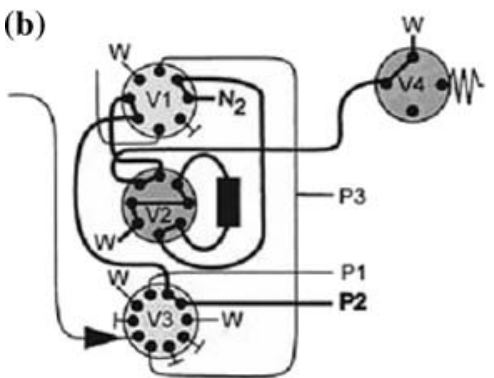

(c)

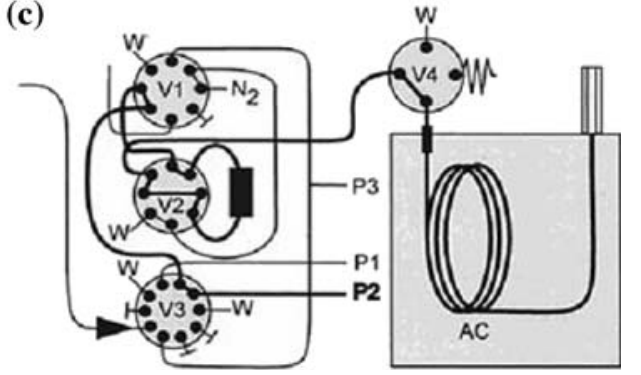

Fig. 5. Schematic of DMAE-SPE-LVI-GC system: 1, Microwave oven; 2, Pre-heater; 3, Extraction vessel; 4, Mixing tee; 5, Thermocouple; 6, Temperature regulator; 7, Restrictor; 8, SPE cartridge; 9, PTV-GC-NPD; 10, Fused-silica leak; V1-V4, Valves; P1-P3, Pumps. Working modes: (a) extraction and trapping; (b) system clean-up and drying with nitrogen; (c) transfer and GC analysis [40]

and, thus, provide more efficient cavitation in the liquid.

In bath systems, the transducer is usually placed below a stainless-steel tank, the base of which is the source of the ultrasound. Some tanks are provided with a thermostatically controlled heater. The ultrasound power levels delivered by most commercial ultrasonic baths are sufficient for cleaning, solvent degassing and extraction of adsorbed metals and organic pollutants from environmental samples, but are less effective for extraction of analytes bound to the matrix. The power should be great enough to cause cavitation within the extraction vessel placed inside the bath. For a bath with a single transducer on the base, the extraction vessel must be located just above the transducer, since power delivery will be at maximum at this position (cf. above). In order to obtain reproducible results, the bath must be either thermostated or preheated at the maximum temperature measured in the liquid under continuous running conditions since most cleaning baths warm up slowly during operation. An important drawback of most clean- ing baths is the lack of power adjustment control. In the literature not a real tendency can be found in models and brands of sonication baths applied.

Probe-type systems can deliver up to 100 -fold greater power to the extraction medium than a bath. One main feature for the successful application of ultrasonic probes is that the ultrasonic energy is not transferred through the liquid medium to the extraction vessel but introduced directly into the system. The probe consists of the following components: (1) a generator which is the source of alternating electrical frequency, and which allows tuning to be carried out for optimum performance; (2) the possibility of pulsed-mode operation of the ultrasonic processor to allow the medium to cool between sound pulses; (3) the upper horn element, a piece of titanium to which the removable horn is attached, forming both the emitter or booster, and the detachable horn itself, usually made of a titanium alloy, which allows the vibration of the fixed horn to be transmitted to a chemical system. Tip erosion can occur as a result of cavitation. Since ultrasound irradiation by means of 


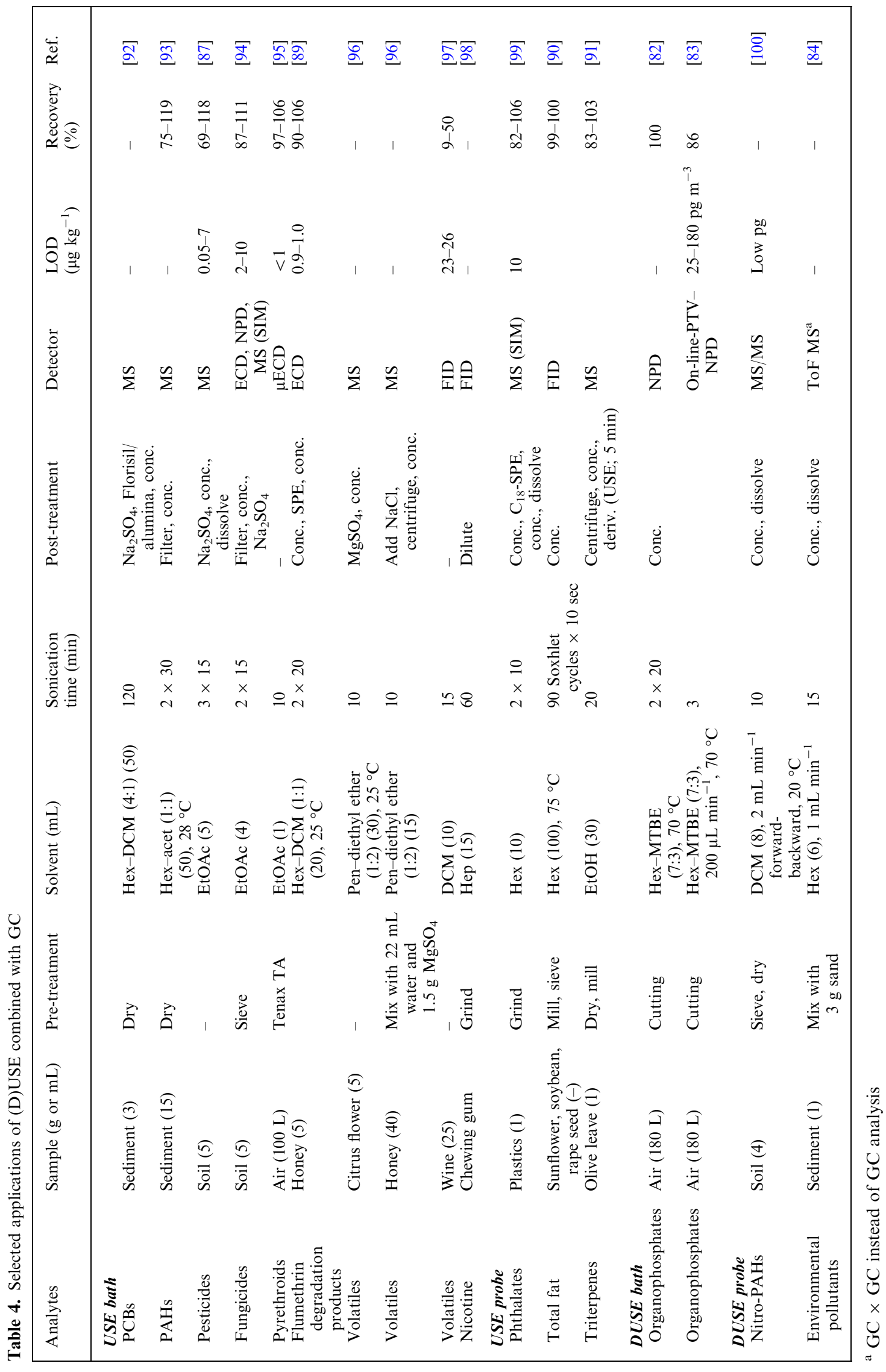




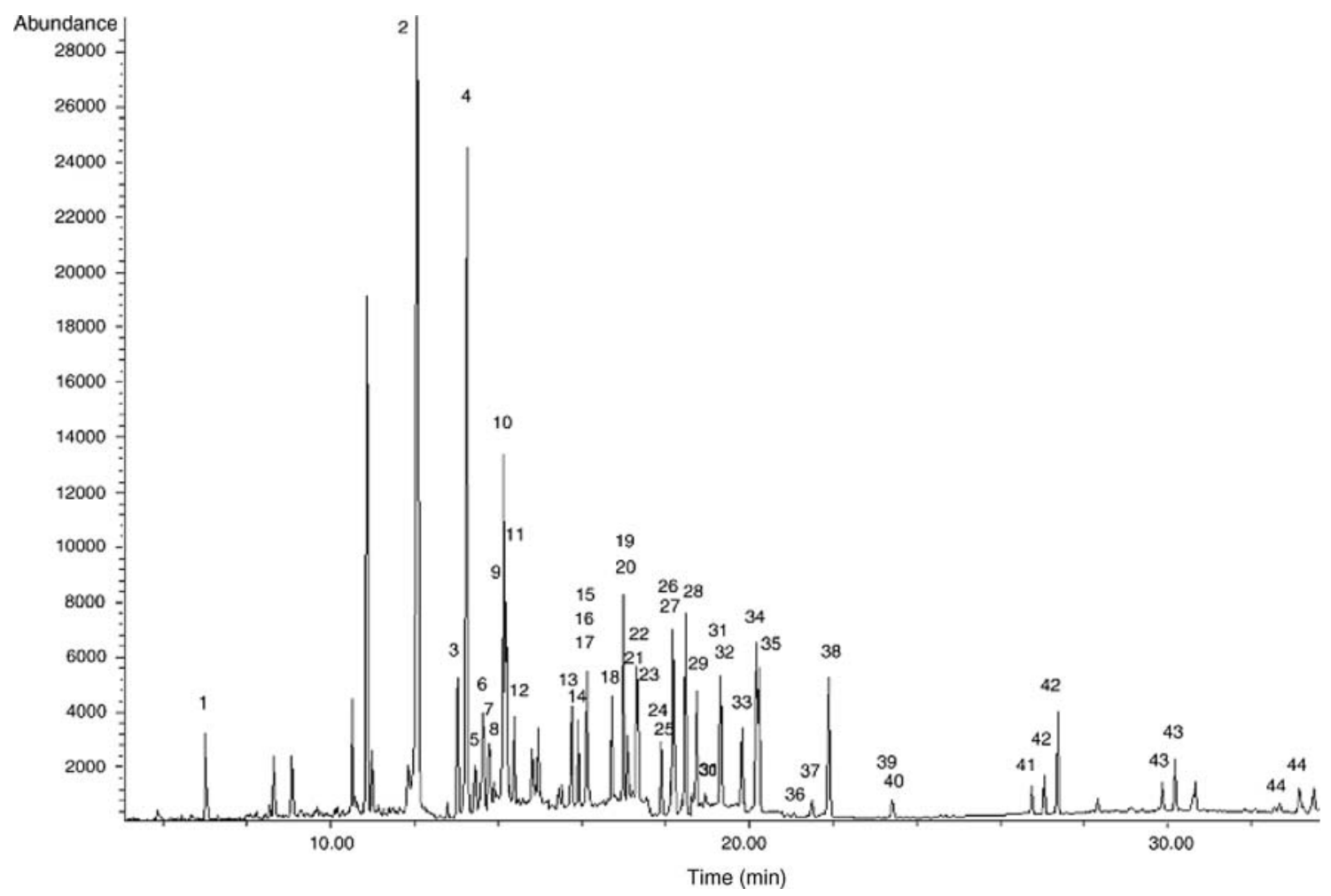

Fig. 6. GC-MS (SIM) chromatogram of a USE extract of a soil spiked at $50-\mu \mathrm{g} \mathrm{kg}{ }^{-1}$ concentration level [87]. 1 = Dichlorvos; $\mathbf{2}=$ Desethylatrazine; $\mathbf{3}=$ Hexachlorobenzene; $\mathbf{4}=$ Dimethoate; $\mathbf{5}=$ Simazine; $\mathbf{6}=$ Atrazine; $\mathbf{7}=$ Propazine; $8=$ Lindane; $9=$ Terbutylazine; $\mathbf{1 0}=$ Propyzamide; $\mathbf{1 1}=$ Fonofos; $\mathbf{1 2}=$ Diazinon; $\mathbf{1 3}=$ Metribuzin; $\mathbf{1 4}=$ Parathion-methyl; $\mathbf{1 5}=$ Simetryn; $\mathbf{1 6}=$ Alachlor; $\mathbf{1 7}=$ Heptachlor; $\mathbf{1 8}=$ Fenitrothion; $\mathbf{1 9}=$ Malathion; $\mathbf{2 0}=$ Metolachlor; $\mathbf{2 1}=$ Aldrin; $\mathbf{2 2}=$ Chlorpyrifos; $\mathbf{2 3}=$ Parathion-ethyl; $\mathbf{2 4}=$ Isodrin; $\mathbf{2 5}=$ Chlorfenvinphos; $\mathbf{2 6}=$ Pendimethalin; $\mathbf{2 7}=$ Heptachlor epoxide; $\mathbf{2 8}=$ Chlorfenvinphos; $29=$ Procymidone; $\mathbf{3 0}=\gamma$-Chlordane; $\mathbf{3 1}=$ Tetrachlorvinphos; $\mathbf{3 2}=$ Endosulfan, I; $\mathbf{3 3}=$ Fenamiphos; $\mathbf{3 4}=4,4^{\prime}$-DDE; $\mathbf{3 5}=$ Dieldrin; $\mathbf{3 6}=$ Endrin; $\mathbf{3 7}=$ Endosulfan, II; $38=4,4^{\prime}$-DDD; $39=$ Endosulfan, sulfate; $40=4,4^{\prime}$-DDT; $41=$ Azinphos-methyl; $\mathbf{4 2}=\lambda$-Cyhalothrin; $\mathbf{4 3}=\alpha$-Cypermethrin; $44=$ Deltamethrin

probes generates a large amount of heat, some cooling of the sonication vessel is required. One should also be aware that volatile sample constituents can be lost due to the 'degassing' effect of the ultrasound power. The probe system mostly used for the applications reported in the literature is the Sonifier 450 (Branson, Danbury, CT, USA).

Most USE applications have been developed using a bath or a probe. Dynamic systems (DUSE) have been used in a few cases only, even though this approach will speed up the USE process considerably. There are two DUSE approaches, open and closed systems.

In open systems, fresh extractant flows continuously through the sample, so the mass transfer equilibrium is displaced to the solubilization of the analyte(s) into the liquid phase. This mode has the disadvantage of serious extract dilution which implies that subsequent time-consuming concentration by sol- vent evaporation [82] or coupling to SPE is required. Somewhat surprisingly, despite its ease of implementation, the latter approach has not been reported yet. Sanchez et al. [83] coupled DUSE to LVI-GC utilizing a PTV injector to analyse organophosphate esters in air. Air filters were desorbed by DUSE with

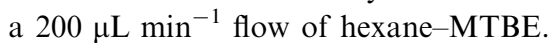
With the PTV in the solvent-vent mode, the entire extract volume was introduced into the GC-NPD system without any clean-up. The LODs of the organophosphate esters were in the range of 25$180 \mathrm{pg} \mathrm{m}^{-3}$ (average recovery, 86\%, RSD, 5-14\% $(n=5)$ at $1 \mathrm{ng} /$ filter $)$.

In closed systems, a pre-set volume of extractant is continuously circulated through the solid sample. Consequently, dilution is less serious than with an open system. The direction of the extractant can be changed at pre-set intervals to avoid undesirable compaction of the sample and any increase in pressure in the dynamic system. After extraction, a valve either directs the extract for collection in a vial or drives it to a continuous manifold for on-line performance of other steps in the analytical process, such as pre-concentration [84].

Applications A selected list of (D)USE applications for the isolation of a range of compounds from a variety of matrices is shown in Table 4. USE is mainly used for environmental (soil, sediment, air) and food and beverage (soybean, honey, wine) samples. In most applications, USE is combined off-line with GC, but there are also several examples of on-line set-ups [83-86].

As an example of a typical USEbased analysis, we quote the protocol for pesticide residue analysis in soil, designed to expand the range of applicability of EPA Method 3550C [87, 88]. $5 \mathrm{~g}$ of soil were placed in a small Erlenmeyer flask and $5 \mathrm{~mL}$ ethyl acetate added. 


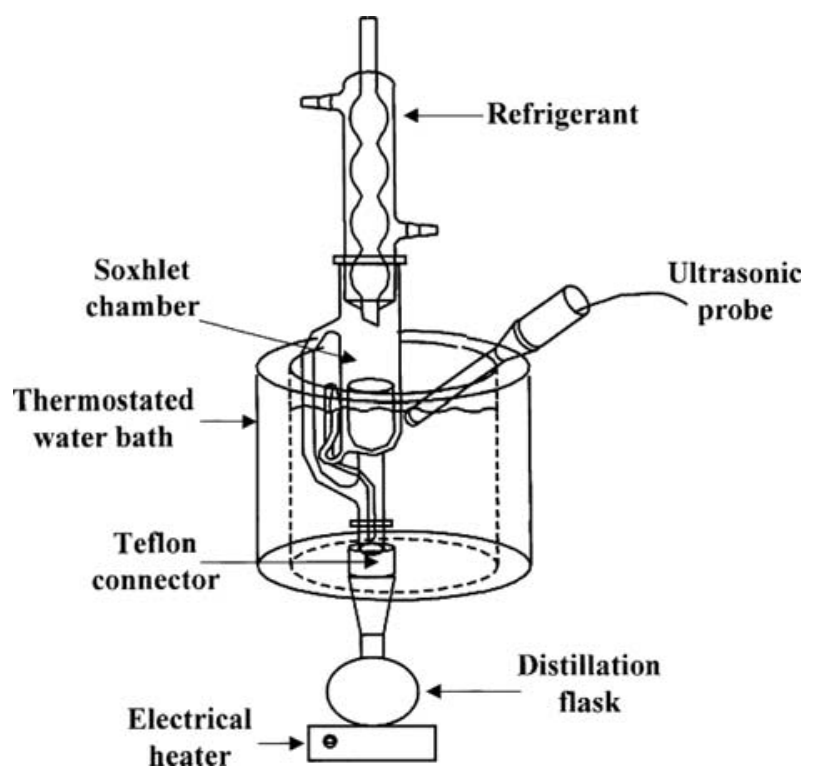

Fig. 7. Schematic of ultrasound-assisted Soxhlet extraction [90]

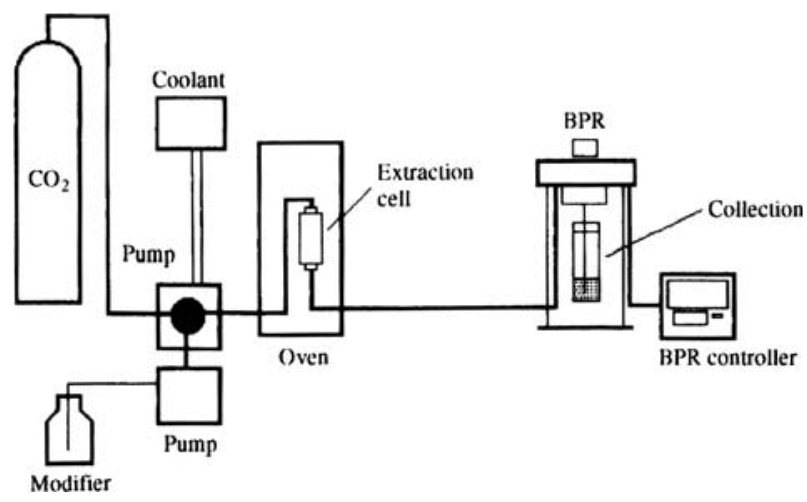

Fig. 8. Schematic of a basic SFE system [41]. BPR, back pressure regulator (with attached controller unit)

After manual agitation the sample was exposed to USE for $3 \times 15 \mathrm{~min}$. After each period, extracts were collected by pouring the extractant through a funnel plugged with cotton wool and overlaid with anhydrous sodium sulphate. The final $15-\mathrm{mL}$ extract is evaporated to dryness and redissolved in $200 \mu \mathrm{L}$ ethyl acetate, and $1 \mu \mathrm{L}$ was analysed by GCMS. LODs were in the $0.05-7.0 \mu \mathrm{g} \mathrm{kg}^{-1}$ range. Figure 6 shows a chromatogram of a $50-\mu \mathrm{g} \mathrm{kg}^{-1}$ spiked soil. The procedure is straightforward and analyte detectability is fully satisfactory. However, the total analysis is somewhat timeconsuming and includes risky solvent evaporation. was located in it. The bath was sonicated by a probe to accelerate the extraction process (Fig. 7). The efficiency was similar to, or even better than, those of conventional Soxhlet extraction and the official ISO method, saving both time and sample manipulation. Recently, the twofold application of USE in a single analytical protocol was reported [91]. The main triterpenes - eleanoic acid, ursolic acid, uvaol and eryuthodiolwere quantitatively leached from olive leaves by 20 -min USE with ethanol. This compares favourably with the $5 \mathrm{~h}$ required by conventional procedures involving maceration. An aliquot of the leachate was silylated prior to GC-MS. Ultrasound-assisted silylation took only $5 \mathrm{~min}$, as against $0.5-3 \mathrm{~h}$ for conventional silylation.

\section{Supercritical Fluid Extraction}

One area that stimulated an interest in enhanced fluid extractions, was supercritical fluid extraction (SFE). This is a long established method, which has been used industrially for many years. However, it was not until an interest was shown in supercritical fluids as chromatographic media that it started to be seriously studied as an extraction technique on an analytical scale. It has since been the subject of numerous books and reviews (e.g., [4, 101-103]).

Almost all SFE employs carbon dioxide (critical point, $30.9^{\circ} \mathrm{C}, 73.8$ bar) as the supercritical fluid: it is an almost ideal solvent since it combines low viscosity and high analyte diffusivities with a high volatility (which makes analyte recovery very simple and provides solvent-free concentrates), and is inexpensive and environmentally friendly. An important drawback of $\mathrm{CO}_{2}$ is its nonpolar character. In order to widen the application range of the technique to include more polar analytes, the preferred route is to employ polar modifiers such as methanol, ethanol, acetone and acetonitrile (1-10\% addition, preferably by means of a separate modifier pump). In addition to a modifier pump, the basic components of an SFE system (Fig. 8) are: a supply of high purity carbon dioxide; a $\mathrm{CO}_{2}$ pump; an oven for the 
extraction vessel; a pressure outlet or restrictor; and a suitable collection vessel for recovery of the extracted analytes. Sample collection can be performed by purging the extract through a solvent or over a suitable adsorbent, such as, Florisil.

SFE comprises two integrated parts, extraction of the analyte from the sample matrix and subsequent collection-or trapping - of the analytes. There are three main collection modes: (1) collection in a vessel containing solvent; (2) trapping on a cartridge packed with an adsorbing or inert solid-phase material and (3) collection in a device that is connected on-line with the chromatographic system. Compared to 'off-line' solvent collection or solid-phase trapping, the on-line technique offers better analyte detectability because the entire extract rather than an aliquot, can be transferred to the chromatographic system. However, sample size should be limited since co-extracted fat or water may easily contaminate the interface used and/or ruin the analytical column. For the rest, it is good to add that all three types of collection require careful optimization, with solvent collection probably being the simplest system to use and the easiest to optimize, and solid-phase trapping offering selectivity by the two-step trapping/elution procedure. On-line collection provides the best sensitivity because the entire extract is introduced into the GC system.

Applications Over the years, SFE has been used for the extraction of PAHs, PCBs and dioxins, aliphatic hydrocarbons and pesticides from soil, sediment and air-borne particulates, in food and fragrance studies, especially for essential oils and fats, for the extraction of polymer additives, natural products, and drugs and their residues. Special attention has always been given to the extraction of thermolabile compounds because the mild conditions of $\mathrm{CO}_{2}$-based SFE will minimize their degradation. Illustrative examples are summarized in Table 5.

In order to give an impression of the wide variety of analyte/matrix combinations for which SFE has been used as sample-preparation method, three stud- ies included in Table 5 are briefly discussed. The extraction of onion oil from fresh onions by means of SFE was reported by Seangcharoenrat and Guyer [104]. Onions were peeled, cut and juiced. The juice was filtered to separate it from the pulp and fed to an Amberlite XAD-16 polymeric sorbent bed. The onion oil was extracted with supercritical $\mathrm{CO}_{2}\left(20.7-28.7 \mathrm{MPa}, 37-50^{\circ} \mathrm{C}\right)$ in the up-flow direction and, after dilution in dichloromethane, the extract was analysed by GC-MS. Rissato et al. [105] used SFE for the analysis of pesticides in honey. A $5 \mathrm{~g}$ honey sample was mixed with $3 \mathrm{~mL}$ water and heated at $40{ }^{\circ} \mathrm{C}$ to improve handling. After lyophilization, the honey samples were poured into a stainless-steel extraction cell in the sandwich mode, using silanized glass wool at the bottom and top. Extraction was performed with $\mathrm{CO}_{2}$ with 10 vol\% acetone as a modifier, at 200 bar and $60{ }^{\circ} \mathrm{C}$ during $5 \mathrm{~min}$. The pesticides were collected on-line on Florisil at $10^{\circ} \mathrm{C}$. After rather time-consuming elution with two $5 \mathrm{~mL}$ solvent mixtures, concentration and redissolution in $1 \mathrm{~mL}$ acetone, only $1 \mu \mathrm{L}$ was analysed by $\mathrm{GC}-$ ECD (Fig. 9). The LODs were better than $0.01 \mathrm{mg} \mathrm{kg}^{-1}$ (recoveries, 75-94\%). Compared with conventional LLE, sample contamination was greatly diminished as sample handling was minimized and the use of organic solvents was reduced (consequently, solvent evaporation was much faster). Garrigós et al. [106] used SFE for the analysis of styrene in polystyrene. Styrene was extracted with supercritical $\mathrm{CO}_{2}$ with collection in dichloromethane. After concentration, the extract was analysed by GC-MS. SFE was found to be more selective than MAE, Soxhlet and HS (less extraction of matrix components) and gave an analyte recovery of about $100 \%$.

The factors that govern the extraction of an analyte from a matrix are the solubility of the analytes in the supercritical fluid, the mass transfer kinetics of the analyte from the matrix to the solution phase, and interactions between the supercritical phase and the matrix (Fig. 10) [107-110]. To put it differently, despite quite a number of promising initial results obtained when $\mathrm{CO}_{2}$ has been used for the extraction of non-polar micro-contaminants from sediments [111], natural products from biological samples [112] or essential oils from plant material [113], SFE has not become as widely and as easily useful as initially expected. One main reason is that SFE has been found too analyte- and, specifically, too matrix-dependent to be readily and routinely applicable for much work involving complex environmental and food samples. This is especially true for environmental samples where analyte/matrix interactions often become stronger in ageing samples: optimization on the basis of spike recoveries may then lead to quite erroneous results. In addition, method development is rather difficult since quite a number of parameters have to be optimized, and there are often technical problems. In both respects, PLEanother 'modern' compressed-fluid technique - is superior. Moreover, PLE can be used with most conventional solvents and can therefore handle polar as well as non-polar compounds, whereas SFE is preferentially employed for non-polar analytes only. On the other hand, on-line coupling to GC is much easier with SFE [114], it is a solvent-free method and miniaturization should not meet with any problems [4]. Dedicated attention is obviously required to underscore the merits of what is now somewhat of a 'niche' technique [115].

\section{Matrix Solid-Phase Dispersion}

The analysis of (semi-) solid environmental, food or biological-sometimes fat-containing - matrices is a challenging problem, with rapid and efficient analyte isolation-and subsequent purification-being of key interest. In 1989, Barker et al. [126] introduced matrix solid-phase dispersion (MSPD) and the technique has since then been discussed in several reviews [127-130]. MSPD involves the direct mechanical blending (for solid samples) or mixing (for semisolid and liquid samples) with, usually, an alkyl-bonded silica SPE sorbentbut, occasionally, also plain silica, Florisil or sand. The added abrasive promotes the disruption of the gross 


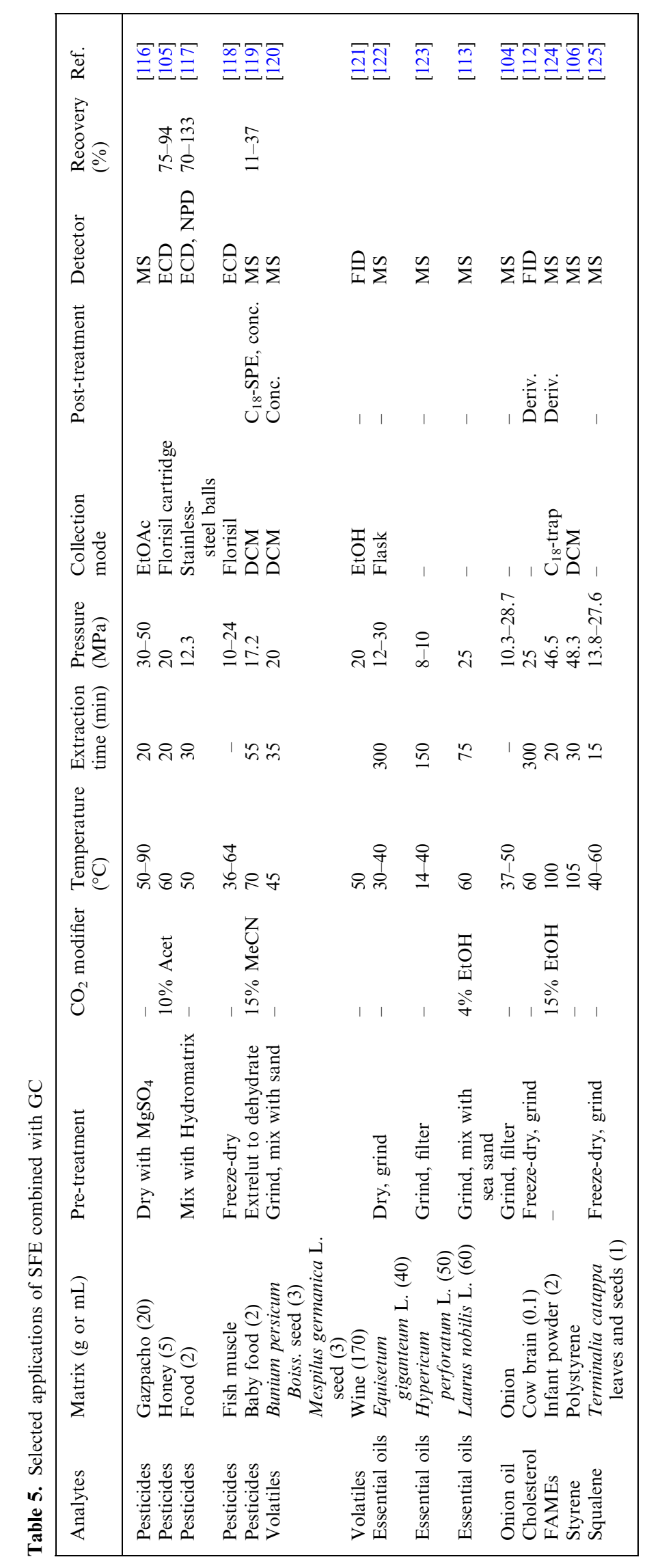


architecture of the sample while, with a bonded silica, sample constituents will dissolve and disperse into the bonded phase, causing a complete disruption of the sample and its dispersion over the surface. When blending or mixing is complete, the homogenized mixture is packed into an empty column or cartridge (with, usually, frits, filters or plugs at both top and bottom). Obviously, there is one main difference here between MSPD and SPE: with the former technique, the sample is distributed throughout the column and not only retained in the first few millimetres. Elution with, preferably, a limited volume of solvent is the final step of the remarkably simple procedure.

The use of small particles for the dispersion sorbent, should be avoided to prevent unduly long elution times or column plugging, and $40 \mu \mathrm{m}$ or less expensive $40-100 \mu \mathrm{m}$ particles are used most frequently. The sample/sorbent ratio usually is about $1: 4$, but may vary up to $1: 1$. The nature of the sorbent used for a specific application also has to be considered. For example, for analyte extraction from animal tissue, $\mathrm{C}_{18}$-bonded silica is the most popular sorbent, while $\mathrm{C}_{8^{-}}$and $\mathrm{C}_{18}$-bonded silicas and Florisil are preferred for plant samples. Florisil has been applied successfully also for other types of sample, e.g., fruit juices, soil and honey. A more selective sorbent, cyanopropyl-bonded silica, has been used to isolate polar analytes such as veterinary drugs from biological fluids and tissues. Recent developments include the use of acidic silica, which will strongly retain basic compounds and facilitate basic/acid group separations. After elution of the basic analytes with a non-polar solvent, the latter class of compounds can be eluted with a relatively polar solvent. Silica treated with sulphuric acid has also been used for efficient fat removal. Sand is sometimes selected to allow the early elution of interferences that would not be retained by any sorbent during the elution of the target analytes.

The elution solvent should effect an efficient desorption of the target analytes while the bulk of the remaining matrix components should be retained. In the literature, a wide variety of solvents has

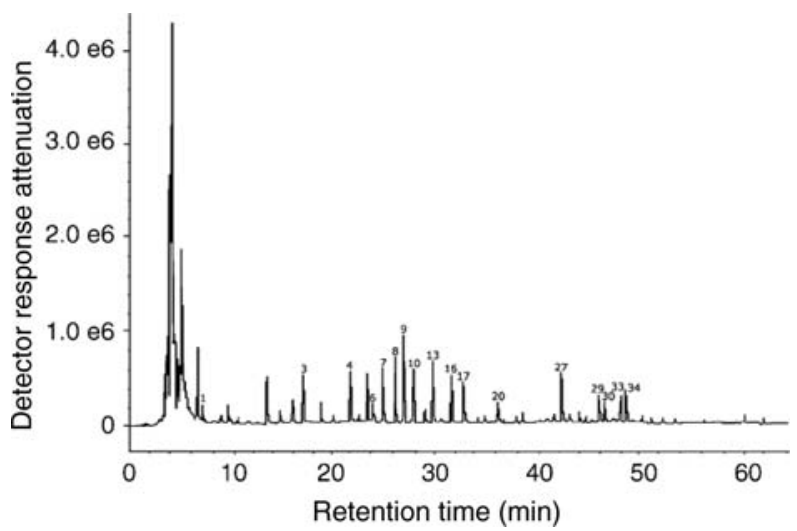

Fig. 9. GC-ECD chromatogram of a honey sample obtained by SFE [105]. 1 = Dichlorvos; $\mathbf{3}=$ Trifluralin; $\mathbf{4}=$ Hexachlorobenzene; $\mathbf{5}=$ Dicloran; $\mathbf{7}=$ Dimethoate; $\mathbf{8}=$ Chlorothalonil; $\mathbf{9}=$ Vinclozolin; $\mathbf{1 0}=$ Aldrin; $\mathbf{1 3}=$ Chlorpyrifos; $\mathbf{1 6}=\alpha$-Endosulfan; $\mathbf{1 7}=$ Hexaconazole; $\quad \mathbf{2 0}=\beta$-Endosulfan; $\quad \mathbf{2 7}=$ Tetradifon; $\quad \mathbf{2 9}=$ Cyflutrin $\quad \mathrm{I} ; \quad \mathbf{3 0}=$ Cyflutrin $\quad$ II; $\mathbf{3 3}=$ Cypermetryn II; $34=$ Cypermytrin III

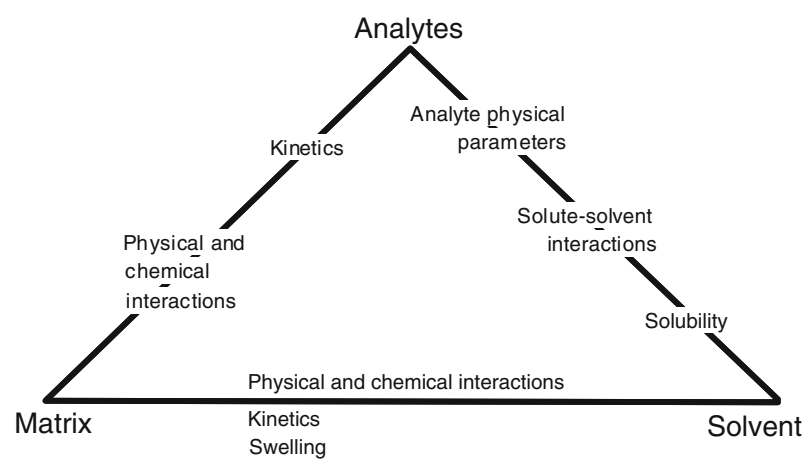

Fig. 10. Factors to be considered when studying an SFE extraction process [108]

been tested, ranging from hexane and toluene, via dichloromethane and ethyl acetate, to alcohols and water at elevated temperatures. Not surprisingly, pesticides are usually eluted with low- or medium-polar solvents, and drugs and naturally occurring compounds with more polar ones. Generally speaking, the nature of the preferred sorbent/solvent combination is mainly determined by the polarity of the target analytes and the type of sample matrix. Keeping this common-sense consideration in mind will facilitate MSPD optimization.

In some cases, eluates from an MSPD column are sufficiently clean to permit direct injection into the GC system [131]. However, more often additional clean-up is required. For some applications, e.g., the analysis of fruits and vegetables, washing the MSPD column with water prior to elution of the analytes generally suffices [131, 132].
Post-MSPD treatment may range from simple filtration or centrifugation, to evaporation-plus-redissolution or aqueous-to-organic extraction, and more versatile SPE. In the last-named case, a suitable sorbent can be packed at the bottom of the MSPD column or the MSPD column can be eluted off- or online onto a conventional SPE cartridge or disk. An interesting development is to combine MSPD and PLE, i.e., to increase the speed of the analysis by applying elevated temperatures and pressures, although these should be relatively mild in order to maintain the selectivity of the MSPD procedure [133].

Applications Three application areas in which MSPD is frequently used are the determination of drugs, organic microcontaminants and naturally occurring compounds (however, with the lastnamed group, MSPD is usually combined with LC, not GC). Table 6 summarizes a 


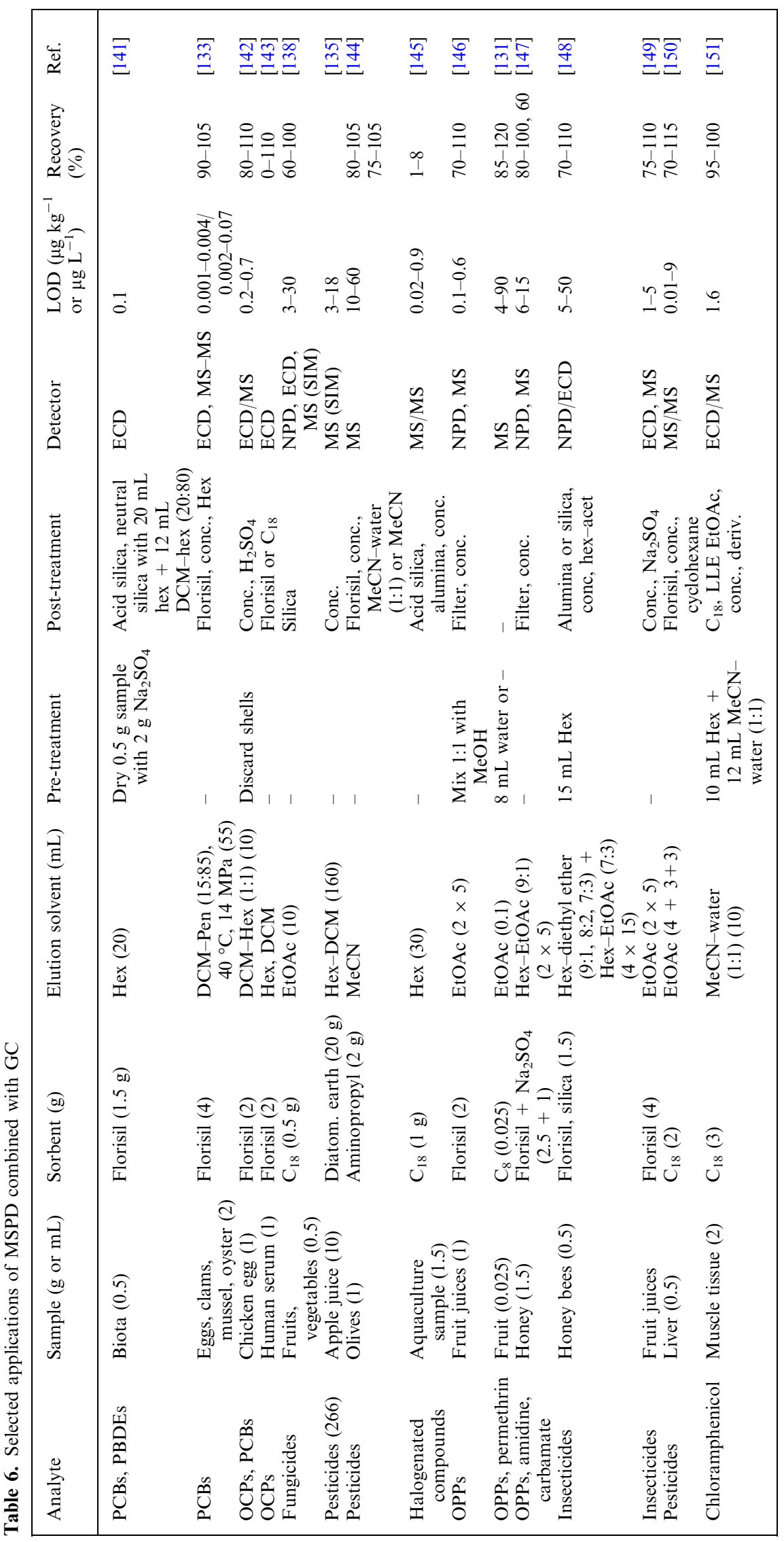




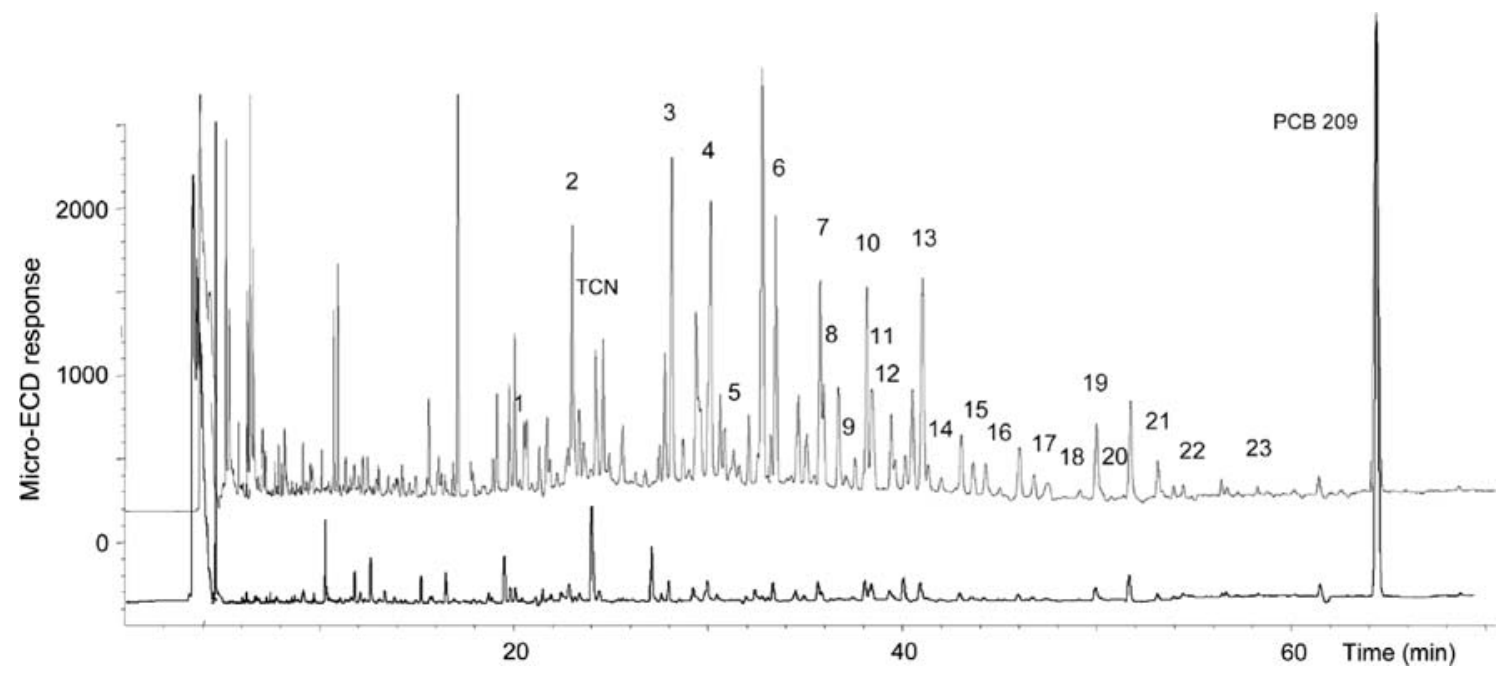

Fig. 11. GC- $\mu \mathrm{ECD}$ chromatograms of a non-spiked meat sample (upper trace) and a procedure blank (lower trace) using miniaturized MSPD [136]. Sample size, 0.1 g. Peak identification: $\mathbf{1}=\mathrm{CB} 28 ; \mathbf{2}=\mathrm{CB} 52 ; \mathbf{3}=\mathrm{CB} 95 ; \mathbf{4}=\mathrm{CB} 101 ; \mathbf{5}=\mathrm{CB} 81 ; \mathbf{6}=\mathrm{CB} 77+\mathrm{CB} 110 ; \mathbf{7}=\mathrm{CB}$ $123+\mathrm{CB} 149 ; \mathbf{8}=\mathrm{CB} 118 ; \mathbf{9}=\mathrm{CB} 114 ; \mathbf{1 0}=\mathrm{CB} 153 ; \mathbf{1 1}=\mathrm{CB} 132 ; \mathbf{1 2}=\mathrm{CB} 105 ; \mathbf{1 3}=\mathrm{CB} 138 ; \mathbf{1 4}=\mathrm{CB} 126+\mathrm{CB} 129+\mathrm{CB} 178 ;$ $\mathbf{1 5}=\mathrm{CB} 183 ; \mathbf{1 6}=\mathrm{CB} 167 ; \mathbf{1 7}=\mathrm{CB} \mathbf{1 5 6} ; \mathbf{1 8}=\mathrm{CB} 157 ; \mathbf{1 9}=\mathrm{CB} 180 ; \mathbf{2 0}=\mathrm{CB}$ 169; $\mathbf{2 1}=\mathrm{CB} 170 ; \mathbf{2 2}=\mathrm{CB} 189 ; \mathbf{2 3}=\mathrm{CB} 194 ; \mathrm{TCN}$ (1,2,3,4-tetrachloronaphthalene), external standard; PCB 209, external standard

number of recent examples of each of these, and provides relevant information on the experimental conditions and analytical performance. In most studies, the amount of sample is seen to be in the 0.5$2 \mathrm{~g}$ range. Large glass columns have been used for applications involving high sample amounts in order to determine trace-level concentrations of PCBs and PCDD/Fs [134] and pesticides [135]. In one study, Chu et al. [135] mixed $10 \mathrm{~g}$ apple juice with $20 \mathrm{~g}$ diatomaceous earth, transferred the mixture to a glass column and leached the pesticide residues with $160 \mathrm{~mL}$ hexane-dichloromethane $(1: 1)$. The eluent was concentrated to $1 \mathrm{~mL}$ and $1 \mu \mathrm{L}$ was injected to GC-MS in SIM mode. LODs for 266 pesticides were 3-18 $\mu \mathrm{g} \mathrm{kg}^{-1}$, with analyte recoveries close to $100 \%$. There are, on the other hand, also several papers which feature miniaturized MSPD of, typically, some 25-100 mg of sample [131, 136, 137]. To quote an example, Ramos et al. [136] analysed PCBs in freeze-dried meat, where only $0.1 \mathrm{~g}$ meat was dispersed with $0.1 \mathrm{~g}$ of acid silica. The recoveries were $80-130 \%$ and the LODs for ECD detection were below $0.3 \mathrm{ng} \mathrm{g}^{-1}$. Figure 11 shows a GC- $\mu$ ECD chromatogram. The approach merits attention because of (1) its practicality if sample size is limited as, e.g., with single-insect studies [137], and (2) the significantly reduced volume of elution solvent, which facilitates further handling. Actually, with solvent volumes as low as a few millilitres, one would expect on-line coupling of MSPD and GC, or LC, to have been implemented but to the best of our knowledge, no papers dealing with this topic have been published so far.

Navarro et al. [138] compared MSPD and LLE for the analysis of fungicides in vegetables with both techniques using ethyl acetate as solvent. The results showed satisfactory agreement, but the LLE extracts contained much more interfering compounds. Picó et al. devoted two (LC-based) studies [132, 139] to a comparison of MSPD, SBSE and SLE (solid-liquid extraction) for the determination of pesticides in fruit with MS detection. The authors concluded that MSPD should be preferred because it is easier to perform and faster, and shows equal accuracy.

In a comparison of MSPD and MAE for the determination (admittedly, by LC) of 16 PAHs in soil, the analytical performance data of the two techniques were found to be closely similar. As for MSPD, extraction and clean-up of the lyophilized samples were carried out in a single step, using a Florisil/silica sorbent mixture [140].

\section{Direct Thermal Desorption}

Thermal desorption (TD) is a valuable alternative to headspace techniques for the isolation of volatile compounds from non-volatile solid, semi-solid and, occasionally, liquid matrices, and a wide variety of applications has been reported in the literature. Although TD is not really a new technique, fully automated systems are only in use for slightly over 10 years. One of the first examples was the use of automated thermal desorption (ATD) for the determination of volatile constituents of plants and food [152]. Typically, a $1-40 \mathrm{mg}$ sample is placed in a desorption cartridge between two glass-wool plugs. By heating the cartridge for a pre-set time, the volatiles are desorbed and, next, adsorbed on a cold Tenax trap. Heating of the trap effects rapid transfer of the analytes to the GC for further analysis. Similarly, TD-GCMS can be used as a screening method, e.g., for chlorinated hydrocarbon contamination in soil [153]. In this case, a dual-tube system was used to enable focusing of the analytes on a Tenax-pluscarbon trap prior to their release and transfer to the GC system. Total analysis including the sample preparation, required less than $1 \mathrm{~h}$. TD is also used to study the relatively low-molecular-mass components present in (oil-containing) 


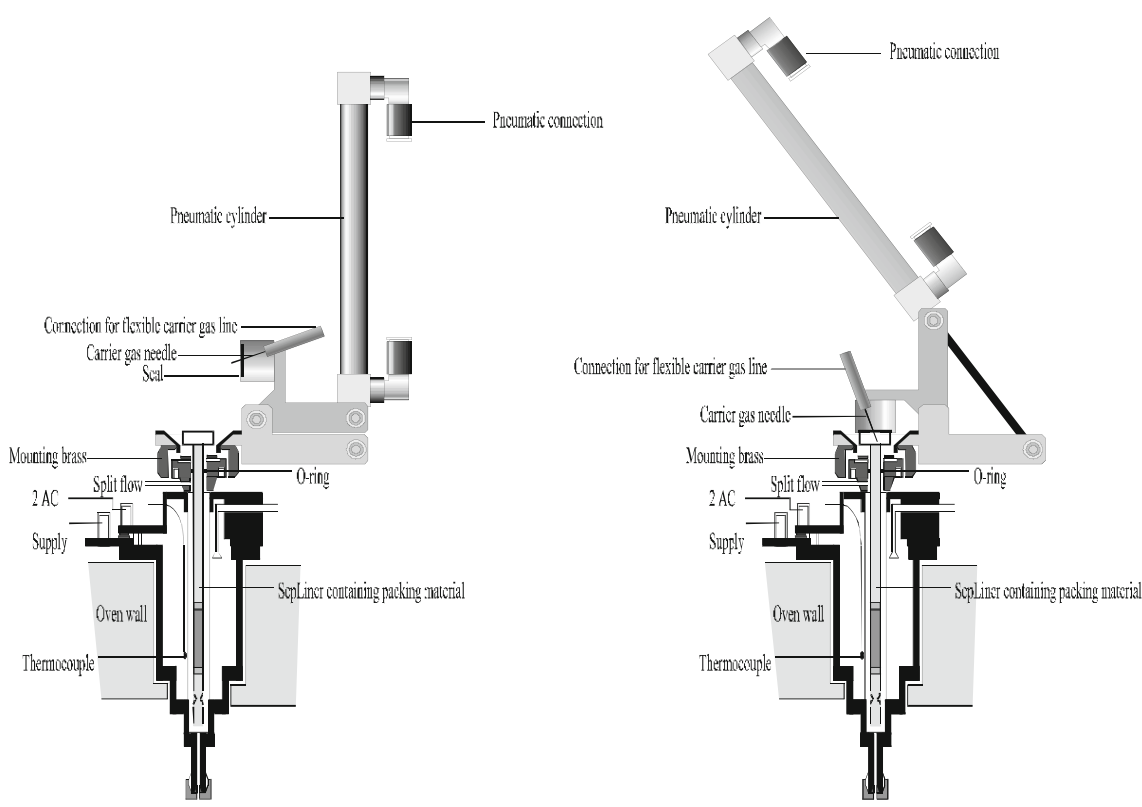

Fig. 12. DTD automated liner exchanging head [163]. Left, open; right, closed

rocks [154, 155]. Pyrolysis techniques are used to study the very-high-molecularmass structures in such samples which are not directly amenable to GC [156, 157]. An inexpensive and user-friendly system for multi-step TD-pyrolysis-GC for use in geochemical analysis was designed by van Lieshout et al. [158]. Thermal treatment was performed inside a PTV injector which served as both the TD unit and the pyrolyser system. Sample amounts ranging from sub-mg amounts up to $2 \mathrm{~g}$ were weighed directly into the liner of the injector. The system was also used for polymer characterization [159].

TD is being increasingly used for the analysis of aerosols (see, e.g., [160, 161]) and, also in this area of application, primarily in order to replace time-consuming procedures involving solvent extraction (and evaporation) by more direct approaches in which (parts of) aerosol-loaded filter material is packed into a GC injector liner and directly subjected to thermal desorption plus instrumental analysis [162]. The main advantages are reduced sample handling and improved analyte detectability (9500 times better LODs than solvent extraction [162]), while there is no need to modify the GC-MS set-up. The practical usefulness of this, so-called direct thermal desorption (DTD) is discussed in some more detail below.

As indicated above and in the section on applications below, the basic instrumentation needed for (D)TD studies is rather simple. However, because of the (semi-) solid nature of most samples, automation of the sample introduction is difficult. In 2002, de Koning et al. [163] designed a system which features fully automated liner exchange. To this end, a Focus XYZ sample preparation robot was equipped with a newly developed injector head to open and close the Optic 2 (ATAS GL, Veldhoven, The Netherlands) injection interface. In Fig. 12 the injector head is shown in the open (left) and closed (right) position. The specially designed liners, capped with a standard crimp cap, are placed in a sample tray and transported to the thermal desorption device. Both liner transport and liner exchange (which can be performed after each analysis) are automated. Two systems are commercially available today, the ALEX (Automatic Liner EXchange) from Gerstel (Mülheim, Germany) [164] and the LINEX (LINer Exchanger) from ATAS GL [165]. As a first application, the wood preservative $N$-cyclohexyl-diazeniumdioxide (HDO) was quantified in $10 \mathrm{mg}$ of sapwood powder by means of DTD-GC-MS $(m / z$ 114). The reproducibility of the procedure (5-10\%) and the LOD (4 mg $\mathrm{HDO} / \mathrm{kg}$ wood) were fully satisfactory [166].

Applications The number of applications of DTD-GC-MS (and DTD$\mathrm{GC} \times \mathrm{GC}-\mathrm{MS})$ is still rather limited but, on the other hand, the published examples do show that the approach can be used successfully for a wide range of samples, and yield interesting results (Table 7). Recent work by three groups of authors is briefly discussed below.

Özel and co-workers used DTD combined on-line with $\mathrm{GC} \times \mathrm{GC}-\mathrm{ToF}$ MS to analyse the essential oil of pistachio hulls [34] and the volatile components of Cheddar cheese [167]. In both cases, $10 \mathrm{mg}$ of sample were placed in a GC injector liner, glass wool being used to hold the sample in place. After a brief purge at ambient temperature to remove water vapour, the DTD programme was started. The head of the first-dimension GC column was cryo-cooled to ensure trapping of the analytes. With the essential oil, some 100 compounds were identified-with the cheese, some 55.

Zimmermann and his group [168171] collected particulate matter $(\mathrm{PM}<2.5 \mu \mathrm{m})$ on quartz fibre filters and placed filter punches representing 1$2.5 \mathrm{~m}^{3}$ of sampled air into an injector liner together with an IS mixture for quantification. DTD-GC-ToF MS revealed the presence of some 1,500 compounds, out of which some 200 could be (semi-)quantified. When $\mathrm{GC} \times \mathrm{GC}$ was used instead of GC, some 10-fold more, i.e., over 10,000 compounds were detected. An example of a DTD$\mathrm{GC} \times \mathrm{GC}-\mathrm{ToF}$ MS contour plot is given in Fig. 13.

A technique which is strongly related to DTD is DMI (or DSI: difficult matrix/ sample introduction) which was first described by Amirav et al. [172, 173]. The authors used an exchangeable micro- or $\mu$-vial which holds the sample and is manually placed in the GC injector using a ChromatoProbe (Varian, Palo Alto, CA, USA) [160, 174]. After purging the injector is heated to evaporate the analytes. At the end of the run, the $\mu$-vial which contains non-volatile sample constituents is removed from the 


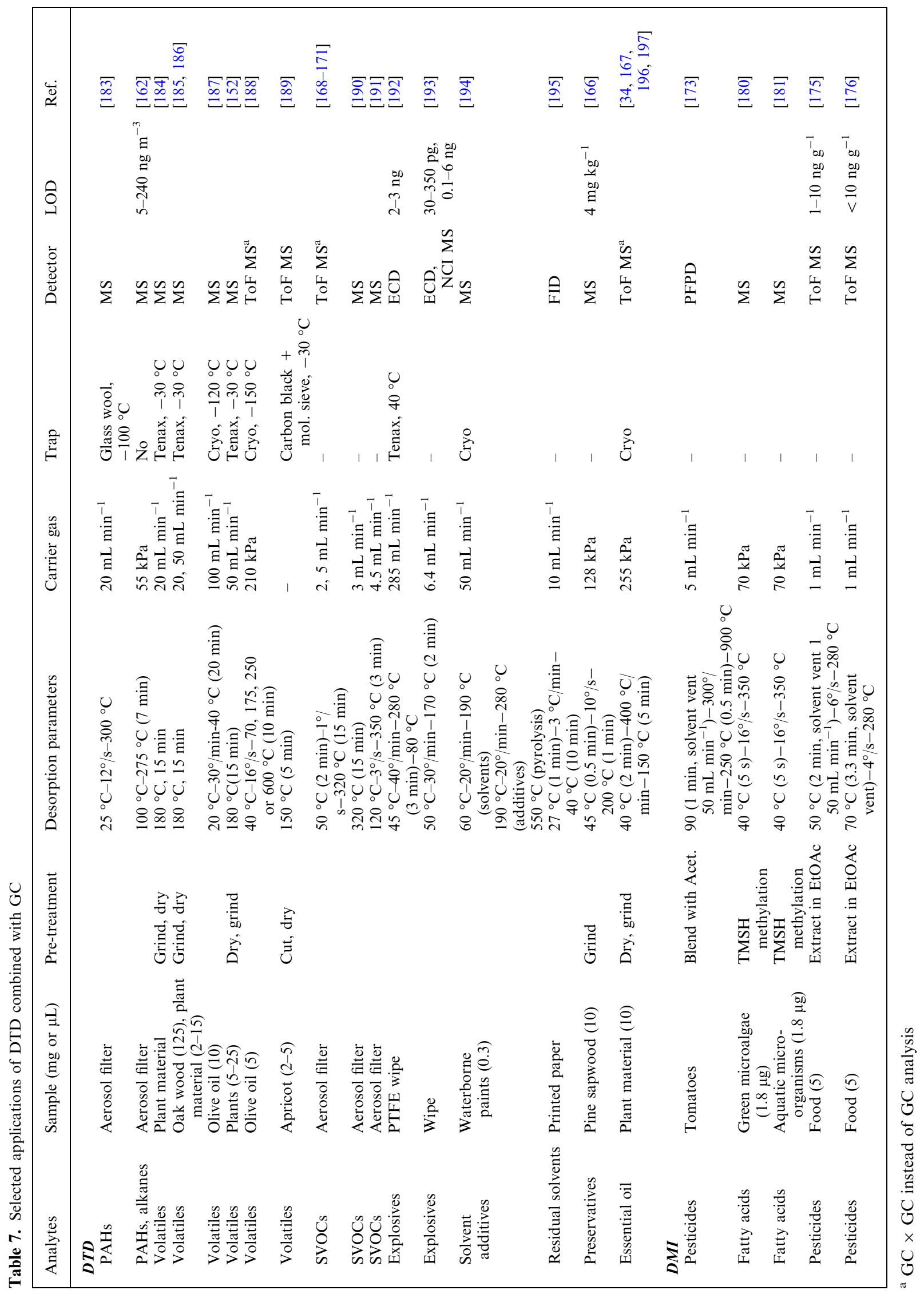


(a)

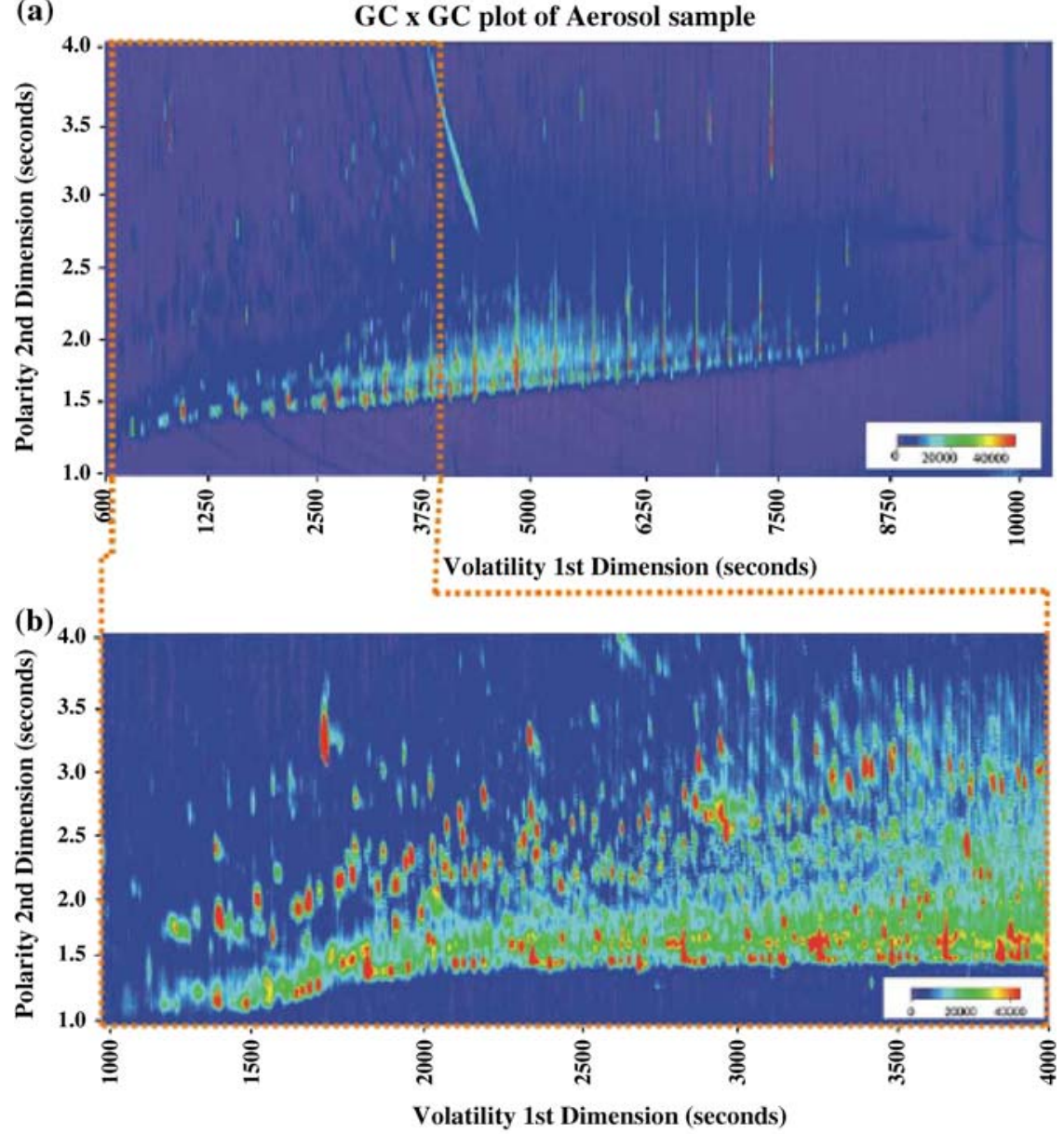

(c) Extracted Peaks overlaid with Bubble plot of chromatographic peaks

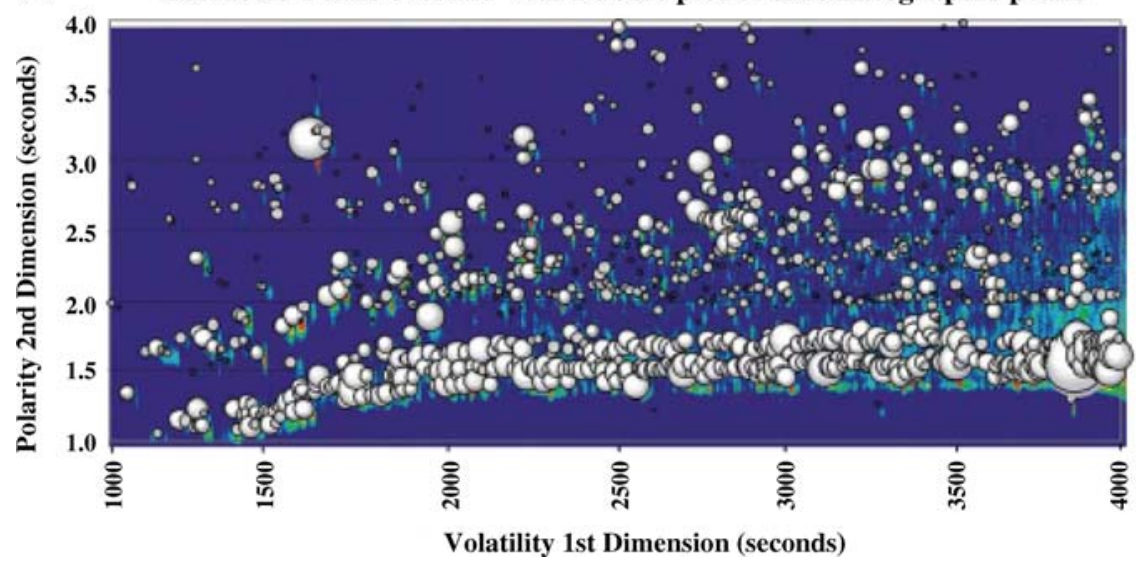

Fig. 13. DTD $-\mathrm{GC} \times \mathrm{GC}-\mathrm{ToF} \mathrm{MS}$ total ion current contour plot of an aerosol sample: (a) shows the full chromatogram of the analysed aerosol and (b) the enlargement of a selected section; (c) represents this section overlaid with a bubble plot generated from the peak apices of the same section [168]

injector. De Koning et al. [175] included this approach in the liner-exchange setup discussed above to analyse pesticides in food by GC-ToF MS. The XYZ sample processing robot now holds a tray with a number of sample extracts, while an additional tray contains an equal number of liners containing a $\mu$-vial. Just before analysis, a fresh liner is placed in the injector. After the sample preparation, the robot injects an amount of sample extract in the $\mu$-vial in the liner for $\mathrm{GC}$ analysis. The LODs were 1$10 \mathrm{ng} \mathrm{g}^{-1}$, which meets the European directives for baby-food analysis. Patel and co-workers published a related study [176] on the use of DMI in contract laboratories. Silanization of the DTD liners was found to be particularly important to mask active sites present in the frit. Elimination of a commonly employed GPC or SPE clean-up step accelerated sample processing and provided a significant reduction of the solvent usage. Other authors [177-179] combined rapid analyte isolation by means of liquid partitioning plus dispersive SPE (to remove fats and waxes) with DMI to determine pesticide residues in vegetables and fruits. Blokker et al. [180] used the DMI approach to record the fatty acid profiles of microalgae and vegetable oils (which included in-unit transesterification of the target compounds into FAMEs) and the chemical analysis of spores and pollen (which could be carried out with less than ten pollen per analysis). Akoto et al. [181] used the same approach for the fatty acid GC-MS profiling of raw biological samples. The authors stated that up to 18 algal and microbial cell samples could be analysed per day.

Özel et al. [34] compared the performance of DTD, steam distillation (SD) and SHWE for the determination of volatile compounds from plant leaves. The authors concluded that the chemical compositions of the volatile fractions obtained by SD and SHWE were similar, but a greater number of compounds was isolated when using DTD. The conclusion partly agrees with a much earlier study [182] where it was shown that, although the chromatographic profiles of plant volatile fractions obtained by SD and DTD were similar, the recovery of both low-volatile and thermolabile compounds were better using DTD.

\section{Solid-Phase Extraction}

In the late 1970s, SPE was introduced for the pre-treatment of aqueous samples. Since that time, off-line and, 
specifically, on-line trace enrichment and clean-up by means of SPE using precolumns or (disposable) cartridges has become a very popular-probably the most popular-column-switching technique in LC. Most techniques and much of the hardware used today for off-line SPE-GC and on-line SPE-GC were adapted from the corresponding LC techniques. In the 1990s, semi- and fully automated systems were designed for both chromatographic techniques, and scores of off-line, at-line and on-line applications were reported. Consequently, many of the more informative reviews [198-200] were published in that period-with environmental applications being the main field of interest for GC-based studies.

SPE cartridges have dimensions of, typically, 10-20 mm length x 1-4.6 mm ID. In most instances the cartridges are packed with $10-30 \mu \mathrm{m}$ sorbents such as C18- or C8-bonded silica or a styrenedivinylbenzene (SDB) copolymer. These are essentially non-selective sorbents because for many applications the SPE step should primarily guarantee the enrichment of analytes covering a wide range of polarities, with the subsequent chromatographic separation (plus detection) step ensuring the proper recognition of the individual compounds. Since separation-plus-detection is much more powerful in GC than in LC analysis, with the former technique the bonded silicas and the copolymer are virtually the only sorbents used in real-life applications. A typical set-up for SPE-GC is depicted in Fig. 14. After cartridge conditioning, a sample volume of, often, some $10 \mathrm{~mL}$ is loaded at a speed of several $\mathrm{mL} \mathrm{min}^{-1}$, the cartridge is cleaned with a few millilitres of water, and dried for some 2030 min with nitrogen at ambient temperature. Next, the enriched analytes are desorbed with as little as $100 \mu \mathrm{L}$ of an organic solvent-frequently ethyl or methyl acetate - and transferred on-line to the GC part of the system for further analysis. There is abundant experimental evidence [201-203] that with, e.g., GCMS, GC-NPD or GC-AED as instrumental analytical techniques, LODs of 5$50 \mathrm{ng} \mathrm{\textrm {mL } ^ { - 1 }}$ can be obtained for a wide variety of micro-contaminants in $10-\mathrm{mL}$ real-life samples.

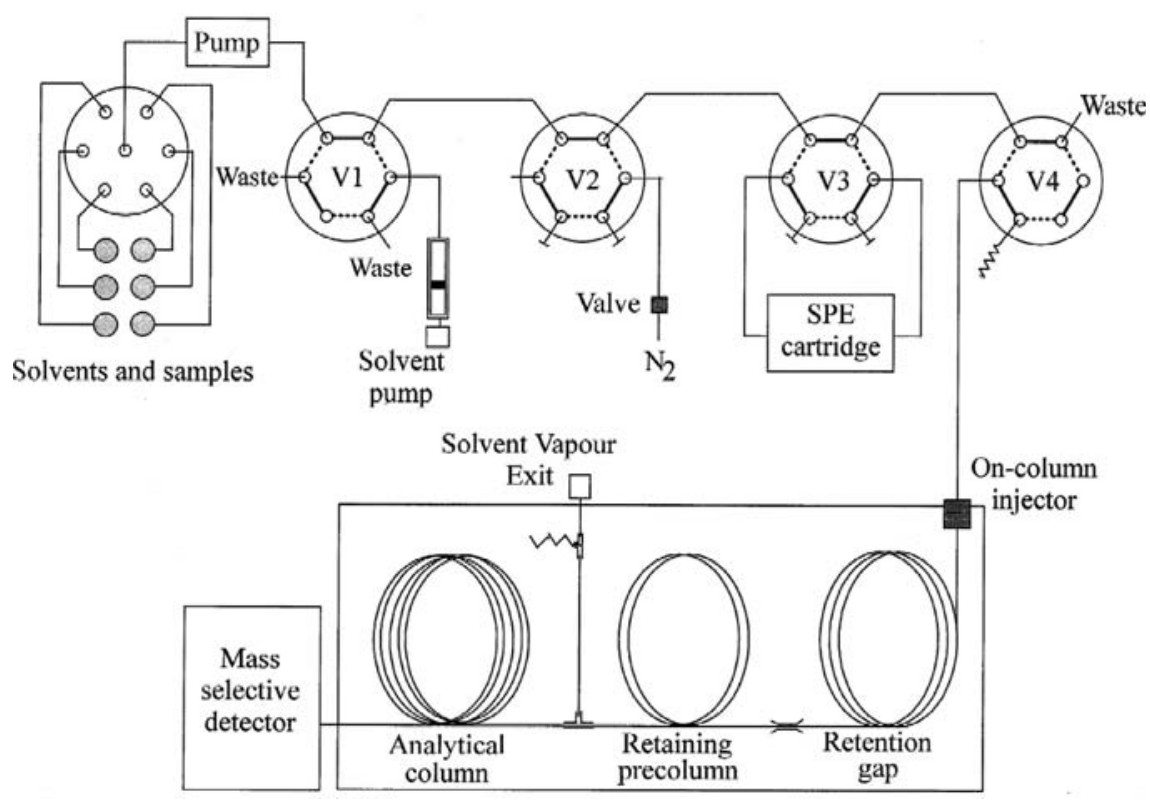

Fig. 14. Scheme of an on-line SPE-GC-MS system [202]

The above conclusion is an important one because (semi-) automated SPE-GC is indeed a very powerful technique but is, at the same time, somewhat more complex than is appreciated by many analysts who, therefore, prefer to use an off-line procedure. The protocol is, then, essentially the same as the one given above and, if desired, the SPE part of the procedure can be carried out fully automatedly on a stand-alone instrument such as the Symbiosis (Spark, Emmen, The Netherlands) - the successor of the highly successful Prospekt - the MPS2SPE (Gerstel) or the ASPEC XL (Gilson, Middleton, WI, USA). However, the SPE eluate containing the analytes is now collected in a vial and, typically, some $25 \mu \mathrm{L}$ are injected by means of LVI-GC. In other words, there is a fourfold loss in performance compared with the on-line operation (25 out of $100 \mu \mathrm{L}$ ), which can either be accepted (if analyte detectability does not create problems) or can be compensated by loading a fourfold larger volume (which usually will not cause breakthrough problems: experience shows that these do not tend to occur for sample volumes of less than $100 \mathrm{~mL}$ ).

One main advantage of the various on-line set-ups briefly referred to above was the substantial sample-volume reduction from the conventional 100-
$200 \mathrm{~mL}$ (combined with classical $1-\mu \mathrm{L}$ injection volumes) to, typically, 10 and sometimes even 1-2 mL, which could be effected without adversely affecting the analytical performance of the procedures. Here, one should add that SPE also is a rewarding technique when ultra-trace levels of, e.g., $0.01-0.5 \mathrm{ng} \mathrm{mL}^{-1}$, of micro-contaminants have to be determined in marine waters. In such cases, sample volumes typically are as large as 5-20 L and off-line procedures involving the use of 47-90 mm diameter $\mathrm{C}_{18}$ or SDB disks or stacked cartridges packed with graphitized black carbon are preferably used.

Applications For the reasons outlined above, most of the selected on-line applications included in Table 8 are from the 1990s rather than the past few years. For readers interested in setting up a system of their own - where aspects such as complete removal of water from the loaded cartridges to prevent GC column problems, re-use of cartridges and complete retention of even volatile analytes are relevant issues - two other papers are recommended [202, 204]. The table also features several very-largevolume applications.

One typical example is described by Hankemeier et al. [202] who used SDBSPE-GC-MS to analyse $10-\mathrm{mL}$ river water samples (without and with spiking 


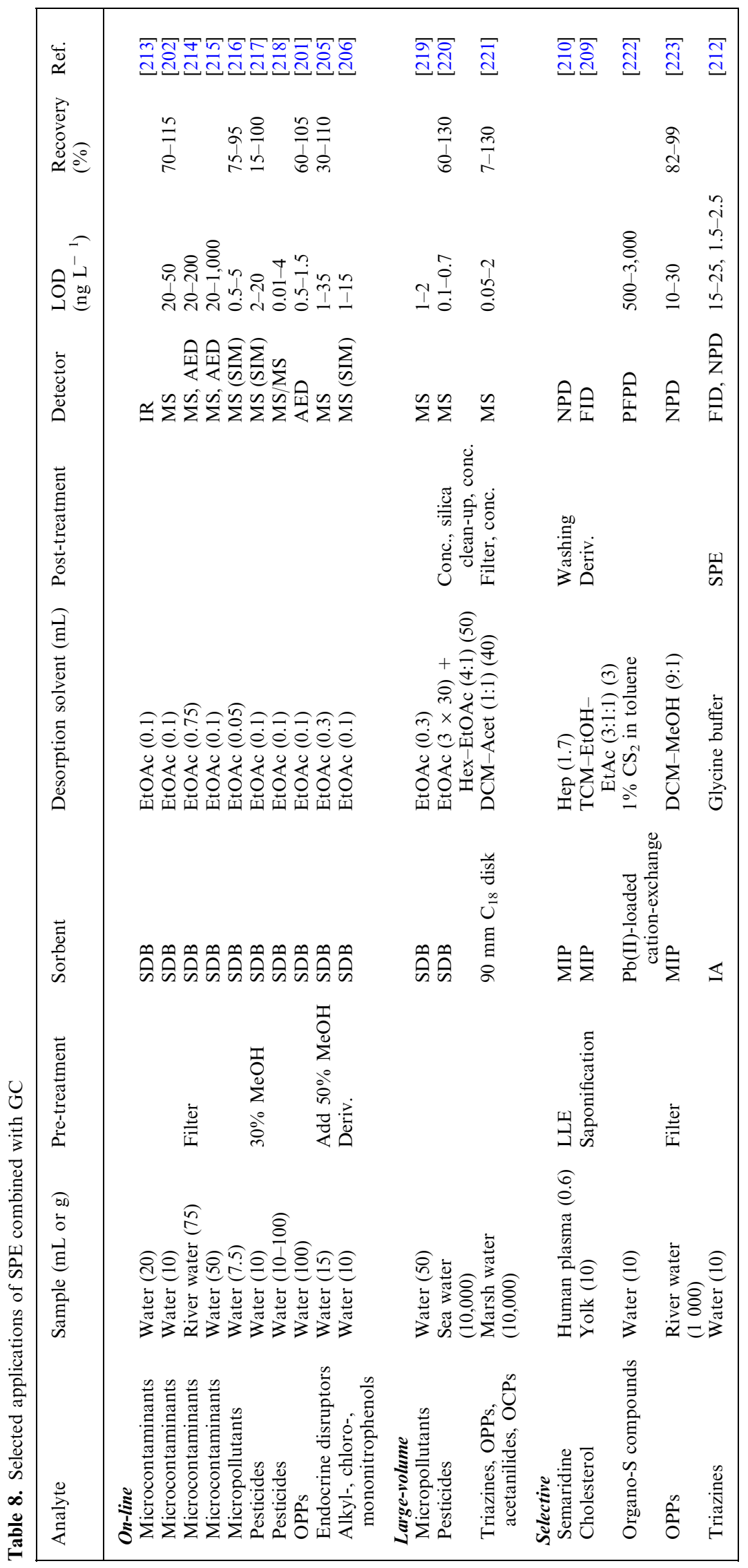


of 86 micro-contaminants at the $0.5 \mu \mathrm{g} \mathrm{L}^{-1}$ level). Full-scan MS traces are shown in Fig. 15. LODs were in the 20-50 ng $\mathrm{L}^{-1}$ range or lower for essentially all analytes. The identification potential of the procedure is illustrated by $m / z$ traces of the four characteristic ions of peak 11 (benzaldehyde) in the raw, i.e., non-spiked, water. Its concentration was calculated to be approx. $40 \mathrm{ng} \mathrm{\textrm {L } ^ { - 1 }}$. A similar approach was used for the analysis of endocrine disruptors such as atrazine, hexachlorobenzene, DDT and benzo[a]pyrene by SPE-GC-MS [205]. In this case the $15-\mathrm{mL}$ water sample contained $50 \%$ methanol to prevent sorption problems. $100 \mu \mathrm{L}$ ethyl acetate were used for analyte desorption. The LODs for the target analytes were 1$40 \mathrm{ng} \mathrm{L}^{-1}$. Jahr [206] used automated SPE-GC-MS to determine 26 alkyl-, chloro-, and nitrophenols (after their insample derivatization) in drinking water and river water. Time-scheduled SIMMS enabled target analysis down to, typically, LODs of 2-10 $\mathrm{ng} \mathrm{L}^{-1}$.

So far, no mention has been made of more specialized SPE phases such as restricted-access media (RAM), molecular imprinted polymers (MIP), immunoaffinity extraction (IAE) phases and other class- or compound-selective sorbents. This is because almost all applications which utilize one of these selective types of sorbent use LC for subsequent analysis (see, e.g., [207, 208]). Although this is, therefore, an area largely beyond the scope of the present review, a few pertinent examples are included in Table 8. Shi et al. [209] analysed cholesterol in yolk. After saponication and the addition of water and hexane, $1 \mathrm{~mL}$ of the organic phase was loaded on the MISPE cartridge. After repeated washing, elution was done with $3 \mathrm{~mL}$ chloroformethanol-acetic acid (3:1:1). The eluate was evaporated to dryness and the residue dissolved in pyridine with subsequent derivatization with BSTFA. Analysis by means of GC-FID showed that MISPE created more selectivity than $\mathrm{C}_{18}$-SPE treatment. However, most of the extra clean-up was created in parts of the GC chromatogram far removed from the analyte position. A rather similar conclusion holds for the MISPEbased determination of semaridine in

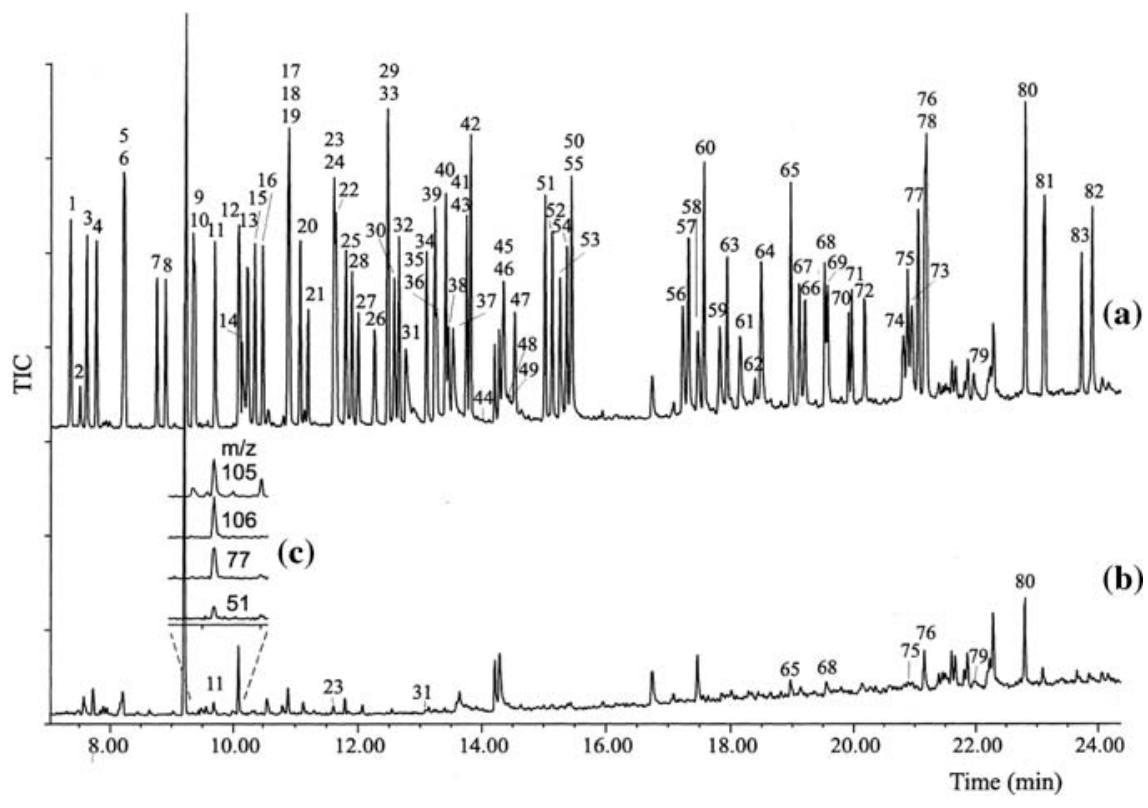

Fig. 15. TIC chromatogram for SPE-GC-MS of $10 \mathrm{~mL}$ of river Rhine water (a) spiked at the $0.5 \mu \mathrm{g} \mathrm{L}{ }^{-1}$ level with 86 microcontaminants and (b) non-spiked. A $50-\mu \mathrm{L}$ volume of methyl acetate was used as presolvent. For peak assignment, see ref. [202]. The insert (c) shows the mass chromatograms of four characteristic masses of benzaldehyde $(\mathrm{m} / \mathrm{z} 51,77,105$ and 106). The time scale for the mass chromatogram is twice as large as for the TIC chromatogram

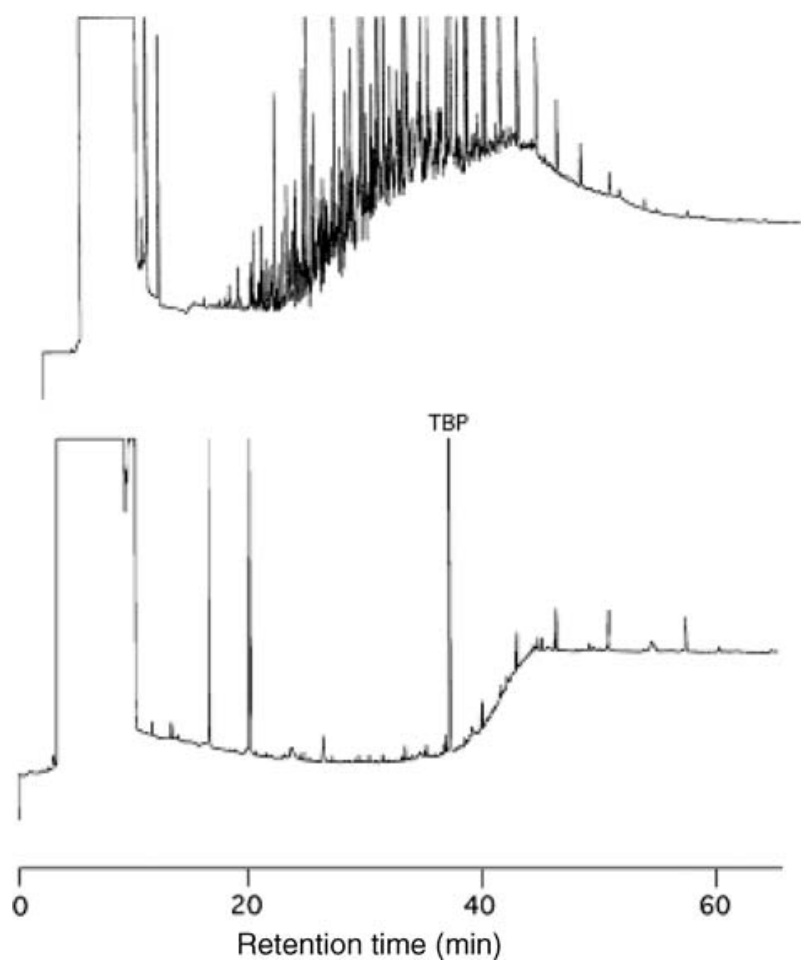

Fig. 16. GC-FID of TBP-spiked diesel sample (top) and the fraction retained by the TBPspecific MIP (bottom) [211]

plasma [210]. For the selective extraction of tributylphosphate (TBP) from diesel, Harvey [211] injected $20 \mu \mathrm{L}$ of diesel on a MIP column $(37 \times 3.0 \mathrm{~mm})$. After elution, the TBP-containing fraction was analysed by LVI-GC-FID. Figure 16, 


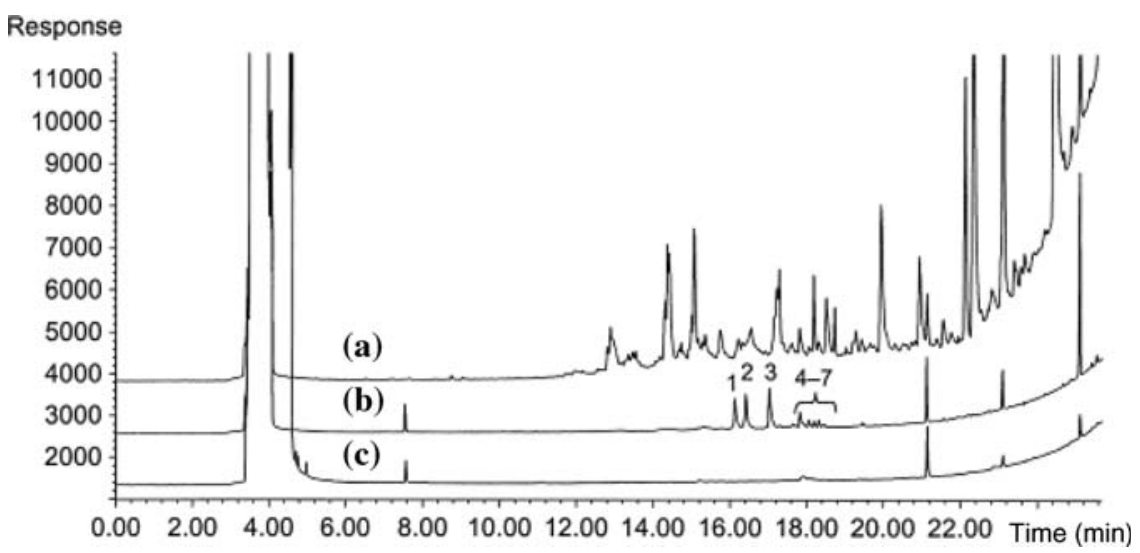

Fig. 17. GC-FID chromatograms of an extract obtained by (a) on-line SPE and (b) on-line IASPE of $10 \mathrm{~mL}$ of municipal waste water, spiked with $1 \mathrm{mg} \mathrm{L}^{-1}$ of seven triazines. (c) Blank run of IASPE-GC-NPD of $10 \mathrm{~mL}$ of HPLC-grade water. $\mathbf{1}=$ Atrazine; $\mathbf{2}=$ Terbuthylazine; $\mathbf{3}=$ Sebuthylazine; $\mathbf{4}=$ Simetryn; $\mathbf{5}=$ Prometryn; $6=$ Terbutryn; $\mathbf{7}=$ Dipropetryn [212]
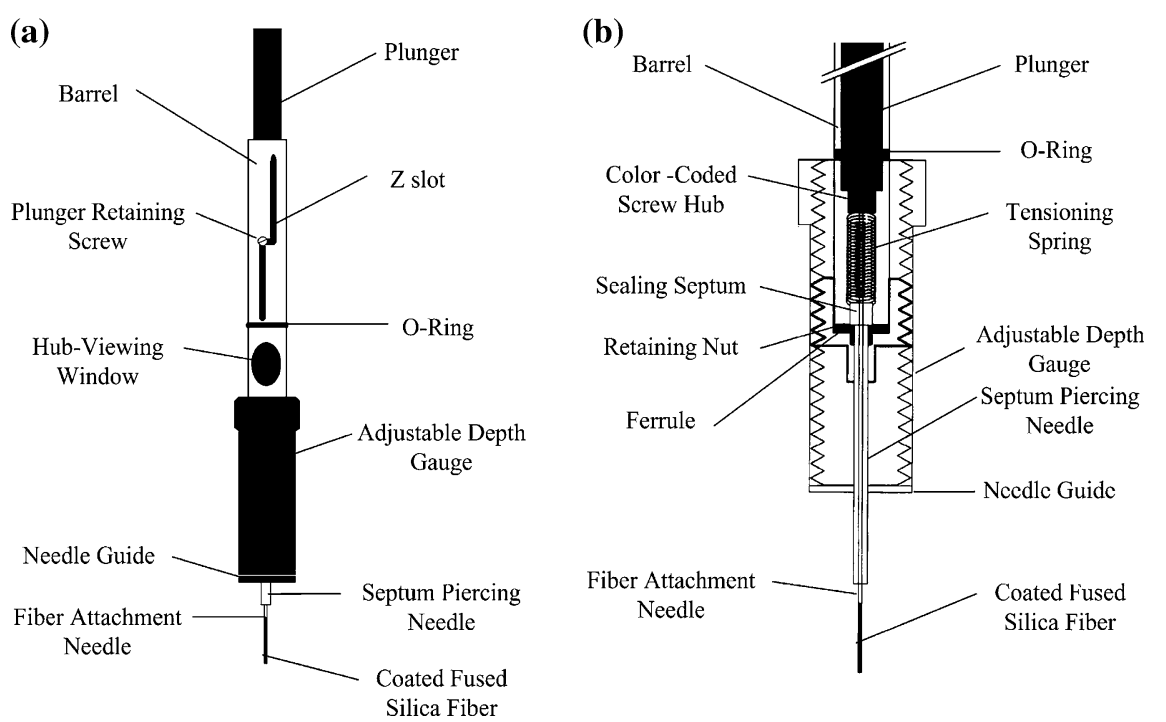

Fig. 18. Commercial SPME device [234]. (a) SPME fibre holder; (b) section view of SPME holder and fibre assembly

shows the chromatogram of that fraction which is (not surprisingly!) much cleaner than the chromatogram of the original diesel sample.

On-line IASPE-GC-FID/NPD was used to determine triazines in $10-\mathrm{mL}$ water samples [212]. Since the material is not compatible with an organic solvent, after enrichment the analytes were eluted with an aqueous glycine buffer and transferred on-line to an SDB cartridge. After clean-up and drying of the cartridge, the entire extract was desorbed with ethyl acetate and transferred on-line to the GC column. The selectivity was such that a non-selective FID could be
Basically, the technique enables the trace enrichment of analytes by the exposure of a fused-silica fibre coated with an appropriate sorbent layer, for a selected time, to a gas or liquid sample, with the subsequent (rapid) desorption of the target analytes by heating the exposed fibre in the injection port of a GC. A number of fibre coatings, which offer a range of analyte solubilities and porosities, are commercially available. These include the highly popular non-polar polydimethyl siloxane (PDMS) and more polar coatings such as PDMSdivinylbenzene copolymers, polyacrylates and mixtures of carboxen (an inorganic adsorbent) and PDMS or divinylbenzene. Their mutually different physicochemical characteristics help to widen the application range of the technique. Fibre coatings are available in increasing thicknesses from 7-150 $\mu \mathrm{m}$, which increases the partitioning ratio of the target analytes - and, hence, analyte detectability - but also increases equilibration times.

The schematic of an SPME device is shown in Fig. 18. The fibre is mounted in a syringe-like device for protection and ease of handling. The needle serves to conveniently pierce the septum of a sample vial or the GC injector. That is, during analyte extraction and desorption, the fibre is exposed but during transfer of the sample to the GC injector, it is inside the protective needle. Obviously, this is an elegant approach, and the fact that no solvent is required is a distinct advantage. On the other hand, it is a disadvantage that the fibres are rather fragile, even though they are shielded when out of the sample or injector; they can also be damaged by the buildup of involatile material from the samples. [To improve the robustness of the technique, Lipinski [231] introduced (automated) solid-phase dynamic extraction (SPDE) which uses needles prepared from stainless-steel capillary columns, with PDMS-coated inner walls.]

In a typical SPME experiment, the coated fibre is exposed directly immersed in, or to the headspace of, a small volume of liquid or sample extract, usually some $2-5 \mathrm{~mL}$. The analytes partition into the stationary phase until plateau 
conditions are reached, which typically takes $2-60 \mathrm{~min}$. The process can be aided by salting-out (addition of, e.g., $25 \% \mathrm{NaCl}$ ) and/or $\mathrm{pH}$ adjustment, sample agitation (to speed up analyte transport from the bulk of the solution to the vicinity of the fibre) and heating [232, 233]. Adverse matrix effects can be avoided by applying a standard addition procedure for quantification or, less frequently, using protective membranes to prevent adsorption of matrix components on the fibre [226].

If selective detection, such as MS in the SIM mode or ECD, is used, LODs for both volatile and semi-volatile analytes typically are in the low-ng $\mathrm{mL}^{-1}$, and sometimes in the $\mathrm{ng} \mathrm{L}^{-1}$, range. However, one should consider that SPME (as is also true for e.g., SBSE; see section on SBSE) is an equilibrium technique. That is, although favourable analytes can be extracted essentially quantitatively, there are also many classes of compounds for which this is certainly not true-actually, it is not unusual to find recoveries of less than $10 \%$ in the published literature (Table 9). For such classes of compounds, conventional SPE (cf. section on SPE) can always provide (substantially) better analyte detectability. Admittedly, non-equilibrium methods can also be used for SPME - and also for SBSE and HS - but this will decrease method sensitivity and will require highly precise timing procedures.

As already indicated above, there are three modes of SPME, viz. the often applied direct-immersion extraction (DISPME) and headspace extraction (HSSPME) and the rarely used membraneprotected SPME (Fig. 19). It will be clear that DI-SPME is a very straightforward technique which does not require further discussion. However, exposing the fragile fibres to highly complex samples-which, in addition, can contain high $\mathrm{NaCl}$ concentrations and/or have a too extreme $\mathrm{pH}-$ may well cause damage and, consequently, lead to erroneous results. The increasingly popular HS-SPME mode primarily serves to protect the fibre coating from such damage by high-molecular-mass material such as humic substances or proteins and other non-volatiles present in the sample matrix. Self-evidently, modifying the sample composition now does not create any problems either. One should note that the amounts of analyte extracted into the fibre coating are the same at equilibrium for DI and HS sampling provided the sample vial, and the volumes of the liquid sample and the gaseous headspace are the same. This is due to the fact that the equilibrium concentration is independent of the fibre location in the sample/headspace system. If the above conditions are not satisfied, a significant sensitivity difference between the two approaches exists only for very volatile analytes.

With membrane-protected SPME the main purpose of the barrier also is to protect the fibre against damage, viz. when very dirty samples have to be analysed. In addition, membrane protection can be used for the determination of analytes having volatilities too low for the headspace approach. In principle, a suitable membrane can add a degree of selectivity to the extraction process. However, the analyst should consider that the kinetics of membrane extraction are substantially slower than for direct extraction, because the analytes must diffuse through the membrane before they can reach the coating.

In the literature, rather much attention is devoted to extending the application range of SPME to more polar compounds. Generally speaking, this is an approach which is not to be recommended today, since most classes of polar compounds can be analysed successfully by means of LC-MS techniques (also see section on Stir-Bar Sorptive Extraction). With the LC-based route, the intact compounds can be subjected to analysis and time-consuming derivatization (which, moreover, often generates artefacts and is frequently not successful at the ultra-trace-level) is avoided. There are, however, also instances when the LC route cannot be used and SPME-cum-derivatization has to be applied [235]. Derivatization can be performed in different ways, with direct derivatization in the sample matrix [236] and on the fibre [237] being most popular. Derivatization in the GC injection port is also used [238]. As regards onfibre derivatization, there are two modes of operation, viz. (1) sampling of the target analytes on the fibre with subsequent exposure of the fibre to the HSderivatizing reagent solution, and (2) exposure of the fibre to the HS analyte solution after it has been exposed to the derivatizing reagent solution. Practical examples of each of these approaches will be given below, in the section on applications.

The SPME technique is marketed by Supelco (Bellefonte, PA, USA). Most reported applications are of the manual type. However, automated analysis can be performed by using systems commercialized by Varian (Palo Alto, CA, USA) [174, 236] and CTC (Zwingen, Switzerland) [239-241]. Recently, Pawliszyn and his group reported the automation of SPME on a 96-well plate format [242], which they claim to be a viable approach compatible with both GC and LC platforms.

Applications In the early years, SPME was used primarily for the determination of relatively volatile compounds of environmental interest [243, 244]. Today, there are also many applications in the biomedical field [245] and for food analysis [246]. Moreover, as was discussed above, the technique is also used for less volatile compounds [234]. A number of relevant applications are listed in Table 9. Some of these are briefly discussed below.

A popular application of SPME is the analysis of aroma compounds in wine. To give an example, Peña et al. [247] determined monoterpenes by adding $\mathrm{NaCl}$ to $7 \mathrm{~mL}$ of wine to obtain a final salt concentration of $25 \%$. SPME was performed by immersing a $100-\mu \mathrm{m}$ PDMS-coated fibre for $15 \mathrm{~min}$ in the sample, with stirring at $1,100 \mathrm{rpm}$. With analyte recoveries of $71-91 \%$, the LODs (TIC MS) were $11-25 \mu \mathrm{g} \mathrm{L}^{-1}$. In the environmental field, HS-SPME was used to determine volatile organochlorines in landfill leachates [248]. $10 \mathrm{~mL}$ of sample were put in a $12-\mathrm{mL}$ vial. No salt was added and the sample was kept at room temperature. The HS-SPME procedure, which used a 10- $\mu \mathrm{m}$ PDMS-coated fibre and stirring at $900 \mathrm{rpm}$, was complete in 2 min. With LODs (SIM MS) of 0.05$0.10 \mathrm{ng} \mathrm{mL}^{-1}$ and analyte recoveries of 


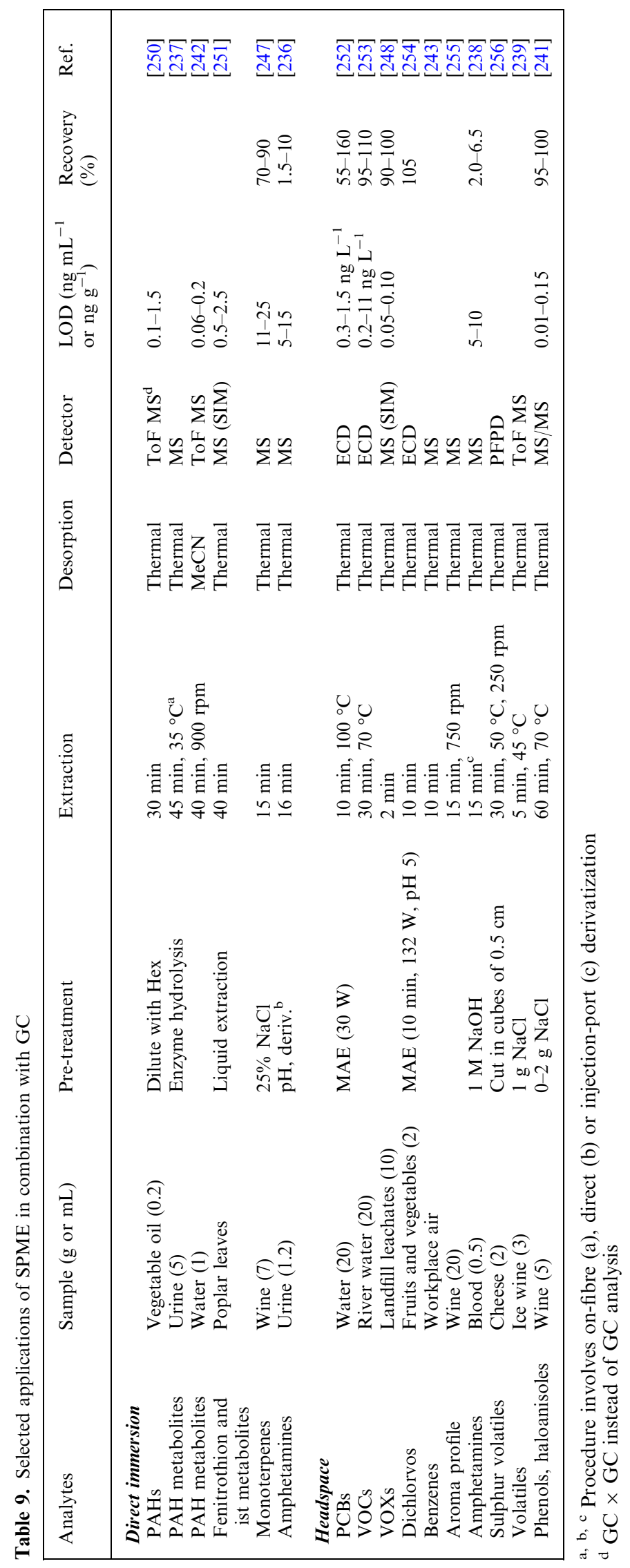


93-100\%, the results were closely similar to those found with conventional headspace (HS) analysis. However, HSSPME was faster than HS (2 min vs. $15 \mathrm{~min}$ ); on the other hand, HS gave more precise results.

As for derivatization, the direct approach has been used for the automated SPME determination of amphetamines (as carbamates) in buffered urine samples, with propylchloroformate as derivatization agent [236]. Analyte recoveries were less than $10 \%$ and the LODs (TIC MS) were somewhat high (5-15 ng mL $\left.\mathrm{m}^{-1}\right)$. The same compounds were also analysed in whole blood via HS-SPME and injection-port derivatization with heptafluorobutyric anhydride [238]. Desorption-cum-derivatization took only $3 \mathrm{~min}$. Finally, the on-fibre alternative was applied for, e.g., PAH metabolites in urine [237]. SPME with an $85-\mu \mathrm{m}$ polyacrylate fibre was rather timeconsuming, i.e., $45 \mathrm{~min}$ at $35^{\circ} \mathrm{C}$ under stirring. After extraction, the fibre was placed in the headspace of a vial containing BSTFA; derivatization at $60{ }^{\circ} \mathrm{C}$ took $45 \mathrm{~min}$. The fibre was then transferred to the hot injection port of the GC and desorbed for $3 \mathrm{~min}$.

As an alternative to SPME, and also SBSE, Burger et al. [249] introduced the use of a sample-enrichment probe (SEP), which was developed primarily for HS analysis. The SEP consists of a thin rod of an inert material, provided at one end with a short sleeve of PDMS for the high-capacity analyte enrichment. After enrichment, the end of the rod carrying the silicone rubber is introduced into the injector and the analytes are subjected to TD-GC. SEP is similar to SPME, but a main difference is that a much larger mass of the sorptive phase is employed. Results of the two techniques for (semi-) volatile organic compounds are stated to be comparable.

\section{Stir-Bar Sorptive Extraction}

In the previous section, the relatively small volume of bound stationary phase used for analyte extraction, was quoted as a main limitation of SPME. This prompted the development of another miniaturized extraction technique by

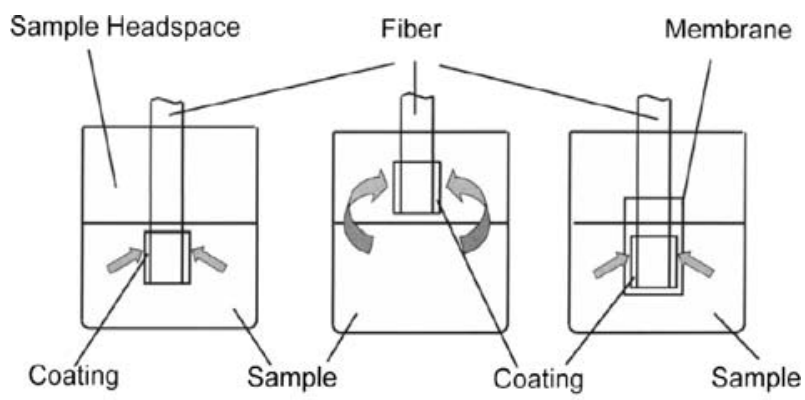

(a)

(b)

(c)

Fig. 19. Modes of SPME operation: (a) DI-SPME, (b) HS-SPME, (c) membrane-protected SPME [226]

Baltussen et al. [257], stir-bar sorptive extraction (SBSE), marketed as the Twister by Gerstel. The technique has been reviewed in several recent papers [258-261].

In SBSE, a magnetic stir bar of, typically, 10-30 $\mathrm{mm}$ length, and coated with $24-47 \mu \mathrm{L}$ of polymethyldisiloxane (PDMS), is rotated in an aqueous sample at some $1,000-1,500 \mathrm{rpm}$ for a preset time which is often very long, i.e., $60 \mathrm{~min}$ or more. After (near-) equilibrium has been reached, the stir bar is removed by hand with tweezers, dipped briefly in distilled water to remove, e.g., absorbed sugars or proteins, placed on tissue paper to remove residual droplets. Rinsing does not cause solute loss, because the adsorbed solutes are present inside the PDMS phase. As an alternative, liquid rinsing with a non-polar solvent such as hexane can be used. Finally, the stir bar is placed in the liner of a thermal desorption system to enable GC analysis [258]. After thermal or liquid desorption, the stir bars can be re-used.

Sample volumes in SBSE typically are on the order of 2-20 mL. There are, however, also several applications which feature sample sizes of 80-200 mL. Since the dimensions of the stir bars selected for analyte extraction are the same as when using more modest volumes, stirring times now frequently are excessive, i.e., 3-15 h [16, 262-264].

As in SPME, analyte extraction from the aqueous phase to the extraction medium is controlled by the partition coefficient between the two phases and, consequently, the $K_{\mathrm{o} / \mathrm{w}}$. Since the amount of sorbent coated on a stir bar is 50-100-fold larger than on an SPME fi- bre, there is a higher phase ratio than in SPME and, hence, a higher extraction efficiency, which results in improved analyte detectability. Today, only PDMS is available as an extraction phase on commercially available stir bars and the large majority of applications therefore use this coating. Here one should add that attempts to apply other coatings have failed mainly because of irreproducible coating or excessive bleeding during thermal desorption [258]. In this context, a recent innovation should be mentioned, viz. the introduction of dual-phase twisters which combine the concentrating capabilities of two sampling materials, PDMS and carbon, which operate in different ways, i.e., by sorption and adsorption, respectively [265]. These stir bars consist of an outer PDMS coating holding an activated carbon material inside. Two magnetic stoppers which close off the ends of the PDMS tube, enable stirring. Increasing recoveries were found for very volatile compounds emitted from plant material and for polar solutes in water.

Most applications of SBSE deal with aqueous samples containing low concentrations of organic compounds. Samples containing high concentrations of solvents, detergents, etc. should be diluted before extraction. If very hydrophobic solutes have to be determined, such as, e.g., PAHs and PCBs, some 10 $\mathrm{vol} \%$ of an organic is added to minimize wall adsorption, as is also done in, e.g., SPE. The negative effect on the partition of the target compounds can be neglected because of their high $K_{\mathrm{o} / \mathrm{w}}$ values; actually, the overall selectivity of the 
procedure will improve because many less hydrophobic compounds will be (partly) flushed to waste. In quite a number of papers, SBSE is combined with in situ derivatization [260, 266-269], especially in order to improve the recoveries of polar analytes with their low $K_{\mathrm{o} / \mathrm{w}}$ values. Derivatization reactions that can be performed in aqueous media include acylation of phenols using acetic anhydride, esterification of acids, acylation of amines using ethyl chloroformate and oximation of aldehydes and ketones using PFBHA. However, in every single instance the analyst should duly consider whether the time-consuming SBSE-cumderivatization procedure should be used or the intact analytes subjected to an LC-based analysis.

SBSE is also used for headspace sorptive extraction (HSSE). A stir bar is hung in the headspace of a sample, often by attaching the magnetic stir bar to a paper clip, which pierces the septum of a headspace vial, by magnetic force. HSSE has been applied to headspace sampling of a wide variety of interesting sample types. These include aromatic and medicinal plants [270], chiral monoterpenes in essential oils in combination with enantio-MDGC-MS [271], coffee [272] and volatile metabolomics from toxigene fungi [273, 274].

Applications SBSE is mainly used for the GC analysis of biological and food samples (Table 10). Some selected applications are briefly discussed below.

Sandra et al. [275] determined fungicides in wine. The authors poured $10 \mathrm{~mL}$ of undiluted wine in a 20 - $\mathrm{mL}$ headspace vial and used a stir bar containing $24 \mu \mathrm{L}$ PDMS to stir the sample for $40 \mathrm{~min}$ at 1,400 rpm. The absorbed compounds were transferred to the GC-MS system by thermal desorption of the stir bar. Although the recoveries were rather low (7-35\%), LODs were in the range of $0.2-$ $2 \mathrm{ng} \mathrm{mL}{ }^{-1}$. In order to determine the seven so-called Ballschmiter PCBs in human sperm, Benijts et al. [276] sonicated $1 \mathrm{~mL}$ of sperm to break the membrane of the spermatozoa and diluted the sample with $9 \mathrm{~mL}$ water-MeOH (1:1). For SBSE, the resulting solution was rotated for $25 \mathrm{~min}$ at $1,000 \mathrm{rpm}$ by a
PDMS-coated stir bar. After thermal desorption, GC-MS was performed in the time-scheduled SIM mode. With analyte recoveries of $30-40 \%$, the LODs were 0.1-3 pg mL ${ }^{-1}$. Kawaguchi et al. [267] applied SBSE for the determination of chlorophenols in $2 \mathrm{~mL}$ of human urine. The sample $\mathrm{pH}$ was adjusted to 11.5 prior to the addition of the derivatization reagent, acetic acid anhydride. SBSE was performed for $60 \mathrm{~min}$ with stirring at $500 \mathrm{rpm}$. GC-MS in the SIM mode resulted in LODs of 10-20 pg mL ${ }^{-1}$ with quantitative analyte recoveries. The extracted-ion-chromtograms for the studied chlorophenols derivates are shown in Fig. 20. HSSE was the sampling method used by Demyttenaere et al. [273] to monitor the mycotoxin production of fungi. The fungi were cultivated in $22-\mathrm{mL}$ vials, and a PDMS stir bar was held in the headspace for $1 \mathrm{~h}$. The mycotoxins were analysed by thermal desorption-GCMS. The authors concluded that SPME is faster (30 min extraction) and simpler, because it does not require a special thermal desorption device and, also, because the concentrations of the target analytes were relatively high. Moreover, SPME can easily be automated and used for fast detection.

\section{Membrane Extraction}

Separation by means of a membrane can be achieved in many ways and very generally, a membrane can be defined as a selective barrier between two phases. When a driving force is applied across a membrane, transport of matter occurs from the donor to the acceptor phase, giving the so-called flux. Separation is achieved when some species are transported to a larger extent than others and, in the ideal case, components of interest are transferred quantitatively, while all other sample components remain in the donor phase.

Membrane separation processes can be classified by means of the driving forces involved. The most important ones are differences of (1) concentration, which cause a molecular flux (transport of molecules), (2) electric potential, which cause an electrical flux (transport of charge) and (3) pressure, which cause a volume flux (transport of bulk liquid or gas). Very often, more than one driving force is present in a membrane separation process.

A wide variety of membrane materials can be used. In many cases, a membrane is a porous network of a synthetic polymer, such as polypropylene, polysulphone or a cellulose derivative. Separation is based only on size-exclusion: sufficiently small molecules can permeate through the pores but larger ones cannot. More selectivity can be obtained with, e.g., ion-exchange membranes, which have positively or negatively charged groups covalently attached to the polymeric membrane material. Separation is now based on both size and charge differences of the various solutes. Non-porous membranes are a rather different class: they consist of a liquid or polymer film, into which a molecule must actually dissolve in order to be able to pass through. For a particular compound, the efficiency of membrane transport now largely depends on its partition coefficients between the different parts of the membrane separation system. Only compounds which are easily extracted from the donor phase into the membrane and, in addition, easily extracted from the membrane into the acceptor phase will be transported. Separation is therefore based on the same principle as in LLE with a subsequent back-extraction and analytes with different physicochemical properties will be extracted to a different extent even if they are of equal size.

Four membrane separation techniques are frequently used for sample preparation. Three of these-dialysis (concentration-driven), electrodialysis (electrically driven) and filtration (pressure-driven) - utilize porous membranes and are combined (mainly) with LC [289, 290]. They are therefore beyond the scope of this review. One technique, socalled membrane extraction, uses nonporous membranes and is combined with LC as well as GC.

The most frequently used membraneextraction system, referred to as supported liquid membrane (SLM), consists of a porous membrane support impreg- 


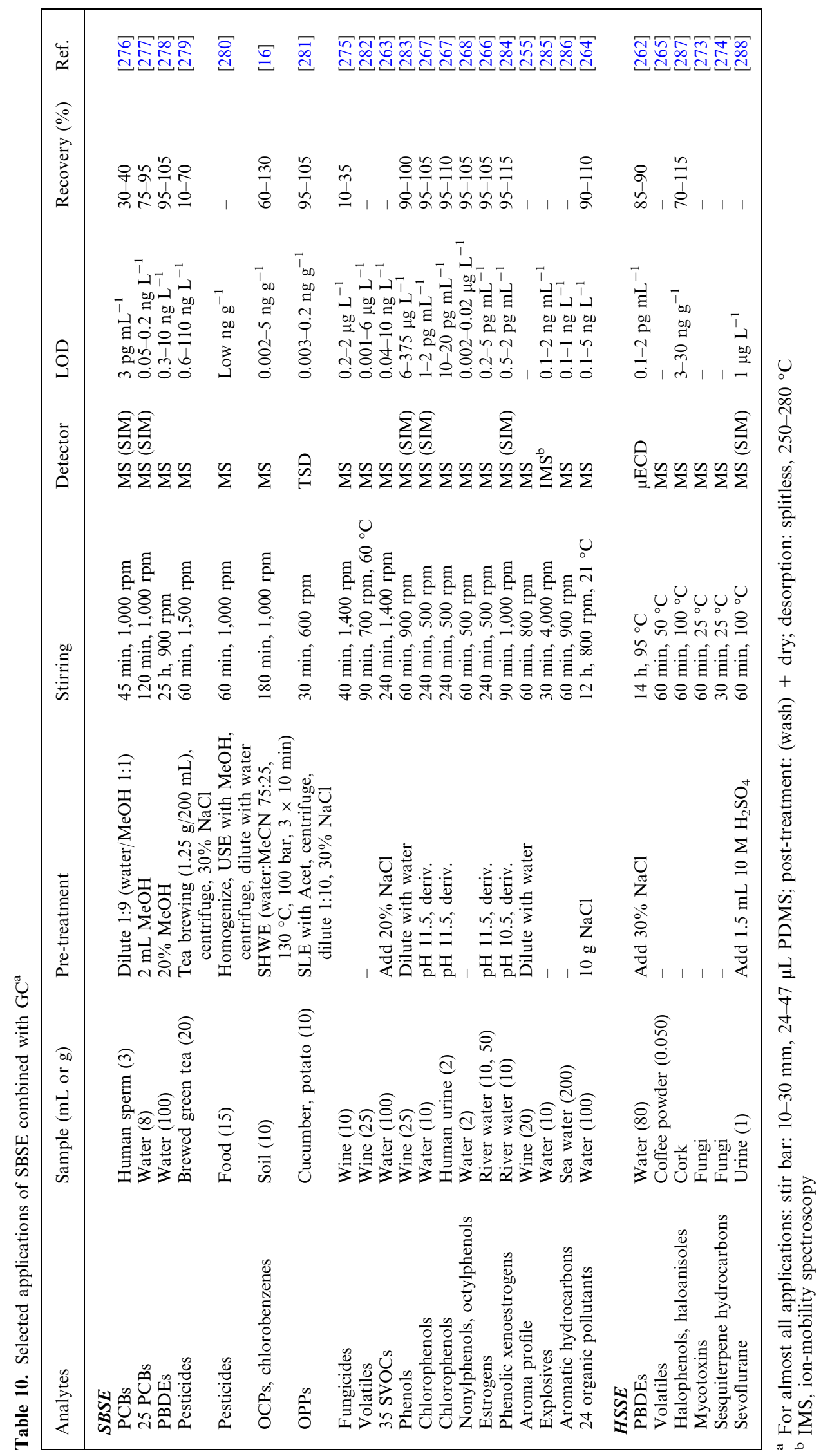




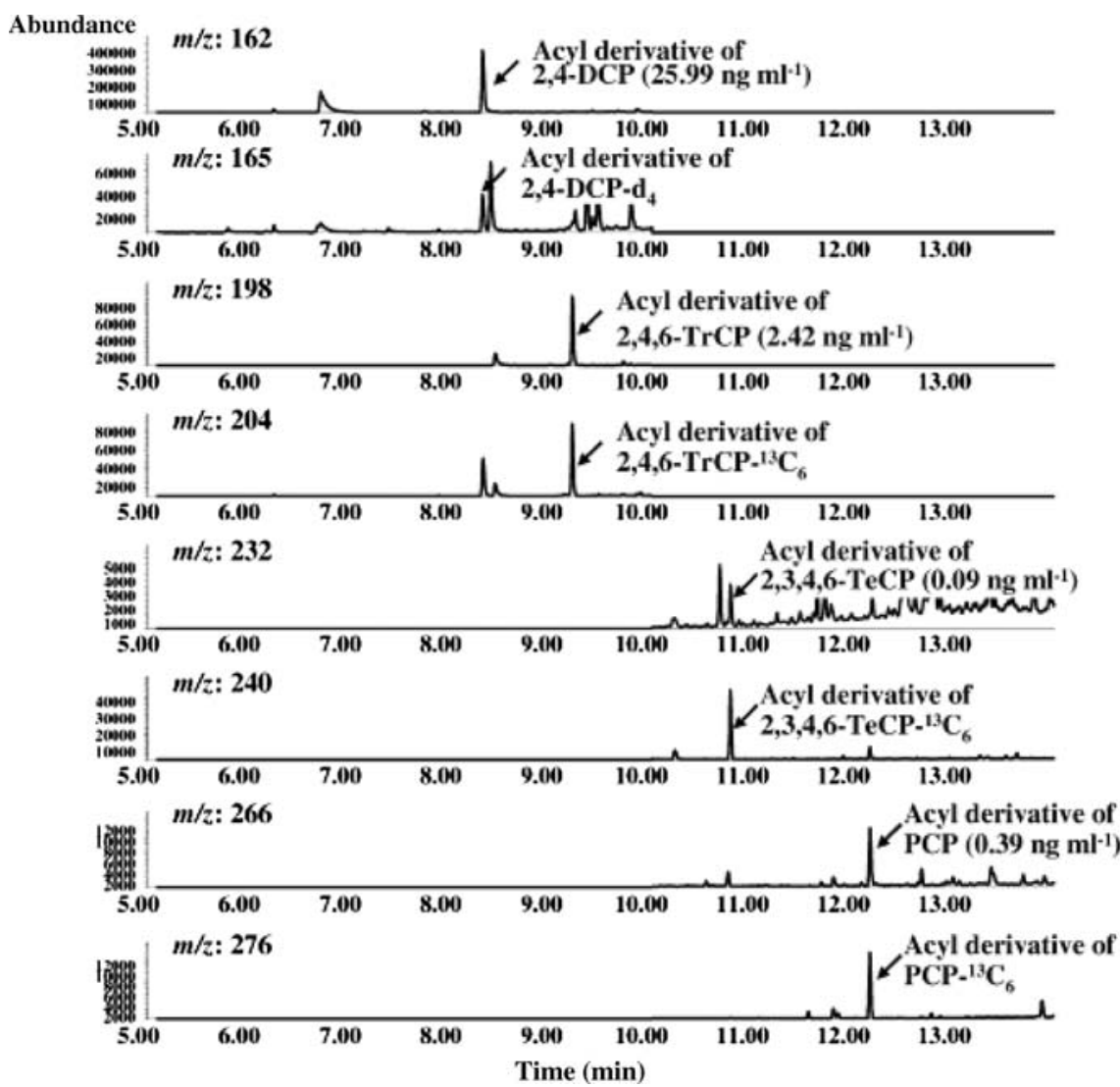

Fig. 20. Chromatograms of chlorophenols and surrogate standards in human urine sample [267]. DCP, dichlorophenol; TrCP, trichlorophenol; TeCP, tetrachlorophenol; PCP, pentachlorophenol

nated with a water-immiscible organic solvent, which is present in the membrane pores. In another approach, nonporous silicone rubber is used as the membrane material. In both cases, the membrane separates two aqueous phases and the sample $\mathrm{pH}$ (donor channel) is adjusted to ensure that the analytes of interest are not charged and are easily extracted into the membrane liquid or the silicone polymer film. The acceptor phase has the proper $\mathrm{pH}$ to effect ionization of the analytes immediately after their passing the membrane to prevent back-extraction. With the silicone membranes one can also add an organic solvent to the acceptor phase to improve the trapping of neutral compounds. The third mode of membrane extraction uses a porous membrane with an organic solvent, both in the membrane pores and in the acceptor channel. Both flat-sheet and hollow-fibre membrane units can be applied. With this technique, micropo- rous membrane LLE (MMLLE), larger extraction surfaces can be achieved with the hollow fibres, which leads to improved extraction efficiency. Countercurrent donor/acceptor solvent flow is usually applied in order to create optimum conditions [21, 291]. MMLLE differs from the other two in that it can be compared to a single LLE step rather than to LLE plus a back-extraction. A common characteristic of all three techniques is that selectivity is obtained because sample components which do not readily dissolve in the membrane liquid, are retained in the donor channel.

When using a stagnant acceptor phase and a flowing donor phase (the most common way of membrane extraction), the donor phase flow-rate will have a distinct influence on the membrane-extraction performance. If low detection limits are required and there are no sample-volume limitations (e.g., with natural waters), the best option is to use a large sample and apply a relatively high donor flow-rate of, often, $1-2 \mathrm{~mL} \mathrm{~min}^{-1}$ [292]. If sample volume is a limiting factor, such as for plasma, the sample is either kept stagnant in the donor channel or pumped at a low flow-rate of typically 25$50 \mu \mathrm{L} \mathrm{min}{ }^{-1}$ [293]. Alternatively, a sample can be passed through the membrane device several times to obtain a better recovery.

Also for membrane extractions, there are some practical limitations and aspects worth taking into account. A problem is the incomplete transfer of analytes from the membrane to the acceptor phase during the sample preparation process. This leads to a decrease in the recovery and, more seriously, to carry-over effects for sequential analyses. Thorough rinsing of the acceptor channel is therefore essential. In general, if analytes are easily extracted into the membrane, they also show large carryover effects obviously because they have a high affinity for the membrane material and are not readily released into the acceptor phase. Since for MMLLE there is no distinction between the membrane solvent and the acceptor phase, there are no problems of slow mass transfer to the acceptor phase or serious carry-over effects with this technique. Leakage of the membrane liquid adversely affects the extraction performance and should be avoided as much as possible. Membranes impregnated with non-polar solvents which are insoluble in water, are generally stable for several weeks without any regeneration. Obviously, with silicone membranes there is no leakage of the membrane material and they are, indeed, quite stable. The continuous use of a single silicone membrane for a period of more than 2 months has been reported [294].

The application of membranes for on-line sample preparation was a trend in the 1990s, where the coupling to an LC system is most straightforward: transferring (part of) the acceptor phase to an injection loop and injecting it is in principle sufficient. In order to couple an SLM and a capillary GC system on-line, pure water is used as the acceptor phase. The analytes are trapped on a polymer sorbent, which is dried with nitrogen 
prior to desorption with an organic solvent, e.g., ethyl acetate. On-line injection to a GC is performed via LVI (also see section on SPE). More suitable for direct coupling to GC is the use of an entirely organic acceptor phase, which has been performed with silicone membranes [295] and MMLLE [296, 297]. Another automated technique of membrane extraction is membrane-assisted solvent extraction (MASE), which was first described by Hauser and Popp [298]. The extraction cell consists of a conventional 20-mL headspace vial with a membrane insert. Membrane bags are made from dense polypropylene, attached to a stainless-steel funnel and fixed with a PTFE ring. The funnel is suspended in the opening of the vial, which is closed with a crimp cap. The vial contains an aqueous sample, typically $15 \mathrm{~mL}$, and the bag $100-800 \mu \mathrm{L}$ organic solvent. After agitation an aliquot of the organic solvent is analysed by LVI-GC. An automated device is manufactured by Gerstel.

The membrane techniques mentioned so far are all characterized by liquid donor as well as acceptor phases. However, for best compatibility with GC a gaseous acceptor phase is the more convenient. This is the approach used in membrane extraction with a sorbent interface (MESI) [300]. The membrane is a polymeric hollow fibre, and the analytes are extracted from the surrounding liquid or gaseous sample (see Fig. 21 for different configurations). A gas inside the hollow fibre transports the analyte molecules into a cold sorbent tube where they are trapped. Next, the analytes are thermally desorbed from the sorbent and guided into the GC. One can also use a catalytic reaction to trap the extracted analytes directly in the gas phase [301]. In an integrated instrument set-up, the GC carrier gas passes through the membrane fibre and the sorbent trap [300]. However, one can also use the technique off-line, e.g., in field sampling. The sorbent trap is then later connected to the GC and desorbed in a separate step [302, 303]. To quote an example of MESI, Brown et al. [304] described the monitoring of trihalomethanes in drinking water. The water was sampled at a flow rate of $2.5 \mathrm{~mL} \mathrm{~min}{ }^{-1}$. Analytes
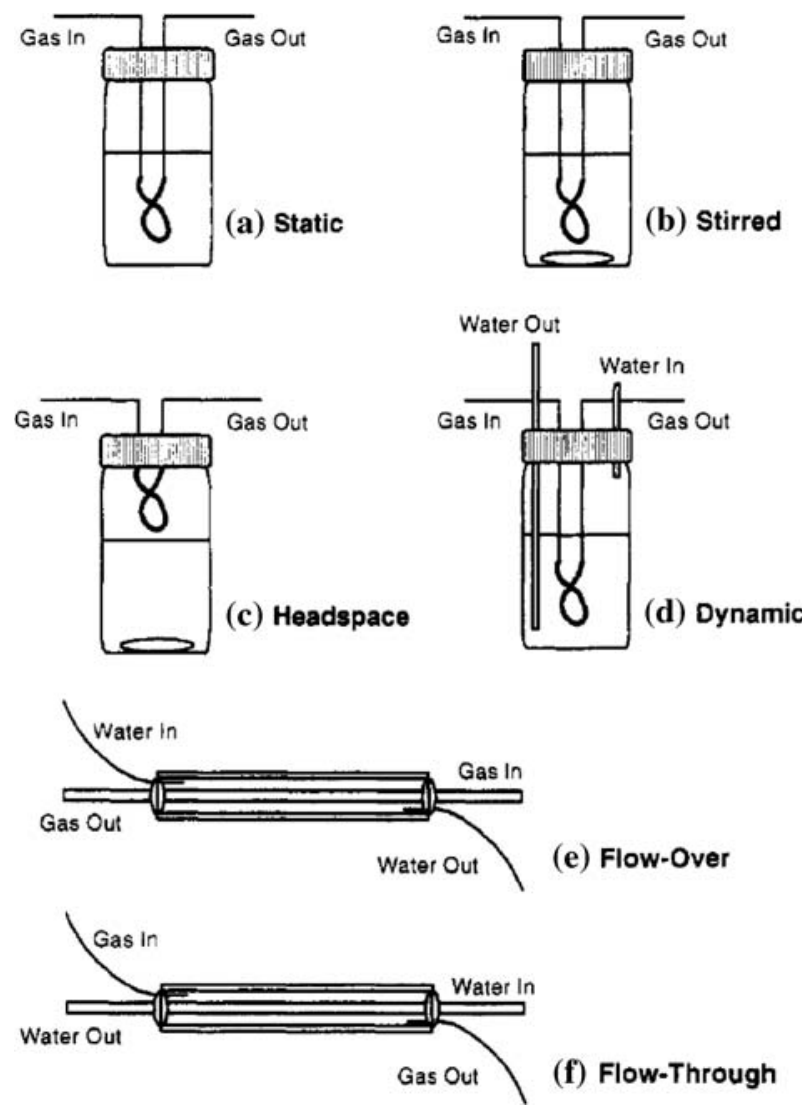

Fig. 21. Different configurations for MESI [299]

were extracted in a helium gas stream of $30 \mathrm{~mL} \mathrm{~min}{ }^{-1}$ and trapped on Tenax. Next, the trap was heated and the analytes were transferred to a GC-ECD system. LODs of trihalomethanes were $0.1-1 \mu \mathrm{g} \mathrm{L}^{-1}$.

Applications A list of selected applications for the isolation of a range of compounds from a variety of matrices is shown in Table 11. This list is restricted to GC applications only. An equally long, if not longer, list could also be compiled for LC. It was stated above that SLM can be combined with GC; however, no recent applications are reported. MASE, MMLLE and MIMS (membrane introduction mass spectrometry) are mainly used for environmental (air, water), and food and beverage (juice, wine) samples; an example of each of these techniques is briefly discussed below. Rodil et al. [305] determined PAHs in water and beverages by means of MASE combined with LVI-GC-MS. A 20-mL headspace vial was filled with $15 \mathrm{~mL}$ of a river water, apple juice, or red wine sample. A polypropylene membrane bag containing $400 \mu \mathrm{L}$ of ethyl acetate, was hung in the sample and the vial closed. After $60 \mathrm{~min}$ of agitation, $100 \mu \mathrm{L}$ of the ethyl acetate extract were analysed by PTVGC-MS (SIM). The LODs were 3$40 \mathrm{ng} \mathrm{L}^{-1}$. On-line MMLLE-GC-MS of PAHs in red wine was reported by Hyötyläinen et al. [296]. The MMLLE unit consisted of two PTFE blocks, both with $11-\mu \mathrm{L}$ grooves. The grooves were separated by a porous polypropylene membrane wetted with the acceptor solvent, toluene. Extraction at a donor flow rate of $0.2 \mathrm{~mL} \mathrm{~min}^{-1}$ took $40 \mathrm{~min}$. The acceptor phase was pumped to a loop in a GC transfer valve. The whole content of the loop was injected into the GC to ensure transfer of the entire extract. The LODs of analytes such as quinalphos and isoproturon for MS detection (scan mode) were in the range of 0.03 $0.4 \mu \mathrm{g} \mathrm{L}^{-1}$. Figure 22 shows the chro- 


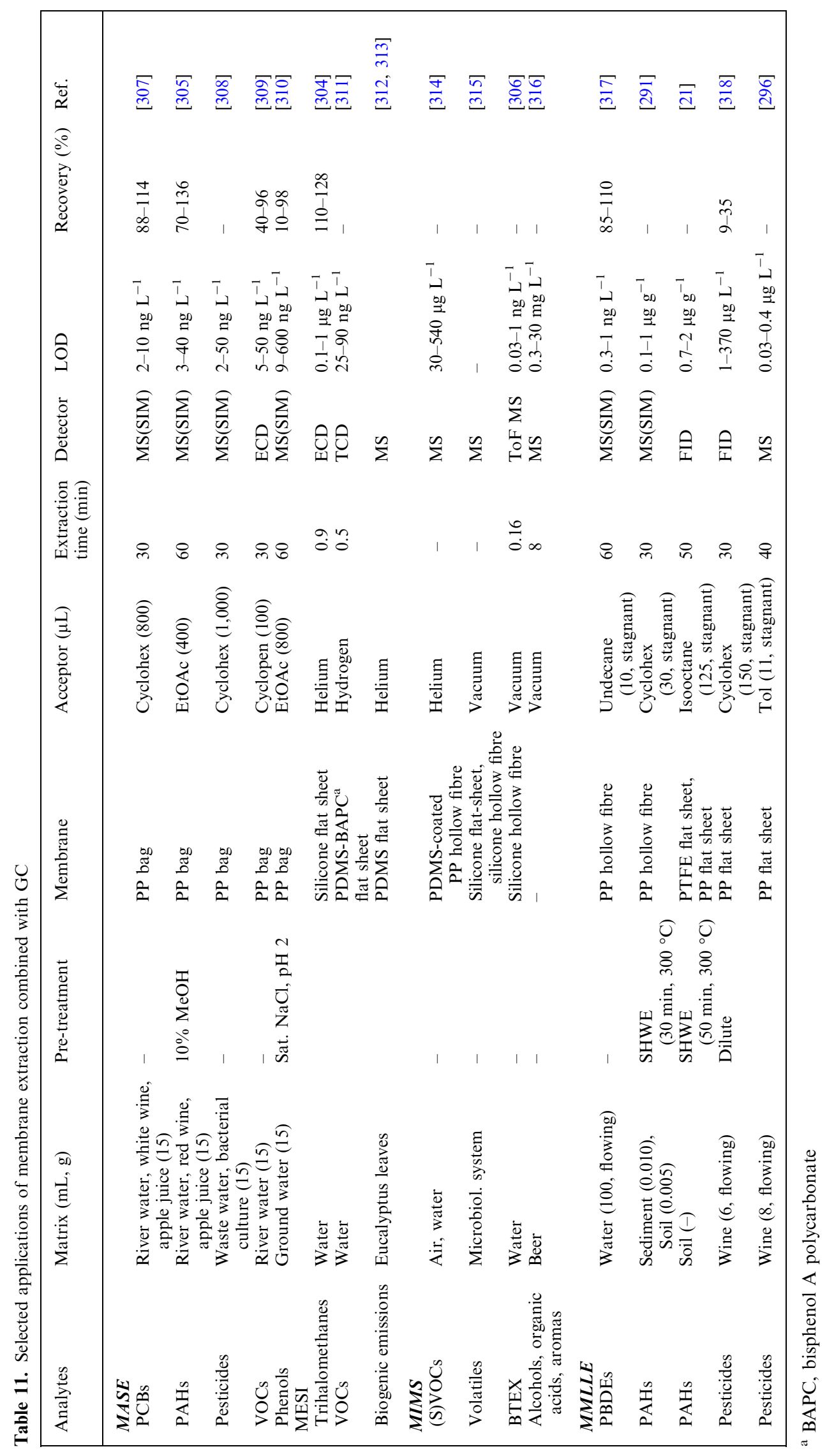


matograms of a blank wine, a spiked red wine and a positive red wine. Direct combination of membrane extraction with MS, so without a GC in between, is possible. Continuous BTEX screening by means of MIMS was described by Oser et al. [306]. A constant flow of water was pumped through a silicone membrane tube. As the sample passes across the inner surface of the membrane, the analytes diffuse through the membrane and evaporate into the MS ion source. LODs obtained by ToF MS were $0.03-1 \mathrm{ng} \mathrm{L}^{-1}$.

\section{Single-Drop Micro-Extraction}

In 1996, Liu and Dasgupta [319], and Jeannot and Cantwell [320] introduced the concept of using a small drop for sample preparation, so-called singledrop micro-extraction (SDME), which combines analyte extraction and preconcentration prior to instrumental analysis. For reviews on SDME, the reader should consult refs. [321-325].

Liu and Dasgupta reported a 'dropin-drop' configuration in which a $1.3-\mu \mathrm{L}$ organic drop, suspended in a larger aqueous drop, extracts the analyte of interest. The system has the advantages of low consumption of organic solvent and the facility of automated backwash. Jeannot and Cantwell introduced a technique where an $8-\mu \mathrm{L}$ drop of organic solvent containing an internal standard is left suspended at the end of a PTFE rod immersed in a stirred aqueous sample solution. After sampling, the rod is withdrawn from the solution and, with the help of a micro-syringe, an aliquot of the drop is injected into a GC system. As a more convenient alternative, microextraction can be performed by suspending a $1-\mu \mathrm{L}$ drop directly from the tip of a microsyringe needle immersed in a stirred aqueous sample. After extraction, the microdrop is retracted back into the needle and, next, transferred to the GC [326, 327]. Figure 23 shows the schematic of an SDME system. Since droplet instability at high stirring speeds can cause problems, while such high speeds are usually beneficial because
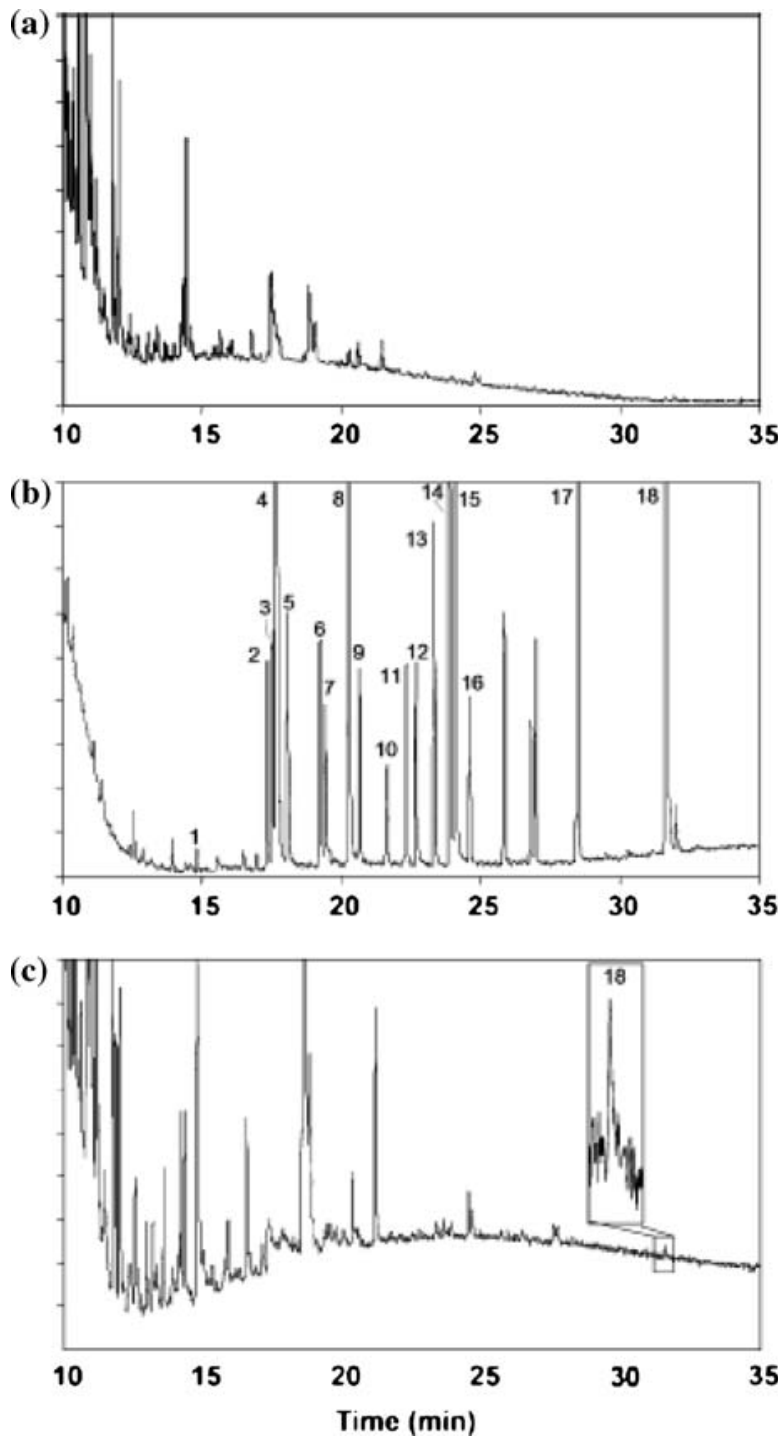

Fig. 22. MMLLE-GC-FID analysis of (a) blank wine, (b) MMLLE extract of a spiked red wine $\left(c=0.05 \mathrm{mg} \mathrm{L}^{-1}\right)$ and (c) MMLLE extract of an Italian red wine containing tetradifon. Peak identification: $\mathbf{1}=$ Aldicarb; $\mathbf{2}=$ Diphenylamine (ISTD); $\mathbf{3}=$ Simazine; $\mathbf{4}=$ Atrazine; $\mathbf{5}=$ Lindane; $\mathbf{6}=$ Terbuthylazine; $\mathbf{7}=$ Metoxuron; $8=$ Metobromuron; $9=$ Vinclozolin; $\mathbf{1 0}=$ Isoproturon; $\mathbf{1 1}=$ Chlortoluron; $\mathbf{1 2}=$ Metazachlor; $\mathbf{1 3}=$ Quinalphos; $\mathbf{1 4}=$ Procymidone; 15 = Endosulfan I; 16 = Endosulfan II; 17 = Endosulfan sulphate; 18 = Tetradifon [296]

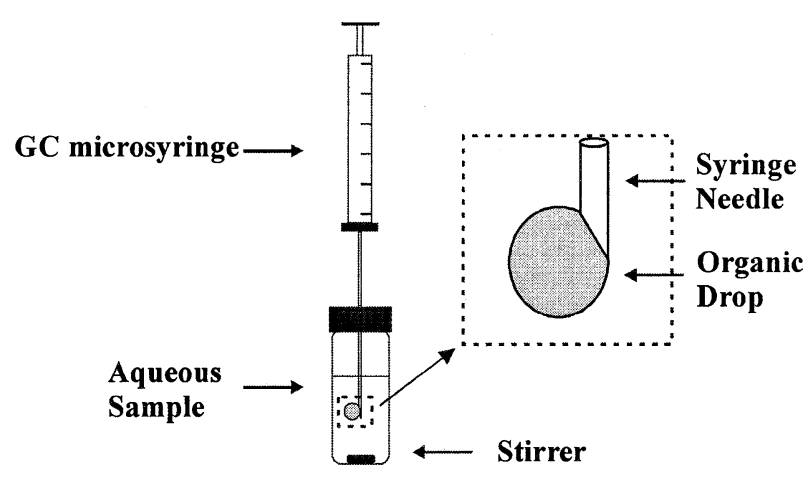

Fig. 23. Schematic of an SDME system [325] 
they enhance extraction, the use of a modified tip design was recommended in recent work [328].

The similarity of SDME and SPME operations suggests that autosamplers that can be used for SPME should also work with SDME. First results using a $2-\mu \mathrm{L}$ drop of hexadecane for BTEX analysis [333] using a CombiPAL (CTC, Zwingen, Switzerland) autosampler, and a standard $10-\mu \mathrm{L}$ microsyringe confirmed this supposition. A single magnet mixer was used to permit temperaturecontrolled extractions while stirring the sample.

In order to improve the extraction efficiency, He and Lee [327] developed dynamic LPME (with $P$ for 'phase' because there is no ' $\mathrm{D}$ for drop' configuration). With this technique, extraction occurs by withdrawing an aqueous sample into a microsyringe already containing an organic solvent. After a dwell time of a few seconds to allow extraction of the analytes into a thin film of organic solvent adhering to the wall of the barrel as the bulk of the solvent is withdrawn back up, the aqueous phase is pushed out. The cycle has to be repeated quite a number of times (20 in the quoted example) before the analyte-enriched organic phase is subjected to GC analysis. In subsequent studies, a programmable syringe pump was used to automate the repetitive sample withdrawal/expelling process.

In continuous-flow micro-extraction (CFME), which evolved from conventional SDME [329], an aqueous sample is pumped continuously into a ca. 0.5$\mathrm{mL}$ glass chamber via a piece of PEEK tubing which serves for both sample delivery and the introduction of the organic solvent. Once the glass chamber is filled with the aqueous sample, the required volume of the extractant is introduced through an injector and moved, together with the sample solution, towards the glass chamber. When it reaches the end of the PEEK tubing, a microdrop is formed which is virtually immobilized near the outlet of the tubing. Since the aqueous sample solution is continuously pumped around the drop of extractant, high enrichment factors can be obtained. After a preset time of extraction, the drop is withdrawn with a microsyringe and transferred to the injector of a GC system.

Another recent addition to the list of drop-type extraction techniques is headspace SDME (HS-SDME) [330]. The technique is rather similar to HS-SPME, the only difference being that the fibre used in SPME is replaced by a liquid microdrop. In the three-phase system, aqueous-phase mass transfer is the ratedetermining step, and a high stirring speed is therefore indicated. Compared with HS-SPME, HS-SDME appears to have similar capabilities in terms of precision and speed of analysis; however, it offers two distinct advantages. Firstly, intuitively, the choice of solvents is wider, if not virtually unlimited, as compared to the limited number of phases currently available for SPME. Solvents can have boiling point below or above the compounds of interest and can cover a wide range of polarities. Secondly, the cost of solvent is negligible compared to that of commercially available SPME fibres. However, the use of SDME for headspace analysis seems relatively difficult, because solvents with relatively low vapour pressures would be preferred. Yet, the most suitable solvents for GC would have relatively high vapour pressures. The difficulty with the latter solvents is clear: they would evaporate too quickly in the headspace during extraction. Thus, in reality, the choice of suitable solvents is fairly limited. In the recent literature, several attempts to improve the evaporation situation by means of semi- or fully automated dynamic HS-SDME were reported [331, 332]. One interesting solution may be the use of the same solvent as sample solvent and drop of extractant [333].

Theoretical considerations concerning the nature and dynamic characteristics of the various micro-extraction processes, and discussions of the influence of various parameters-e.g., drop size, sampling time, solvent selection, salt addition, dwell time - are presented in several of the reviews and papers cited above, notably in [322].

Applications In the literature, some 50 applications of SDME-type sample preparation combined with GC have been reported. The main application areas are environmental, bio and food analysis, and a wide variety of analytes has been determined (Table 12). Several selected applications are briefly discussed below.

In an interesting study, HS-SDME and simultaneous derivatization were applied for the determination of acetone in human blood as a diabetes biomarker [334]. A 1-mL blood sample was introduced in a headspace vial. Derivatization and extraction of acetone were performed by using $2 \mu \mathrm{L} n$-decane containing PFBHA, at an extraction temperature of $25^{\circ} \mathrm{C}$ and an extraction time of $4 \mathrm{~min}$. Analyte recovery was $88 \%$ and the LOD for MS detection was $2 \mathrm{nM}$. In another study, OPPs were determined in orange juice [335]. 5\% $\mathrm{NaCl}$ was added to $5 \mathrm{~mL}$ of orange juice for salting out the analytes of interest. SDME was performed by immersing the syringe needle in the sample, exposing a 1.6- $\mu \mathrm{L}$ drop of toluene during $15 \mathrm{~min}$ (stirring at $400 \mathrm{rpm}$ ). With analyte recoveries of $76-108 \%$, the LODs for FPD detection were below $5 \mu \mathrm{g} \mathrm{L}^{-1}$. A third example shows that even SDME can be miniaturized [336]. In so-called drop-to-drop solvent micro-extraction (DDSME), the extraction of methoxyacetophenone isomers from water was performed in a $100-\mu \mathrm{L}$ vial containing one drop $(7 \mu \mathrm{L})$ of water. A $0.5-\mu \mathrm{L}$ drop of toluene was exposed to the sample for 5-min extraction (stirring at $360 \mathrm{rpm}$ and room temperature). The extractant was directly injected into a GC-MS system and LODs of $1 \mathrm{ng} \mathrm{m \textrm {m } ^ { - 1 }}$ were obtained for all isomers.

Since SDME is strongly related to SPME, the two techniques are frequently compared. To quote an example, Palit et al. [337] studied the use of SDME and SPME for the analysis of chemical warfare agents such as dimethyl methylphosphonate, sesquimustard and Sarin in water. Under optimized SDME conditions, LODs with MS detection were in the range of $10-75 \mu \mathrm{g} \mathrm{L}^{-1}$. SDME was found to extract analytes of diverse structure, while SPME was not effective in the case of polar analytes. The authors also preferred SDME with regard to, e.g., cost, time of analysis and versatility. 


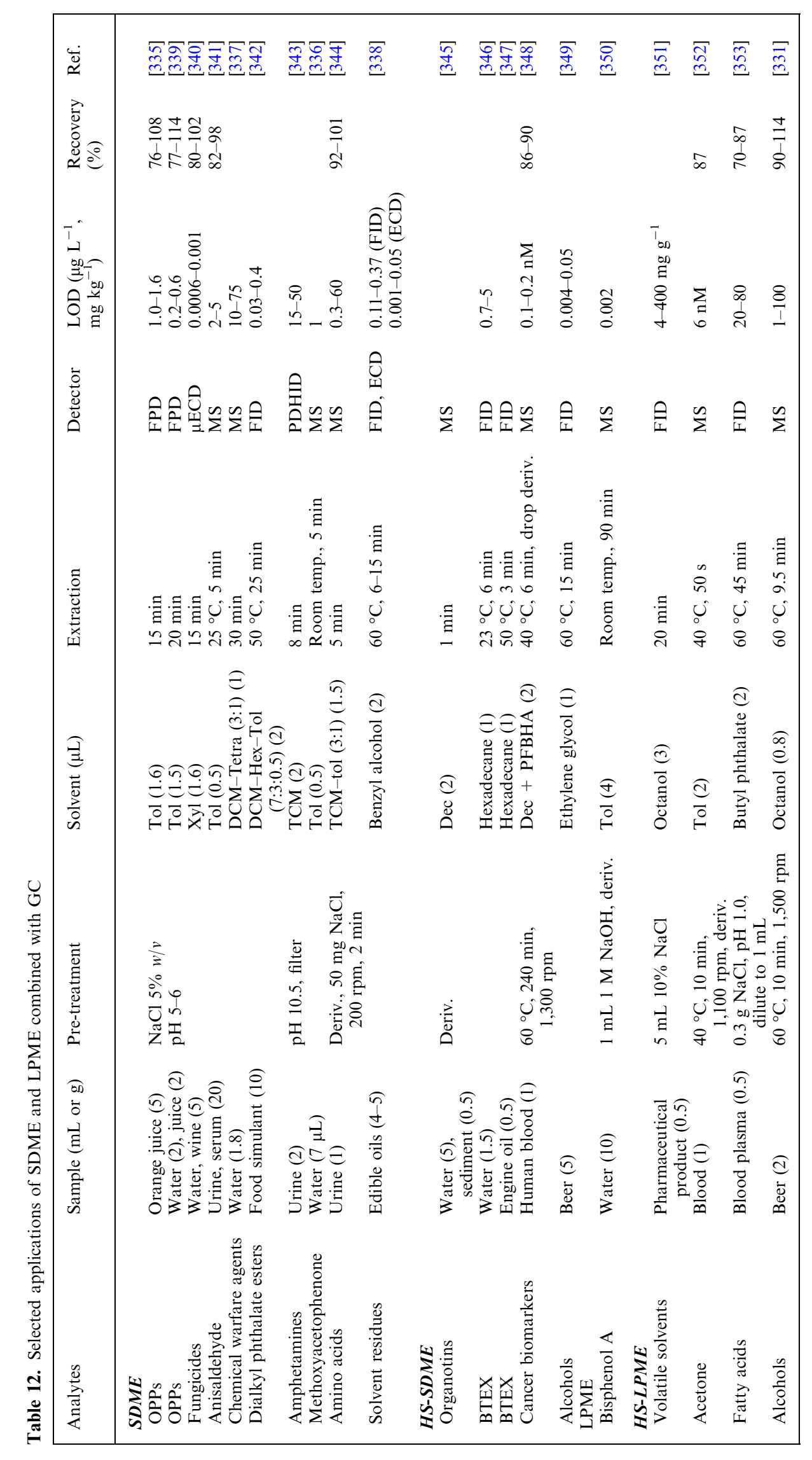


Michulec and Wardencki [338] used SDME-GC-ECD and-FID to determine (chlorinated) hydrocarbon solvent residues in edible and pharmaceutical oils. SDME was found to be as rapid and precise as SPME. On the other hand, the linear range was much narrower, and the LODs were higher than for SPME procedures. However, the LODs easily met the requirements for the quoted applications. In such cases, it is a clear advantage that SDME requires no special equipment.

\section{Headspace and Purge- and-Trap}

Headspace techniques are well suited for sample preparation prior to the GC determination of volatiles in liquid and (semi-)solid samples. Instead of direct sampling, a gas phase in equilibrium with the sample material is sampled and analysed. In most instances, a considerable enrichment of the analytes can also be obtained in the gas phase, which improves analyte detectability. Moreover, because only the gas phase in equilibrium with the sample is injected, contamination issues are absent, even for very 'dirty' samples. The practicability of the method drew much attention after the first publication in 1958 [354], and instruments for fully automated headspace sampling in combination with GC were marketed soon after by Perkin Elmer (Shelton, CT, USA). Today, there is hardly an adequately equipped laboratory in the environmental, food or drugs area which is without a headspace instrument. The state of the art of headspace analysis is documented in book chapters and reviews, which also discuss a wide variety of applications (see, e.g., [355-360]). The main variable is the distribution constant of an analyte between the gas phase and the liquid or solid phase; the more the equilibrium is shifted to the gas phase, the more sensitive the analyte can be determined. The distribution constant, in its turn, primarily depends on the vapour pressure of the analyte and the activity coefficient of the analyte in the matrix.
There are two experimental approaches in headspace analysis. If the sample is in equilibrium with the gas phase in a closed vessel, then the method of analysis is referred to as static headspace, or HS. If a carrier gas is passed over, or through, the sample and the extracted volatile compounds accumulated in a cryogenic or sorbent trap, then the method is generally referred to as dynamic headspace, gas-phase stripping or purge-and-trap, with P\&T as the common acronym.

\section{HS Analysis}

In HS analysis, the volatiles in the sample material are equilibrated with a gas phase above the sample in a closed vial. After a predetermined equilibration time, part of the gas phase is (automatedly) withdrawn from the vessel, and injected into a GC system. For compounds which, because of low distribution constants, largely remain in the liquid or solid matrix, an obvious way to enhance the analyte concentration in the gas phase is to increase their vapour pressure by increasing the equilibration temperature or to decrease the activity coefficient by, e.g., increasing the ionic strength of the solution ('salting out'). In liquids, analyte diffusion generally is fast enough for equilibrium to be reached in a short time and many HS systems have stirring facilities to aid this. In (semi)solids, however, diffusion is often very slow and procedures such as grinding of the sample are used to speed up the analysis.

After equilibrium has been established in the carefully thermostated vial, the gas phase is sampled using a syringe for manual procedures or automatically using commercially available pneumatic headspace analysers. Pneumatic sampling ensures that both the pressure and volume of the headspace sampled are identical for all samples and standards. A constant pressure is obtained by pressurizing the headspace vials with an inert gas to a pressure at least equal to the column inlet pressure. The sample is then either expanded directly into the column or to a sample loop of a thermostated gas-sampling valve. Instead of first filling a loop, a pressurized headspace gas can also be expanded directly into the GC column by using a socalled balanced sampling system [357, 361].

Another procedure to collect the static headspace from a sample is the use of a sorbent. The adsorbent is allowed to stay in the headspace for a specific period of time and at a constant temperature. After equilibrium has been reached, (an aliquot of) the solid sorbent is transferred to a thermal desorber. In the past this procedure was often performed using small paperbags ('teabags') filled with Tenax or another polymer sorbent. Today, an SPME fibre is typically used (HS-SPME; see section on SPME). However, one has to be aware that, with this technique, the distribution is between the fibre and the matrix. Consequently, even though raising the temperature increases the analyte concentration in the headspace, it reduces the deposition on the fibre because the vapour concentration of the analyte increases above the sample, but also above the fibre. HS-SPME can therefore give a selectivity which markedly differs from that of HS analysis: HS will favour the volatile analytes, but HS-SPME the less volatile compounds.

Finally, one should keep in mind the overriding importance of rigorously controlling the temperature both during analysis, from sample to sample, and from sample to standard, in order to ensure reliable quantification and adequate repeatability/reproducibility. Meeting these demands is facilitated by using automated HS samplers.

\section{P\&T Analysis}

In P\&T analysis, a sample is continuously purged with an inert gas (commonly helium) and volatiles are transported from the sample to a trap with sufficiently high retention power (e.g., Tenax, activated carbon or silica) for the analytes to be collected without the risk of breakthrough. After purging, the trap is heated and the trapped volatiles are released onto a GC column, usually via a cold trap (Fig. 24). P\&Twhich, in principle, enables quantitative analyte isolation - is an effective way of achieving much better analyte detect- 
ability than equilibrium-type HS: under favourable conditions low- and subng $\mathrm{L}^{-1}$ LODs can be obtained for many VOCs. The key parameters in P\&T optimization are purge time, flow rate and temperature. Extending the purge time will, generally speaking, enhance the recovery of the analytes of interest. However, highly volatile compounds may be (partly) lost if purge times are too prolonged and/or the trap displays insufficient retention. As for the purge temperature, since less volatile and/or more water-soluble analytes will be removed only partly even under optimized conditions, careful control of the temperature of the sample vessel is required for precise quantification. For the rest, for obvious reasons elevated temperatures will enhance analyte recovery. However, the disadvantage is that more water vapour will be carried over into the trap and the GC analytical system. Actually, water management is a serious problem in P\&T (much more than in HS sampling where the gas volumes are relatively small) because a large amount of water vapour from the liquid sample matrix is also transported by the inert gas. Since cold traps, which are frequently used to collect the analytes, easily become blocked through the large amount of vapour, it is important to remove the moisture from the purge gas before it enters the cold trap. Inorganic desiccants, water condensers, pre-separation on a column packed with Tenax or another such sorbent, or selective permeation through a polymeric (often a Nafion) membrane are all used to this end. However, each of these alternatives unfortunately, has specific disadvantages which invariably cause the uncontrollable loss of particular classes of analytes. For details, the reader should consult the literature [362].

Vendors of HS and P\&T systems are Perkin Elmer which markets the LSC 2000 and LSC 3000, Tekmar (Mason, OH, USA) with the Tekmar-3000, Stratum PTC and Velocity XPT, and Quma (Wuppertal, Germany) with the QHSS 20/40/100/111.

Applications Over the years, a large number of mutually divergent applications have been published which use HS

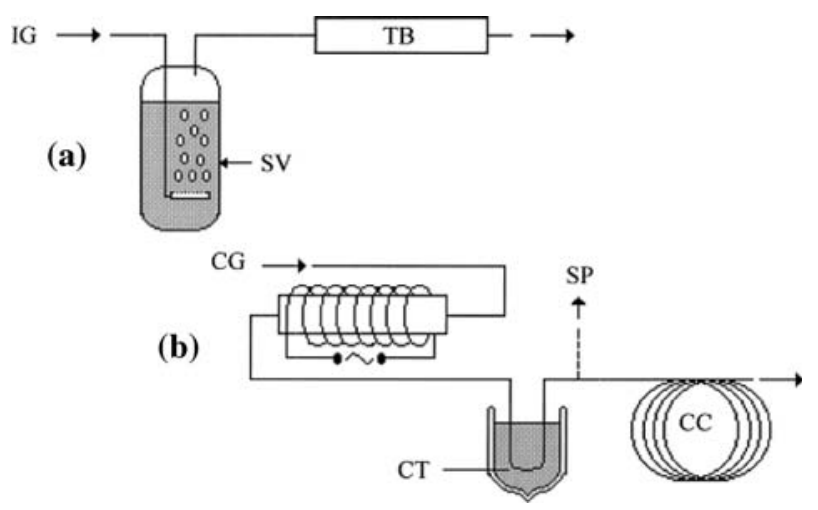

Fig. 24. Schematic of $P \& T$ with cryogenic trapping. (a) Sample purge and collection of the stripped volatiles in a trap and (b) desorption from the trap and introduction into the gas chromatograph. IG, inert purge gas; CG, carrier gas; TB, adsorbent tube; SV, sample vessel; CT, cryogenic trap; SP, split (optional); CC, capillary column. [361]

or P\&T for sample preparation. A selection of recent contributions to this field is summarized in Tables 13 and 14, respectively.

In an interesting study, Cudjoe et al. [363] identified pheromones in ladybugs that can affect the bouquet and taste of wine, using HS-GC-MS in the SIM mode. For this analysis, five ladybugs were placed in a headspace vial that was equilibrated for $20 \mathrm{~min}$ at $95{ }^{\circ} \mathrm{C}$. The headspace gas was transferred by balanced sampling with an injection time of $30 \mathrm{~s}$. Hippodemia convergens posed the highest threat to wine production due to the high levels of methoxypyrazines found in them. In another paper, P\&T sampling was used to determine volatiles in fruits [364]. $15 \mathrm{~mL}$ of fruit pulp were equilibrated at $80{ }^{\circ} \mathrm{C}$ and subjected to a 35-min purge with helium. The extracted volatiles were trapped on a mixture of Tenax/silica/charcoal kept at $30^{\circ} \mathrm{C}$. After purging, the trap was heated to $180^{\circ} \mathrm{C}$, to transfer the analytes to a $\mathrm{GC}-$ MS system. In general it was concluded that in the total volatile profile, the compounds belonging to the terpene and alcohol classes decrease during maturation of the fruit from the half-ripe to the ripe stage.

In environmental analysis, $\mathrm{Hu}-$ ybrechts et al. [365] determined 27 VOCs in marine water. P\&T of a $60-\mathrm{mL}$ sample $\left(45^{\circ} \mathrm{C}, 20 \mathrm{~min}\right)$ was used to trap the analytes on a multibed sorbent. After desorption at $275^{\circ} \mathrm{C}$, the analytes were refocused on a cryotrap $\left(-150^{\circ} \mathrm{C}\right)$, and, next, rapidly desorbed at $260^{\circ} \mathrm{C}$. LODs for GC-MS (SIM) analysis were 0.2$7 \mathrm{ng} \mathrm{L}^{-1}$ for 23 of the target VOCs. For dichloromethane, chloroform, benzene and 1,4-dichlorobenzene, the LODs were 20-40 ng L ${ }^{-1}$. Finally, Roose et al. [366] determined VOCs in eel samples by means of on-line P\&T-GC-MS. $15 \mathrm{~g}$ of sample were homogenized with a blender and transferred to a sample vial containing $25 \mathrm{~mL}$ of water. The volatiles were forced out by purging the sample for $34 \mathrm{~min}$ at $70{ }^{\circ} \mathrm{C}$. The trapped analytes were desorbed in the backflush mode into the cryofocusing module and, next, released by rapidly heating this module from -120 to $200{ }^{\circ} \mathrm{C}$. Analytical performance was fully satisfactory with analyte recoveries of $80-99 \%$ and LODs of $0.003-0.2 \mathrm{ng} \mathrm{g}^{-1}$ (when using fullscan MS). A typical chromatogram is shown in Fig. 25.

\section{Conclusions}

Essentially all modern reviewers emphasize that sample treatment is a key aspect of trace-level organic analysis and that it is often the most time-consuming and least sophisticated step. It is also recognized that, even though state-ofthe-art instrumental chromatographic techniques are sufficiently mature to enable hyphenation with powerful (usually MS-based) detectors that provide high information density, sample preparation is still necessary in most instances. This 
Table 13. Selected applications of HS combined with GC

\begin{tabular}{|c|c|c|c|c|c|c|c|c|c|}
\hline Analytes & $\begin{array}{l}\text { Sample } \\
\text { (g or } \mathrm{mL} \text { ) }\end{array}$ & Pre-treatment & $\begin{array}{l}\text { Equilibration } \\
\text { time } \\
\text { (min) }\end{array}$ & $\begin{array}{l}\text { Temperature } \\
\left({ }^{\circ} \mathrm{C}\right)\end{array}$ & Sampling & $\begin{array}{l}\text { Transfer } \\
\text { line }\left({ }^{\circ} \mathrm{C}\right)\end{array}$ & Detector & LOD & Ref. \\
\hline BTEX & Olive oil (10) & - & 25 & 95 & $\begin{array}{l}\text { Loop } / 110^{\circ} \mathrm{C} / \\
\quad 3 \mathrm{~mL}\end{array}$ & 120 & MS & $3-9 \mathrm{ng} \mathrm{mL}^{-1}$ & [367] \\
\hline BTEX & Water (15) & $\begin{array}{l}2.2 \mathrm{~g} \mathrm{KCl} \\
300 \mu \mathrm{L} \\
5 \mathrm{M} \mathrm{HNO}_{3}\end{array}$ & 20 & 70 & $\begin{array}{c}\text { Loop } / 110^{\circ} \mathrm{C} / \\
3 \mathrm{~mL}\end{array}$ & 120 & MS & - & [368] \\
\hline VOXs & $\begin{array}{l}\text { Landfill } \\
\quad \text { leachates (5) }\end{array}$ & - & 15 & 75 & $\begin{array}{c}\text { Loop } / 110^{\circ} \mathrm{C} / \\
1 \mathrm{~mL}\end{array}$ & 110 & MS & $0.05 \mathrm{ng} \mathrm{mL}^{-1}$ & [248] \\
\hline Volatiles & $\begin{array}{l}\text { Bacterial } \\
\text { biodegradation }\end{array}$ & - & 20 & 80 & $\begin{array}{l}\text { Syringe } / 81{ }^{\circ} \mathrm{C} / \\
0.4 \mathrm{~mL}\end{array}$ & - & MS & - & [369] \\
\hline $\begin{array}{l}\text { Residual } \\
\text { solvents }\end{array}$ & $\begin{array}{l}\text { Pharmaceutical } \\
\text { drugs }(0.2)\end{array}$ & - & 60 & 80 & $\begin{array}{c}\text { Loop } / 85^{\circ} \mathrm{C} / \\
1 \mathrm{~mL}\end{array}$ & 85 & FID & $0.3-8 \mu \mathrm{g} \mathrm{mL}^{-1}$ & [370] \\
\hline Aldehydes & Wodka (5) & Deriv. & 30 & 70 & $\begin{array}{l}\text { Balanced } \\
\text { pressure/ } \\
0.5 \mathrm{~min}\end{array}$ & 90 & $\mathrm{ECD}$ & $0.02-4 \mu \mathrm{g} \mathrm{L}^{-1}$ & [371] \\
\hline TATP & $\begin{array}{l}\text { Post-explosion } \\
\text { debris }\end{array}$ & - & 30 & 90 & Syringe $/ 1 \mathrm{~mL}$ & - & MS & $0.1 \mathrm{ng}$ & [372] \\
\hline Epichlorohydrin & $\begin{array}{l}\text { Drinking } \\
\text { water (5) }\end{array}$ & $300 \mathrm{~g} \mathrm{NaCl} \mathrm{L}^{-1}$ & 22 & 80 & Loop & - & ECD & $40 \mu \mathrm{g} \mathrm{L}^{-1}$ & [373] \\
\hline Pheromones & Ladybugs (5) & - & 20 & 90 & $\begin{array}{l}\text { Balanced } \\
\text { pressure/ } \\
0.5 \mathrm{~min}\end{array}$ & 95 & MS(SIM) & - & [363] \\
\hline
\end{tabular}

is true, not only because many solid and semi-solid matrices cannot be handled directly anyway, but also because (1) analyte enrichment is required to reach concentration levels in the final extract that permit reliable compound identification and quantification, and (2) removal of interfering sample constituents (e.g., fat, proteins, sulphur, grit or strongly adsorbing materials) is often needed to maintain the performance of the analytical set-up over prolonged periods of time. Another conclusion, frequently to be read between the lines-i.e., in the applications which are discussed and in information provided in the tables which are included - is that for a large majority of all challenging analytical problems detection is done with an MS instrument, with ToF MS and ion-trap MS/ MS gradually coming into their own next to quadrupole MS. One major exception is the use of selective and, more so, highly sensitive ECD detection for, specifically, aromatic organohalogen micro-contaminants.

To phrase things differently, many workers state that, since there is an obvious need for faster, more costeffective and environmentally friendly analytical methods, there is also a clear need to improve the performance provided by the classical methods of sample preparation. In the past two decades, several tens of newly designed and, also, upgraded older methods have been reported and the progress made in this area is continually being reviewed. One striking general observation is that, despite the improved performance of the (GC) separation plus (MS) detection step effected in the past 10 or so years, sample preparation is, in many instances, as extensive today as it was in the 1990s. This is especially remarkable because, in the same period of time, comprehensive $2 \mathrm{D}-\mathrm{GC}$, or $\mathrm{GC} \times \mathrm{GC}$, with its considerably improved overall chromatographic resolution, has arrived on the scene to facilitate the analysis of highly complex samples [390]. The obvious conclusion is that much of the steps forward made in the fields of sample preparation and instrumental analysis have been used not to simplify the procedures, but to enhance the quality of the information.

To our opinion, conclusions such as those given above, are more relevant than a detailed discussion of the characteristics of the individual samplepreparation techniques. Moreover, an interesting comparison of many of the techniques included in the present review has recently been given by Hyötyläinen and Riekkola [391]. Nevertheless, some brief comments should be presented also here.

As regards solid and semi-solid samples, PLE is a promising technique, and features short extraction times and low solvent consumption. SFE and PLE share several beneficial characteristics but, because PLE can be used with all conventional solvents, its application range is distinctly wider than that of SFE with (modified) $\mathrm{CO}_{2}$. SFE moreover has a matrix-dependent extraction mechanism and optimization is rather demanding. On the other hand, SFE typically is the method of choice for thermolabile compounds.

With MAE, proper solvent selection is the key to a successful-and, often rapid-extraction; hexane-acetone (1:1) has been shown to be a fairly ideal 'general purpose' mixture. The technique offers little selectivity and clean-up after extraction is needed in most instances. Almost all MAE applications involve offline procedures since operation of the technique as part of a dynamic system is difficult. The beneficial role of ultrasound assistance in USE, but also to accelerate digestion, sample dissolution or enhance reaction kinetics, is well documented [80, 81]. In many instances, USE and US leaching are efficient alternatives to more 


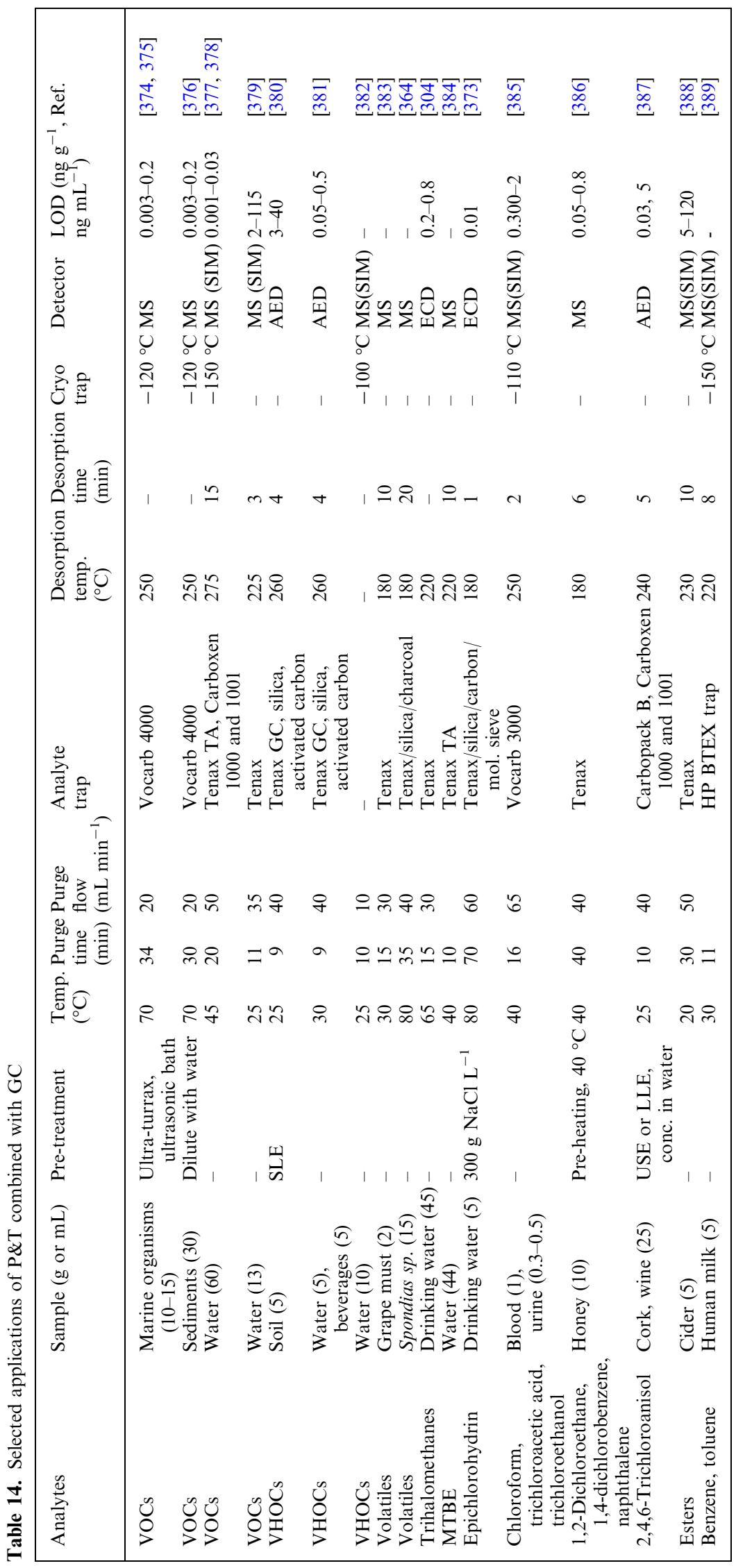




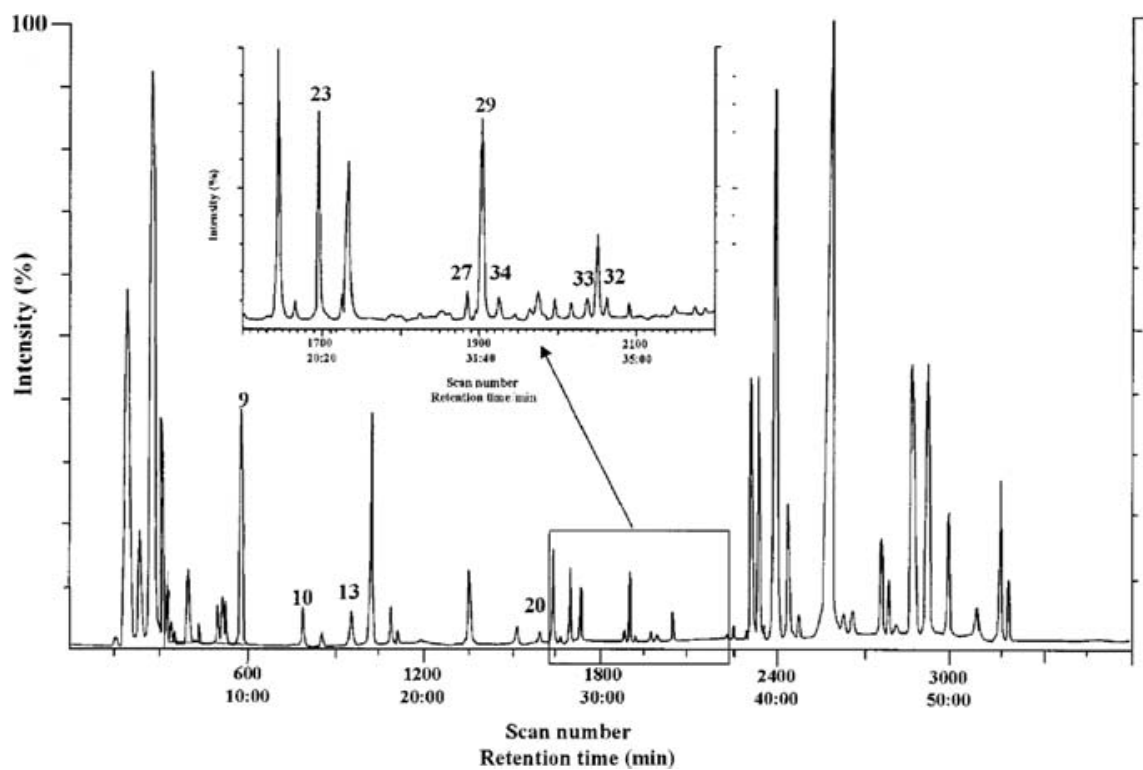

Fig. 25. P\&T-GC-MS chromatogram of $15 \mathrm{~g}$ of eel from the river Scheldt: $\mathbf{9}=$ Chloroform; $\mathbf{1 0}=1,1,1$-Trichloroethane; $\quad \mathbf{1 3}=$ Benzene; $\quad \mathbf{2 0}=$ Toluene; $\quad \mathbf{2 3}=$ Tetrachloroethene; $\mathbf{2 7}=$ Chlorobenzene; $\mathbf{2 9}=$ Ethylbenzene; $\mathbf{3 2}=o$-Xylene; $\mathbf{3 3}=$ Styrene; $\mathbf{3 4}=$ Bromoform [366]

conventional approaches, and quantification is fully satisfactory if a probe device rather than an ultrasound bath is used. Because of the low overall temperature during the operation, analyte thermolability is no serious problem. The inherent advantage of dynamic/continuous systems merits more attention. USE is often compared with MAE. It is simpler and, sometimes, also faster than that technique. On the other hand, USE is considered less robust and particle size can be a critical factor.

MSPD is a technique designed to simultaneously disrupt and disperse a sample over a properly selected solid support. The combination of extraction and clean-up, short extraction times, small sample size and use of little sorbent and solvent(s) are main advantages. The very simplicity of MSPD explains why additional treatment will usually be required prior to GC analysis. If, however, such treatment comprises three, four or even more steps (Table 6), one may seriously doubt the cost-, and time-, effectiveness of the approach.

DTD is a recently introduced samplepreparation technique which has been applied already to a variety of difficult matrices and can be fully automated, although at considerable cost. The extracts are rather clean and rewarding results are obtained for very small samples such as a few pollen [163] or small pieces of cheese [167]. The main limitations are the determination of thermolabile and very high-boiling compounds.

For the analysis of aqueous/liquid samples, SPE is no doubt the most efficient and flexible technique. This is also frequently indicated by other reviewers. If combined with GC analysis, nonselective sorbents are preferred because collecting a wide (polarity) range of analytes is more important than creating selectivity. In other words, using a commercial copolymer sorbent is, generally speaking, a better approach than designing another MISPE material. A variety of SPE formats for off-line, online and semi- or fully automated operation is (commercially) available and for miniaturized (ca. $1 \mathrm{~mL}$ ), conventionalsize (ca. $100 \mathrm{~mL}$ ) and large-scale $(1 \mathrm{~L}$ and over) applications. Compared with other-frequently equilibrium-typetechniques, a much larger analyte enrichment can usually be achieved with exhaustively extracting SPE. From among the equilibrium techniques, SPME and SBSE are probably best known. One main advantage is that they are both solvent-free. On the other hand, for a fair number of applications, reaching equilibrium conditions is timeconsuming. This is especially true for SBSE, which has the additional disadvantage that quite some manual handling is required and automation is essentially impossible. Generally speaking, this makes SPME - for which fully automated systems are commercially available - a much more attractive option, even though its application range is relatively limited [258]. Recently introduced SDME is an inexpensive equilibrium-type alternative, with 'drop-size' extraction volumes as an attractive feature. Unfortunately, the prolonged extraction times needed to reach equilibrium may cause drop dissolution. If sample agitation is used to enhance extraction, proper procedures have to be used to prevent drop dislodgement. In summary, SDME is not without its technical problems.

There are several more points which briefly require our attention. For example, from among the goals mentioned in the introductory text of this section, environmental friendliness is repeatedly emphasized in the published literature and solvent-free techniques are therefore recommended. On the other hand, despite all the emphasis frequently given to high sample throughput, speed is often given insufficient attention. In addition, designing sample-preparation methods that are easily coupled on-line to the GC-MS system usually has no high priority and the substantial gain that can be effected by injecting the entire (online) instead of a minor aliquot of (offline) sample extract is often overlooked. The obvious disadvantages of equilibrium methods - i.e., the risk of low analyte recovery and the problem of long analyte-extraction times if the application range of the method is unduly expanded-usually are insufficiently considered. On the positive side, several of the more recently developed methods, notably DTD and SDME - and also SPME - enable miniaturization or are, in essence, micro methods. It is also 
good that reviewers such as Smith [392] and Kristensson [393] emphasize that derivatization and/or analyte labelling should be avoided whenever possible. The additional, often multi-step, procedures adversely affect sample throughput and cost of analysis. Artefacts are often created and the application is not always validated at the ultra-trace level. With many LC-MS techniques being available to study the intact analytes - a distinct advantage when identification is a primary goal-derivatization is an acceptable approach only in cases such as, for example, the methylation of fatty acids and transesterification of lipids, the silylation of selected steroids or the acylation of amines.

One aspect that is not always given due attention is distinguishing targetcompound monitoring and profiling entire samples (see, e.g., [391]). In the former case, in which the search is limited to specific, pre-identified compounds, proper optimization of the sample preparation to create a suitably selective procedure may be useful, although it will often be superfluous because of the selectivity inherent in the GC-MS part of the analysis. In the much more challenging profiling situation, in which all constituents of a sample are regarded as analytes, non-selective and (close to) exhaustive analyte extraction are key issues. [If necessary, a straightforward LCtype fractionation may be included as a first step.] Equilibrium methods such as SBSE, SPME and MMLLE should not be selected for such studies, specifically not because the extraction behaviour of the unknown compounds cannot be predicted. Instead, robust non-selective SPE should be used. Similarly, with volatile organic compounds, P\&T is a more powerful-i.e., much more sensitive, and automatable - technique than HS-SPME, although one may argue that the difference is not too large in this case because the focus on volatile analytes creates a situation in between target monitoring and profiling. Finally, one should take into account that there is an increasing use of $\mathrm{GC} \times \mathrm{GC}$ instead of GC. This significantly helps to unravel the composition of many food, fish and biota as well as soil, sediment and aerosol samples: applying the comprehensive technique should be seriously considered whenever profiling of such samples is required.

In summary, the developments described in this chapter demonstrate that in the field of sample preparation, a variety of approach routes is continually being opened, optimized and, next, often modified. They serve many different purposes such as, e.g., simplifying the overall analytical procedure and/or enhancing its performance, increasing sample throughput, facilitating analyte identification or enabling more reliable quantification. Or, as a young scientist wrote in 2005 [393]:

Actually, as is increasingly being said by experts in the field, we are rapidly creating conditions in which it is not performing the analyses and handing in the results, but the subsequent data handling and data interpretation which will become the stumbling block. In other words, while still working on solving the analytical problems of the present generation, those of the next generation are already looming on the horizon.

This statement is still valid today or, in other words, the efforts of the "next generation" are still urgently required.

$\begin{array}{ll}\text { Glossary } & \\ \text { Acet } & \text { Acetone } \\ \text { AED } & \text { Atomic emission detector } \\ \text { ASE } & \text { Accelerated solvent extraction } \\ \text { ATD } & \text { Automated thermal desorption } \\ \text { Benz } & \text { Benzene } \\ \text { BSTFA } & \begin{array}{l}\text { N,O-bis(Trimethylsilyl) } \\ \text { trifluoroacetamide }\end{array} \\ \text { BTEX } & \text { Benzene, toluene, ethylbenzene, } \\ & \text { and xylenes } \\ \text { ButOAc } & \text { Butyl acetate } \\ \text { CFME } & \text { Continuous-flow micro- } \\ & \text { extraction } \\ \text { Conc. } & \text { Concentrate } \\ \text { CTME } & \text { cis/trans } \text { Methyl ester } \\ \text { Cyclohex } & \text { Cyclohexane } \\ \text { Cyclopen } & \text { Cyclopentane } \\ \text { DCM } & \text { Dichloromethane } \\ \text { DDSME } & \begin{array}{l}\text { Drop-to-drop solvent } \\ \text { micro-extraction }\end{array} \\ \text { Dec } & \text { Decane } \\ \text { Deriv. } & \text { Derivatization } \\ \text { DI- } & \begin{array}{l}\text { Direct-immersion solid-phase } \\ \text { micro-extraction }\end{array} \\ \text { SPME } & \text { Dynamic microwave-assisted } \\ \text { DMAE } & \begin{array}{l}\text { extraction } \\ \end{array}\end{array}$

DMI Difficult/dirty matrix introduction

$\begin{array}{ll}\text { DSI } & \text { Difficult sample introduction } \\ \text { DTD } & \text { Direct thermal desorption }\end{array}$

DUSE Dynamic ultrasound-assisted extraction

ECD Electron-capture detector

EPA Environmental Protection Agency

EtAc Acetic acid

EtOAc Ethyl acetate

EtOH Ethanol

FAME Fatty acid methyl ester

FID Flame ionization detector

FMAE Focused microwave-assisted extraction

FPD Flame photometric detector

GC Gas chromatography

$\mathrm{GC} \times \mathrm{GC}$ Comprehensive twodimensional gas chromatography

GPC Gel permeation chromatography

Hep Heptane

Hex Hexane

HexOAc Hexyl acetate

HRMS High-resolution mass

HS Hectrometry

HS- Headspace liquid-phase microLPME extraction

HS- Headspace single-drop micro-

SDME

HS-

SPME

HSSE

IAE

IASPE

IMS

IR

ISTD

$\mathrm{K}_{\mathrm{o} / \mathrm{w}}$

LC

LOD

LLE

LPME Liquid-phase micro-extraction

LVI Large-volume injection

MAE Microwave-assisted extraction

MASE Membrane-assisted solvent extraction

$\mathrm{MeCN} \quad$ Acetonitrile

$\mathrm{MeOH}$ Methanol

MESI Membrane-extraction sorbent interface

MIMS Membrane-introduction mass spectrometry

MIP Molecularly imprinted polymer

MISPE Molecularly imprinted solidphase extraction

MMLLE Microporous membrane liquidliquid extraction 


\begin{tabular}{|c|c|c|c|}
\hline MS & Mass spectrometer & $\mathrm{TD}$ & Thermal desorption \\
\hline MSPD & Matrix solid-phase dispersion & Tetra & Tetrachloromethane \\
\hline MTBE & Methyl tert-butyl ether & $\mathrm{TIC}$ & Total ion current \\
\hline NPD & Nitrogen phosphorus detector & TMSH & Trimethylsulphonium \\
\hline NPLC & $\begin{array}{l}\text { Normal-phase liquid } \\
\text { chromatography }\end{array}$ & ToF MS & $\begin{array}{l}\text { hydroxide } \\
\text { Time-of-flight mass }\end{array}$ \\
\hline $\mathrm{OCP}$ & Organochlorine pesticide & & snectrometry \\
\hline OPP & Organophosphorus pesticides & Tol & Toluene \\
\hline P\&T & Purge \& trap & TSD & Thermionic specific detector \\
\hline PAH & Polycyclic aromatic & USE & Ultrasound-assisted extraction \\
\hline PBDE & $\begin{array}{l}\text { hydrocarbons } \\
\text { Polybrominated diphenyl ether }\end{array}$ & $\mathrm{VH}$ & $\begin{array}{l}\text { Volatile halogenated organic } \\
\text { compound }\end{array}$ \\
\hline PCB & Polychlorinated biphenyl & VOC & Volatile organic compound \\
\hline $\mathrm{PCDD} / \mathrm{F}$ & $\begin{array}{l}\text { Polychlorinated dibenzo- } p \text { - } \\
\text { dioxin/furane }\end{array}$ & $\begin{array}{l}\text { VOX } \\
\text { Xyl }\end{array}$ & $\begin{array}{l}\text { Volatile organic halogens } \\
\text { Xylene }\end{array}$ \\
\hline PDHID & $\begin{array}{l}\text { Pulsed-discharge helium } \\
\text { ionization detector }\end{array}$ & & \\
\hline PDMS & Polydimethylsiloxane & & \\
\hline PEEK & Polyetheretherketone & pel & ess \\
\hline
\end{tabular}

Pen

PFBHA $O$-(2,3,4,5,6-Pentafuorobenzyl) hydroxylamine hydrochloride

PFE Pressurized fluid extraction

PFPD Pulsed flame photometric detector

PHWE Pressurized hot-water extraction

PID Photoionization detector

PLE Pressurized liquid extraction

PMAE Pressurized microwave-assisted extraction

POP Persistent organic pollutant

$\mathrm{PP}$

PTFE Polytetrafluoroethylene (Teflon)

PTV Programmed temperatue vaporizer

QqQ Triple quadrupole

RAM Restricted-access media

RSD Relative standard deviation

Sat. Saturated

SBSE Stir-bar sorptive extraction

SCD Sulphur chemiluminescence detector

SD Steam distillation

SDB Styrene-divinylbenzene

SDME Single-drop micro-extraction

SEP Sample-enrichment probe

SFE Supercritical fluid extraction

SHWE Subcritical hot-water extraction

SIM Single ion monitoring

SLE Solid-liquid extraction

SLM Supported liquid membrane

SPE Solid-phase extraction

SPDE Solid-phase dynamic extraction

SPME Solid-phase micro-extraction

SVOC Semi-volatile organic compound

TATP Triacetone triperoxide

TCD Thermal conductivity detector

TCM Chloroform
This article is distributed under the terms of the Creative Commons Attribution Noncommercial License which permits any noncommercial use, distribution, and reproduction in any medium, provided the original author(s) and source are credited.

\section{References}

1. Richter BE, Ezzell JL, Felix D, Roberts KA, Later DW (1995) Am Lab 27:24

2. Ramos L, Kristenson EM, Brinkman UATh (2002) J Chromatogr A 975:3

3. Smith RM (2002) J Chromatogr A 975:31

4. Mendiola JA, Herrero M, Cifuentes A, Ibañez E (2006) J Chromatogr A 1152:234

5. Hyötyläinen T (2007) J Chromatogr A 1153:14

6. Ezzell JL, Richter BE, Felix WD, Black SR, Meikle JE (1995) LC-GC Int 13:24

7. Björklund $E$, Nilsson $T$, Bøwadt $S$ (2000) Trends Anal Chem 19:434

8. Ding WH, Fann JCH (2000) J Chromatogr A 866:79

9. Windal I, Miller DJ, de Pauw E, Hawthorne SB (2000) Anal Chem 72:3916

10. Waksmundzka M, Petruczynik A, Dragan $\mathrm{A}$, Wianowska $\mathrm{D}$, Dawidowick $\mathrm{AL}$ Sowa I (2004) J Chromatogr B 800:182

11. Klejdus B, Vacek J, Adam V, Zehnalek J, Kizek R, Trnkova L, Kuban V (2004) J Chromatogr B 806:101

12. Richter BE, Jones BA, Ezzell JL, Porter NL, Avdalovic N, Pohl C (1996) Anal Chem 68:1033

13. Richter BE (2000) J Chromatogr A $874: 217$

14. Vematsu M, Franck EV (1980) J Phys Chem Ref Data 9:2191
15. Richter P, Sepúlveda B, Oliva R, Calderón K, Seguel R (2003) J Chromatogr A 994:169

16. Rodil R, Popp P (2006) J Chromatogr A 1124:82

17. Garrido Frenich A, Martínez JL, Vidal, Cruz Sicilia AD, González Rodríguez MJ, Plaza Bolaños P (2006) Anal Chim Acta 558:42

18. Ramos L, Vreuls JJ, Brinkman UATh (2000) J Chromatogr A 891:275

19. Bautz H, Polzer J, Stieglitz L (1998) J Chromatogr A 815:231

20. Lüthje K, Hyötyläinen T, RautiainenRämä M, Riekkola M-L (2005) Analyst 130:52

21. Kuosmanen K, Hyötyläinen T, Hartonen $\mathrm{K}$, Jönsson JA, Riekkola M-L (2003) Anal Bioanal Chem 375:389

22. Suchan P, Pulkrabová J, Hajšlová J, Kocourek V (2004) Anal Chim Acta 520:193

23. Dabrowski Ł, Giergielewicz-Możajska $\mathrm{H}$, Biziuk M, Gaca J, Namieśnik J (2002) J Chromatogr A 957:59

24. Wiberg K, Sporring S, Haglund $\mathrm{P}$, Björklund E (2007) J Chromatogr A 1138:55

25. Ramos JJ, Dietz C, González MJ, Ramos L (2007) J Chromatogr A 1152:254

26. Liguori L, Heggstad K, Hove HT, Julshamn K (2006) Anal Chim Acta 573574:181

27. Concha-Graña E, Turnes-Carou MI, Muniategui-Lorenzo S, López-Mahía P, Fernández-Fernández E, Prada-Rodríguez D (2004) J Chromatogr A 1047:147

28. Barriada-Pereira M, González-Castro MJ, Muniategui-Lorenzo S, LópezMahía P, Prada-Rodríguez D, Fernández-Fernández E (2007) Talanta 71:134

29. Díaz-Cruz MS, Barceló D (2006) J Chromatogr A 1132:21

30. Dagnac T, Bristeau S, Jeannot R, Mouvet C, Baran N (2005) J Chromatogr A 1067:225

31. Canosa P, Pérez-Palacios D, GarridoLópez A, Tena MT, Rodríguez I, Rubí E, Cela R (2007) J Chromatogr A 1161:105

32. Van de Weghe H, Vanermen G, Gemoets J, Lookman R, Bertels D (2006) J Chromatogr A 1137:91

33. Curren MSS, King JW (2001) J Agric Food Chem 49:2175

34. Özel MZ, Göğüş F, Hamilton JF, Lewis AC (2005) Anal Bioanal Chem 382:115

35. Deng Ch, Ji J, Wang X, Zhang X (2005) J Sep Sci 28:1237

36. Göğüş F, Özel MZ, Lewis AC (2006) Flavour Fragr J 21:122

37. Özel MZ, Kaymaz H (2004) Anal Bioanal Chem 379:1127

38. Deng Ch, Wang A, Shen S, Fu D, Chen J, Zhang X (2005) J Pharm Biomed Anal $38: 326$

39. Eikani MH, Golmohammad F, Rowshanzamir S (2007) J Food Eng 80:735

40. Ericsson M, Colmsjö A (2003) Anal Chem 75:1713

41. Dean JR (1998) Extraction methods for environmental analysis. Wiley, New York 
42. Camel V (2000) Trends Anal Chem 19:229

43. Letellier M, Budzinski H (1999) Analusis $27: 259$

44. Lopez-Avila V, Benedicto J (1996) Trends Anal Chem 15:334

45. Saim N, Dean JR, Abdullah Md P, Zakaria Z (1997) J Chromatogr A 791:361

46. Lopez-Avila V (2000) Microwave-assisted extraction. In: Wilson ID (ed) Encyclopedia of separation science. Academic Press, London, p 1389

47. Sparr Eskilsson C, Björklund E (2000) J Chromatogr A 902:227

48. Hummert K, Vetter W, Luckas B (1996) Chromatographia 42:300

49. Düring R-A, Gäth St (2000) Fresenius J Anal Chem 368:684

50. Dean JR, Barnadas IJ, Fowlis IA (1995) Anal Proc 32:305

51. López de Sabando O, Gómez de Balugera Z, Goicolea MA, Rodríguez E, Sampedro MC, Barrio RJ (2002) Chromatographia 55:667

52. Ericsson M, Colmsjö A (2002) J Chromatogr A 964:11

53. Young JC (1995) J Agric Food Chem 43:2904

54. Luque de Castro MD, Jimenez-Carmona MM, Fernandez-Perez V (1999) Trends Anal Chem 18:708

55. Hasty E, Revesz R (1995) Am Lab 66(27):66-74

56. Ericsson M, Colmsjö A (2000) J Chromatogr A 877:141

57. Lopez-Avila V, Young R, Teplitsky N (1996) J Assoc Off Anal Chem Int 79:142

58. Ramil Criado M, Rodríguez Pereiro I, Cela Torrijos R (2004) Talanta 63:533

59. Parera J, Santos FJ, Galceran MT (2004) J Chromatogr A 1046:19

60. Bayen S, Lee HK, Obbard JP (2004) J Chromatogr A 1035:291

61. Regueiro J, Llompart M, García-Jares C, Cela R (2006) J Chromatogr A 1137:1

62. Yusà V, Pardo $\mathrm{O}$, Pastor $\mathrm{A}$, de la Guardia M (2006) Anal Chim Acta 557:304

63. García M, Rodríguez I, Cela R (2007) J Chromatogr A 1152:280

64. Shu YY, Tey SY, Wu DKS (2003) Anal Chim Acta 495:99

65. Fuentes E, Báez ME, Reyes D (2006) Anal Chim Acta 578:122

66. Barriada-Pereira M, González-Castro MJ, Muniategui-Lorenzo S, LópezMahía P, Prada-Rodríguez D, Fernández-Fernández E (2007) Talanta 71:1345

67. Papadakis EN, Vryzas Z, Papadopoulou-Mourkidou E (2006) J Chromatogr A 1127:6

68. Esteve-Turrillas FA, Aman CS, Pastor A, de la Guardia M (2004) Anal Chim Acta 522:73

69. Sanusi A, Guillet V, Montury M (2004) J Chromatogr A 1046:35

70. Basheer Ch, Obbard JPh, Lee HK (2005) J Chromatogr A 1068:221

71. Zhu X, Su Q, Cai J, Yang J (2006) Anal Chim Acta 579:88
72. Díaz-Vázquez LM, García O, Velázquez Z, Marrero I, Rosario O (2005) J Chromatogr B 825:11

73. Latorre A, Lacorte S, Barceló D, Montury M (2005) J Chromatogr A 1065:251

74. Morales S, Canosa P, Rodríguez I, Rubí E, Cela R (2005) J Chromatogr A 1082:128

75. Bartolomé L, Cortazar E, Raposo JC, Usobiaga A, Zuloaga O, Etxebarria N, Fernández LA (2005) J Chromatogr A 1068:229

76. Gfrerer M, Lankmayr E (2005) Anal Chim Acta 533:203

77. Lui R, Zhou JL, Wilding A (2004) J Chromatogr A 1038:19

78. Gatidou G, Zhou JL, Thomaidis NS (2004) J Chromatogr A 1046:41

79. Bendicho C, Lavilla I (2000) Ultrasound extractions. In: Wilson ID (ed) Encyclopedia of separation science. Academic Press, London, p 1448

80. Luque-García JL, Luque de Castro MD (2003) Trends Anal Chem 22:41

81. Priego-Capote F, Luque de Castro MD (2004) Trends Anal Chem 23:644

82. Sanchez C, Ericsson M, Carlsson H, Colmsjö A, Dyremark E (2002) J Chromatogr A 957:227

83. Sanchez C, Ericsson M, Carlsson H, Colmsjö A (2003) J Chromatogr A 993:103

84. Moralez-Muñoz S, Vreuls RJJ, de Castro MD (2005) J Chromatogr A 1086:122

85. Moralez-Muñoz S, Luque de Castro MD (2005) J Chromatogr A 1066:1

86. Caballo-López A, Luque de Castro MD (2003) J Chromatogr A 998:51

87. Gonçalves C, Alpendurada MF (2005) Talanta 65:1179

88. US EPA (2000) Ultrasonic extraction, test methods for evaluating solid waste, Method 3550C, Rev. 3, US Environmental Protection Agency, Washington DC, USA, November

89. Zhou J, Xue X, Li Y, Zhang J, Wu L, Chen L, Zhao J (2007) J Sep Sci 30:1912

90. Luque-García JL, Luque de Castro MD (2004) J Chromatogr A 1034:237

91. Sánchez Ávila N, Priego Capote F, Luque de Castro MD (2007) J Chromatogr A $1165: 158$

92. Moret I, Piazza R, Benetti M, Gambaro A, Barbante C, Cescon P (2001) Chemosphere 43:559

93. Banjoo DR, Nelson PK (2005) J Chromatogr A 1066:9

94. Sánchez-Brunete C, Miguel E, Tadeo JL (2002) J Chromatogr A 976:319

95. Barro R, Garcia-Jares C, Llompart M, Bollain MH, Cela R (2006) J Chromatogr A 1111:1

96. Alissandrakis E, Daferera D, Tarantilis PA, Polissiou M, Harizanis PC (2003) Food Chem 82:575

97. Cabredo-Pinillos S, Cedrón-Fernández T, González-Briongos M, Puente-Pascual L, Sáenz-Barrio C (2006) Talanta 69:1123
98. Zuo Y, Zhang L, Wu J, Fritz JW, Medeiros S, Rego Ch (2004) Anal Chim Acta 526:35

99. Shen H-Y (2005) Talanta 66:734

100. Priego-López E, Luque de Castro MD (2003) J Chromatogr A 1018:1

101. Smith RM, Hawthorne SB (1997) Supercritical fluids in chromatography and extraction. Elsevier, Amsterdam

102. Zougagh M, Valcárcel M, Ríos A (2004) Trends Anal Chem 23:399

103. Pourmortazavi SM, Hajimirsadeghi SS (2007) J Chromatogr A 1163:2

104. Saengcharoenrat Ch, Guyer DE (2004) J Food Eng 63:33

105. Rissato SR, Galhiane MS, Knoll FRN, Apon BM (2004) J Chromatogr A 1048:153

106. Garrigós MC, Marín ML, Cantó A, Sánchez A (2004) J Chromatogr A 1061:211

107. Poole CF, Poole SK (1996) Anal Commun $33: 11 \mathrm{H}$

108. Tehrani J (1993) Am Lab 2:40

109. McNally MEP (1995) Anal Chem 67:308A

110. Taylor LT (1995) Anal Chem 68:364A

111. Hawthorne SB, Miller DJ (1987) J Chromatogr 403:63

112. Vedaraman N, Srinivasakannan C, Brunner G, Ramabrahman BV, Rao PG (2005) J Supercrit Fluids 34:27

113. Santoyo S, lloría R, Jaime L, Ibañez E, Señoráns FJ, Reglero G (2006) Eur Food Res Technol 222:565

114. Hyötyläinen T, Riekkola M-L (2004) Anal Bioanal Chem 378:1962

115. Ramos L, Ramos JJ, Brinkman UATh (2005) Anal Bioanal Chem 381:119

116. Aguilera A, Brontos M, Rodríguez M, Valverde A (2003) J Agric Food Chem 51:5616

117. Poutska J, Holadová K, Hajšlová J (2003) Eur Food Res Technol 216:68

118. Antunes P, Gil O, Bernardo-Gil MG (2003) J Supercrit Fluids 25:135

119. Chuang JC, Hart K, Chang JS, Boman LE, Van Emon JM, Reed AW (2001) Anal Chim Acta 444:87

120. Pourmortazavi SM, Ghadiri M, Hajimirsadeghi SS (2005) J Food Compos Anal 18:439

121. Karásek P, Planeta J, Varad'ová Ostrá E, Mikešová $\mathrm{M}$, Goliás J, Roth $\mathrm{M}$, Vejrosta J (2003) J Chromatogr A 1002:13

122. Michielin EMZ, Bresciani LFV, Danielski L, Yunes RA, Ferreira SRS (2005) J Supercrit Fluids 33:131

123. Smelcerovic A, Lepojevic Z, Djordjevic S (2004) Chem Eng Technol 27:1327

124. Ashraf-Khorassani M, Ude M, DoaneWeideman T, Tamczak T, Taylor LT (2002) J Agric Food Chem 50:1822

125. Ko T-F, Weng Y-M, Chiou RY-Y (2002) J Agric Food Chem 50:5343

126. Barker SA, Long AR, Short CR (1989) J Chromatogr A 475:353

127. Kristenson EM, Ramos L, Brinkman UATh (2006) Trends Anal Chem 25:96

128. Barker SA (2007) J Biochem Biophys Meth 70:151 
129. Bogialli S, Di Corcia A (2007) J Biochem Biophys Meth 70:163

130. Hercegová A, Dömötörová M, Matisová E (2007) J Chromatogr A 1153:54

131. Kristenson EM, Haverkate EGJ, Slooten CJ, Ramos L, Vreuls RJJ, Brinkman UATh (2001) J Chromatogr A 917:277

132. Blasco C, Font G, Picó Y (2002) J Chromatogr A 970:201

133. Gómez-Ariza JL, Bujalance M, Giráldez I, Velasco A, Morales E (2002) J Chromatogr A 946:209

134. Ramos L, Eljarrat E, Hernandez LM, Rivera J, Gonzalez MJ (1999) Chemosphere 38:2577

135. Chu X-G, Hu X-Z, Yao H-Y (2005) J Chromatogr A 1063:201

136. Ramos J-J, Gonzalez M-J, Ramos L (2004) J Sep Sci 27:595

137. Kristenson EM, Shahmiri S, Slooten CJ, Vreuls RJJ, Brinkman UATh (2004) Chromatographia 59:1

138. Navarro M, Picó Y, Marín R, Mañes J (2002) J Chromatogr A 968:209

139. Soler C, Mañes J, Picó Y (2004) J Chromatogr A 1048:41

140. Pena MT, Casais MC, Mejuto MC, Cela R (2007) J Chromatogr A 1165:32

141. Martínez A, Ramil M, Montes R, Hernanz D, Rubí E, Rodríguez I, CelaTorrijos R (2005) J Chromatogr A 1072:83

142. Valsamaki VI, Boti VI, Sakkas VA, Albanis TA (2006) Anal Chim Acta 573574:195

143. Matos Lino C, Ferreira Azzolini CB, Valente Nunes DS, Rocha Silva JM, Noronha da Silveira MI (1998) J Chromatogr B 716:147

144. Ferrer C, Gómez MJ, García-Reyes JF, Ferrer I, Thurman EM, Fernández-Alba AR (2005) J Chromatogr A 1069:183

145. Carro AM, Lorenzo RA, Fernández F, Rodil R, Cela R (2005) J Chromatogr A 1071:93

146. Albero B, Sánchez-Brunete C, Tadeo JL (2003) J Agric Food Chem 51:6915

147. Sánchez-Brunete C, Albero B, Miguel E, Tadeo JL (2002) J Assoc Off Anal Chem $85: 128$

148. Morzycka B (2002) J Chromatogr A 982:267

149. Tadeo JL, Sánchez-Brunete C (2003) Chromatographia 57:793

150. Frenich AG, Bolaños PP, Martínez-Vidal JL (2007) J Chromatogr A 1153:194

151. Kubala-Drincic H, Bazulic D, SapunarPostruznik J, Grubelic M, Stuhne G (2003) J Agric Food Chem 51:871

152. Esteban JL, Matrínez-Castro I, Morales R, Fabrellas B, Sanz J (1996) Chromatographia 43:63

153. Cuppett CM, Findeis PM, Klotz JC, Woods LA, Strein TG (1999) LC GC N Am 17:532

154. Püttmann W (1991) J Chromatogr $552: 325$

155. Gerard L, Elie M, Landais P (1994) J Appl Pyrol 29:137

156. Garg AK, Philip RP (1994) Org Geochem $21: 383$
157. Larter SR, Senftle JT (1985) Nature 318:277

158. van Lieshout MPM, Janssen H-G, Cramers CA, van den Bos GA (1997) J Chromatogr A 764:73

159. van Lieshout MPM, Janssen H-G, Cramers CA, Hetem MJJ, Schalk HJP (1996) J High Resolut Chromatogr 19:193

160. Hays MD, Lavrich RJ (2007) Trends Anal Chem 26:88

161. Fox RL (1999) Anal Chem 71:109R

162. Ho SSH, Yu J (2004) J Chromatogr A 1059:121

163. de Koning JA, Blokker $\mathrm{P}$, Jüngel $\mathrm{P}$, Alkema G, Brinkman UATh (2002) Chromatographia 56:185

164. http://www.gerstel.com/ALEX_eng.pdf

165. http://www.atasgl.com

166. Jüngel $\mathrm{P}$, de Koning $\mathrm{S}$, Brinkman UATh, Melcher E (2002) J Chromatogr A 953:199

167. Göğüş F, Özel MZ, Lewis AC (2006) J Sep Sci 29:1217

168. Welthagen W, Schnelle-Kreis J, Zimmermann R (2003) J Chromatogr A 1019:233

169. Schnelle-Kreis J, Sklorz M, Peters A, Cyrys J, Zimmermann R (2005) Atmos Environ 39:7702

170. Schnelle-Kreis J, Welthagen W, Sklorz M, Zimmermann R (2005) J Sep Sci 28:1648-1657

171. Vogt L, Gröger T, Zimmermann R (2007) J Chromatogr A 1150:2

172. Amirav A, Dagan S (1997) J Mass Spectrom 3:105

173. Jing H, Amirav A (1997) Anal Chem 69:1426

174. http://www.varianinc.com

175. De Koning $\mathrm{S}$, Lach $\mathrm{G}$, Linkerhägner $\mathrm{M}$, Löscher R, Tablack PH, Brinkman UATh (2003) J Chromatogr A 1008:247

176. Patel K, Fussell RJ, Goodall DM, Keely BJ (2003) Analyst 128:1228

177. Anastassiades M, Lehotay SJ, Stajnbaher D, Schenck FJ (2003) J AOAC Int 86:412

178. Patel K, Fussell RJ, Goodall DM, Keely BJ (2004) Food Addit Contam 21:658

179. Čajka T, Maštovská K, Lehotay SJ, Hajšlová J (2005) J Sep Sci 28:1048

180. Blokker P, Pel R, Akoto L, Brinkman UATh (2002) J Chromatogr A 959:191

181. Akoto L, Pel R, Irth H, Brinkman UATh, Vreuls RJJ (2005) J Anal Appl Pyrol 73:69

182. Esteban JL, Martinez-Castro I, Sanz J (1993) J Chromatogr A 657:155

183. Hays MD, Smith ND, Kinsey J, Dong Y, Kariher P (2003) J Aerosol Sci 34:1061

184. Sanz J, Soria AC, García-Vallejo MC (2004) J Chromatogr A 1024:139

185. Pérez-Coello MS, Sanz J, Cabezudo MD (1997) J Chromatogr A 778:427

186. García MA, Sanz J (2001) J Chromatogr A 918:189

187. Zunin P, Boggia R, Lanteri S, Leardi R, De Andreis R, Evangelisti F (2004) J Chromatogr A 1023:271
188. de Koning S, Kaal E, Janssen H-G, Van Platerink Ch, Brinkman UATh (2008) J Chromatogr A 1186:228

189. Göğüș F, Özel MZ, Lewis AC (2007) Talanta 73:321

190. Helmig D, Bauer A, Müller J, Klein W (1990) Atmos Environ 24A:179

191. Falkovich AH, Rudich Y (2001) Environ Sci Technol 35:2326

192. Waddell R, Dale DE, Monagle M, Smith SA (2005) J Chromatogr A 1062:125

193. Sigman ME, Ma Ch-Y (1999) Anal Chem 71:4119

194. Nakamura S, Takino M, Daishima S (2001) J Chromatogr A 912:319

195. Mielle P, Souchaud M, Landy P, Guichard E (2006) Sens Actuators B 116:161

196. Özel MZ, Göğüș F, Lewis AC (2006) Anal Chim Acta 566:172

197. Özel MZ, Göğüș F, Lewis AC (2006) J Chromatogr A 1114:164

198. Mol HGJ, Janssen H-GM, Cramers CA, Vreuls JJ, Brinkman UATh (1995) J Chromatogr A 703:277

199. Hankemeier Th, Brinkman UATh (2000) In: Niessen WMA (ed) Current practice of gas chromatography-mass spectrometry. Marcel Dekker, New York, pp 155

200. Louter AJH, Vreuls JJ, Brinkman UATh (1999) J Chromatogr A 842:391

201. Hankemeier Th, Louter AJH, Rinkema FD, Brinkman UATh (1995) Chromatographia 40:119

202. Hankemeier TH, van Leeuwen SPJ, Vreuls JJ, Brinkman UATh (1998) J Chromatogr A 811:117

203. Hankemeier Th, Kok SJ, Vreuls RJJ, Brinkman UATh (1999) J Chromatogr A $841: 75$

204. Hankemeier Th (2000) PhD Thesis, Chap. 3.2, Free University, Amsterdam

205. Brossa L, Marcé RM, Borrull F, Pocurull E (2003) J Chromatogr A 998:41

206. Jahr D (1998) Chromatographia 47:49

207. Caro E, Marcé RM, Borrull F, Cormack PAG, Sherrington DC (2006) Trends Anal Chem 25:143

208. Tamayo FG, Turiel E, Martín-Esteban A (2007) J Chromatogr A 1152:32

209. Shi Y, Zhang J-H, Shi D, Jiang M, Zhu Y-X, Mei S-R, Zhou Y-K, Dai K, Lu B (2006) J Pharm Biomed Anal 42:549

210. Andersson LI, Paprica A, Arvidsson T (1997) Chromatographia 46:57

211. Harvey SD (2005) J Sep Sci 28:1221

212. Dallüge J, Hankemeier Th, Vreuls RJJ, Brinkman UATh (1999) J Chromatogr A 830:377

213. Hankemeier Th, Hooijschuur E, Vreuls RJJ, Brinkman UATh (1998) J High Resolut Chromatogr 21:341

214. Mol HGJ, Hankemeier Th, Brinkman UATh (1999) LC GC Int 12:108

215. Hankemeier Th, Rozenbrand J, Adahchour M, Vreuls JJ, Brinkman UATh (1998) Chromatographia 48:273

216. de Koning S, Van Lieshout M, Janssen H-G, Brinkman UATh (2000) J Microcol Sep 12:153 
217. Pocurull E, Aguilar C, Borrull F, Marcé RM (1998) J Chromatogr A 818:85

218. Verma KK, Louter AJH, Jain A, Pocurull E, Vreuls JJ, Brinkman UATh (1997) Chromatographia 44:372

219. Hankemeier Th, Steketee PC, Vreuls JJ (1999) Fresenius J Anal Chem 364:106

220. Weigel S, Bester K, Hühnerfuss H (2001) J Chromatogr A 912:151

221. Tř́ska J (1995) Chromatographia 40:712

222. Beiner K, Popp P, Wennrich R (2002) J Chromatogr A 968:171

223. Zhu X, Yang J, Su Q, Cai J, Gao Y (2005) J Chromatogr A 1092:161

224. Arthur CL, Pawliszyn J (1990) Anal Chem 62:2145

225. de Alpendurada MF (2000) J Chromatogr A 889:3

226. Lord H, Pawliszyn J (2000) J Chromatogr A 885:153

227. Dietz Ch, Sanz J, Cámara C (2006) J Chromatogr A 1103:183

228. Pawliszyn J (ed) (1997) Solid-phase microextraction-theory and practice. Wiley, New York

229. Pawilszyn J (ed) (1999) Applications of solid-phase microextraction. Royal Society of Chemistry, Cambridge

230. Sheppers Wercinski SA (1999) Solidphase microextraction: a practical guide. Marcel Dekker, New York

231. Lipinski J (2001) Fresenius J Anal Chem 369:57

232. Chai M, Pawliszyn J (1995) Environ Sci Technol 29:693

233. Motlagh S, Pawliszyn J (1993) Anal Chim Acta 284:265

234. Mester Z, Sturgeon R, Pawliszyn J (2001) Spectrochim Acta B 56:233

235. Stashenko EE, Martínez JR (2004) Trends Anal Chem 23:553

236. Ugland HG, Krogh M, Rasmussen KE (1999) J Pharm Biomed Anal 19:463

237. Gmeiner G, Krassnig C, Schmid E, Tausch H (1998) J Chromatogr B 705:132

238. Namera A, Yashiki M, Liu J, Okajima $\mathrm{K}$, Hara $\mathrm{K}$, Imamura $\mathrm{T}$, Kojima $\mathrm{T}$ (2000) Forens Sci Int 109:215

239. Setkova L, Risticevic S, Pawliszyn J (2007) J Chromatogr A 1147:213

240. http://www.ctc.ch

241. Pizarro C, Pérez-del-Notario N, González-Sáiz JM (2007) J Chromatogr A 1166:1

242. Hutchinson JP, Setkova L, Pawliszyn J (2007) J Chromatogr A 1149:127

243. Hook GL, Kimm GL, Hall T, Smith Ph A (2002) Trends Anal Chem 21:534

244. Koziel JA, Novak I (2002) Trends Anal Chem 21:840

245. Augusto F, Valente ALP (2002) Trends Anal Chem 21:428

246. Aulakh JS, Malik AK, Kaur V, SchmittKopplin P (2005) Crit Rev Anal Chem 35:71

247. Peña RM, Barciela J, Herrero C, García-Martín S (2005) Talanta 67:129

248. Flórez Menéndez JC, Fernández Sánchez ML, Fernández Martínez E, Sánchez Uría JE, Sanz-Medel A (2004) Talanta 63:809
249. Burger BV, Marx B, le Roux M, Burger WJG (2006) J Chromatogr A 1121:259

250. Purcaro G, Morrison P, Moret S, Conte LS, Marriott Ph J (2007) J Chromatogr A 1161:284

251. Sánchez A, Millán S, Sampedro MC, Unceta N, Rodríguez E, Goicolea MA, Barrio RJ (2008) J Chromatogr A 1177:170

252. Shu YY, Wang SS, Tardif M, Huang Y (2003) J Chromatogr A 1008:1

253. Huang Y, Yang Y-C, Shu YY (2007) J Chromatogr A 1140:35

254. Chen Y-I, Su Y-S, Jen J-F (2002) J Chromatogr A 976:349

255. Alves RF, Nascimento AMD, Nogueira JMF (2005) Anal Chim Acta 546:11

256. Burbank HM, Qian MC (2005) J Chromatogr A 1066:149

257. Baltussen E, Sandra P, David F, Cramers C (1999) J Microcol Sep 11:737

258. David F, Sandra P (2007) J Chromatogr A 1152:54

259. Picó Y, Fernández M, Ruiz MJ, Font G, Biochem J (2007) Biophys Meth 70:117

260. Kawaguchi M, Ito R, Saito K, Nakazawa H (2006) J Pharm Biomed Anal 40:500

261. Fontanals N, Marcé RM, Borrull F (2007) J Chromatogr A 1152:14

262. Montes R, Rodríguez I, Rubí E, Cela R (2007) J Chromatogr A 1143:41

263. León VM, Llorca-Pórcel J, Álvarez B, Cobollo MA, Muñoz S, Valor I (2006) Anal Chim Acta 558:261

264. Huertas C, Morillo J, Usero J, GraciaManarillo I (2007) Talanta 72:1149

265. Bicchi C, Cordero C, Liberto E, Rubiolo P, Sgorbini B, David F, Sandra P (2005) J Chromatogr A 1094:9

266. Kawaguchi M, Ishii Y, Sakui N, Okanouchi $\mathrm{N}$, Ito $\mathrm{R}$, Inoue $\mathrm{K}$, Saito $\mathrm{K}$, Nakazawa H (2004) J Chromatogr A 1049:1

267. Kawaguchi M, Ishii Y, Sakui N, Okanouchi N, Ito R, Saito K, Nakazawa H (2005) Anal Chim Acta 533:57

268. Kawaguchi M, Inoue K, Yoshimura M, Ito R, Sakui N, Nakazawa H (2004) Anal Chim Acta 505:217

269. Kawaguchi M, Ito R, Sakui N, Okanouchi N, Saito K, Nakazawa H (2006) J Chromatogr A 1105:140

270. Bicchi C, Cordero C, Iori C, Rubiolo P, Sandra P (2000) J High Resolut Chromatogr 23:539

271. Kreck M, Schrarrer A, Bilke S, Mosandl A (2002) Flav Fragr J 17:32

272. Bicchi C, Iori C, Rubiolo P, Sandra P (2002) J Agric Food Chem 50:449

273. Demyttenaere JCR, Moriña RM, Sandra P (2003) J Chromatogr A 985:127

274. Demyttenaere JCR, Moriña RM, de Kimpe N, Sandra P (2004) J Chromatogr A 1027:147

275. Sandra P, Tienpont B, Vercammen J, Tredoux A, Sandra T, David F (2001) J Chromatogr A 928:117

276. Benijts T, Vercammen J, Dams R, Pham Tuan H, Lambert W, Sandra P (2001) J Chromatogr B 755:137
277. Popp P, Keil P, Montero L, Rückert M (2005) J Chromatogr A 1071:155

278. Llorca-Porcel J, Martínez-Sánchez G, Álvarez B, Cobollo MA, Valor I (2006) Anal Chim Acta 569:113

279. Ochiai N, Sasamoto K, Kanda H, Nakamura S (2006) J Chromatogr A 1130:83

280. Sandra P, Tienpont B, David F (2003) J Chromatogr A 1000:299

281. Liu W, Hu Y, Zhao J, Xu Y, Guan Y (2005) J Chromatogr A 1095:1

282. Zalacain A, Martín J, Alonso GL, Salinas MR (2007) Talanta 71:1610

283. Díez J, Domínguez C, Guillén DA, Veas R, Barroso CG (2004) J Chromatogr A 1025:263

284. Kawaguchi M, Inoue $\mathrm{K}$, Yoshimura M, Sakui N, Okanouchi N, Ito R, Yoshimura Y, Nakazawa H (2004) J Chromatogr A 1041:19

285. Lokhnauth JK, Snow NH (2006) J Chromatogr A 1105:33

286. Roy G, Vuillemin R, Guyomarch J (2005) Talanta 66:540

287. Lorenzo C, Zalacain A, Alonso GL, Salinas MR (2006) J Chromatogr A 1114:250

288. Accorsi A, Morrone B, Benzo M, Gandini C, Raffi GB, Violante FS (2005) J Chromatogr A 1071:131

289. Jönsson JA, Mathiasson L (2000) J Chromatogr A 902:205

290. Hylton K, Mitra S (2007) J Chromatogr A 1152:199

291. Kuosmanen K, Hyötyläinen T, Hartonen K, Riekkola M-L (2003) Analyst $128: 434$

292. Knutsson M, Nilvé G, Mathiasson L, Jönsson JÅ, Sundin P (1996) Anal Lett 29:1619

293. Pálmarsdóttir S, Thordarson E, Edholm LE, Mathiasson L, Jönsson JA (1997) Anal Chem 69:1732

294. Melcher RG, Bakke DW, Hughes GH (1992) Anal Chem 64:2258

295. Melcher RG, Bouyoucos SA (1990) Proc Contr Qual 1:63

296. Hyötyläinen T, Lüthje K, RautiainenRämä M， Riekkola M-L (2004) J Chromatogr A 1056:267

297. Hyötyläinen T (2008) J Chromatogr A 1186:39

298. Hauser B, Popp P (2001) J Sep Sci 24:551

299. Yang MJ, Harms S, Luo YZ, Pawliszyn J (1994) Anal Chem 66:1339

300. Pratt KF, Pawliszyn J (1992) Anal Chem 64:2101

301. Shen Y, Pawliszyn J (2001) J Sep Sci $24: 623$

302. Matz G, Kibelka G, Dahl J, Lenneman F (1999) J Chromatogr A 830:365

303. San Juan A, Guo X, Mitra S (2001) J Sep Sci 24:599

304. Brown MA, Miller S, Emmert G (2007) Anal Chim Acta 592:154

305. Rodil R, Schellin M, Popp P (2007) J Chromatogr A 1163:288

306. Oser H, Coggiola MJ, Young SE, Crosley DR, Hafer V, Grist G (2007) Chemosphere 67:1701 
307. Schellin M, Popp P (2003) J Chromatogr A $1020: 153$

308. Hauser B, Schellin M, Popp P (2004) Anal Chem 76:6029

309. Schellin M, Popp P (2006) J Chromatogr A 1103:211

310. Schellin M, Popp P (2005) J Chromatogr A 1072:37

311. Ciucanu I, Chiriac A (2002) J Sep Sci 25:447

312. Wang L, Lord H, Morehead R, Dorman F, Pawliszyn J (2002) J Agric Food Chem 50:6281

313. Liu X, Pawliszyn R, Wang L, Pawliszyn J (2004) Analyst 129:55

314. Allen TM, Cisper ME, PhH Hemberger, ChW Wilkerson (2001) Int J Mass Spectrom 212:197

315. Lloyd D, Thomas KL, Cowie G, Tammam JD, Williams AG (2002) J Microbiol Meth 48:289

316. Tarkiainen V, Kotiaho $\mathrm{T}$, Matilla I, Virkajärvi I, Aristidou A, Ketola RA (2005) Talanta 65:1254

317. Fontanals N, Barri T, Bergström S, Jönsson JA (2006) J Chromatogr A 1133:41

318. Hyötyläinen T, Tuutijärvi T, Kuosmanen K, Riekkola M-L (2002) Anal Bioanal Chem 372:732

319. Liu H, Dasgupta PK (1996) Anal Chem 68:1817

320. Jeannot MA, Cantwell FF (1996) Anal Chem 68:2236

321. Xu L, Basheer Ch, Lee HK (2006) J Chromatogr A 1152:184

322. Wardencki W, Curyło J, Namieśnik J (2007) J Biochem Biophys Meth 70:275

323. Lambropoulou DA, Albanis TA (2007) J Biochem Biophys Meth 70:195

324. Psillakis E, Kalogerakis N (2003) Trends Anal Chem 22:565

325. Psillakis E, Kalogerakis N (2002) Trends Anal Chem 21:53

326. Jeannot MA, Cantwell FF (1997) Anal Chem 69:235

327. He Y, Lee HK (1997) Anal Chem 69:4634

328. Ahmadi F, Assadi Y, Milani Hosseini SMR, Rezaee M (2006) J Chromatogr A 1101:307

329. Liu Y, Hashi Y, Lin J-M (2007) Anal Chim Acta 585:294

330. Theis AL, Waldack AJ, Hansen SM, Jeannot MA (2001) Anal Chem 73:5651

331. Saraji M (2005) J Chromatogr A 1062:15

332. Ouyang G, Zhao W, Pawliszyn J (2005) Anal Chem 77:8122

333. Wood DC, Miller JM, Christ I (2004) LCGC Eur 17:573

334. Dong L, Shen X, Deng Ch (2006) Anal Chim Acta 569:91

335. Zhao E, Han L, Jiang S, Wang Q, Zhou Z (2006) J Chromatogr A 1114:269

336. Wu H-F, Yen J-H, Chin Ch-Ch (2006) Anal Chem 78:1707

337. Palit M, Pardasani D, Gupta AK, Dubey DK (2005) Anal Chem 77:711
338. Michulec M, Wardencki W (2006) Chromatographia 41:191

339. Xiao Q, Hu B, Yu Ch, Xia L, Jiang Z (2006) Talanta 69:848

340. Liu Y, Zhao E, Zhou Z (2006) Anal Lett 39:2333

341. Liu B-M, Malik P, Wu H-F (2004) Rapid Commun Mass Spectrom 18:1059

342. Battle R, Nerín C (2004) J Chromatogr A $1045: 29$

343. Casari C, Andrews ARJ (2001) Forensic Sci Int 120:165

344. Fiamegos YC, Nanos Ch G, Stalikas CD (2004) J Chromatogr B 813:89

345. Colombini V, Bancon-Montigny $\mathrm{Ch}$, Yang L, Maxwell P, Sturgeon RE, Mester Z (2004) Talanta 63:555

346. Przyjazny A, Kokosa JM (2002) J Chromatogr A 977:143

347. Kokosa JM, Przyjazny A (2003) J Chromatogr A 983:205

348. Li N, Deng Ch, Yin X, Yao N, Shen X, Zhang X (2005) Anal Biochem 342:318

349. Tankeviciute A, Kazlauskas R, Vickackaite V (2001) Analyst 126:1674

350. Kawaguchi M, Ito R, Endo N, Okanouchi N, Sakui N, Saito K, Nakazawa H (2006) J Chromatogr A 1110:1

351. Wang $\mathrm{X}$, Jiang $\mathrm{T}$, Yuan $\mathrm{J}$, Cheng $\mathrm{Ch}$, Liu J, Shi J, Zhao R (2006) Anal Bioanal Chem 385:1082

352. Deng Ch, Li N, Wang X, Zhang X, Zeng J (2005) Rapid Commun Mass Spectrom 19:647

353. Tan L, Zhao XP, Liu XQ, Ju HX, Li JS (2005) Chromatographia 62:305

354. Bovijn L, Pirotte J, Berger A (1958) Gas Chromatography, Desty DH (ed), Butterworths, London, p 310

355. Kolb B, Ettre LS (2006) Static headspace-gas chromatography: theory and practice, 2nd edn. Wiley, Chichester

356. Snow N, Slack GC (2002) Trends Anal Chem 21:608

357. Kolb B (2000) Headspace gas chromatography. In: Wilson ID (ed) Encyclopedia of separation science. Academic Press, London, p 489

358. Chaintreau A (2000) Sample preparation, headspace techniques. In: Meyers RA (ed) Encyclopedia of analytical chemistry. Wiley, Chichester, p 4229

359. Dewulf J, van Langenhove H (2002) Trends Anal Chem 21:637

360. Roose P, Brinkman UATh (2005) Trends Anal Chem 24:897

361. Kolb B (1999) J Chromatogr A 842:163

362. Poole C (2003) The essence of chromatography. Elsevier, Amsterdam, The Netherlands, Chapter 3.7.3

363. Cudjoe E, Wiederkehr TB, Brindle ID (2005) Analyst 130:152

364. Narain N, de Sousa Galvão M, Suely Madruga M (2007) Food Chem 102:726

365. Huybrechts T, Dewulf J, Moerman O, van Langenhove $\mathrm{H}$ (2000) J Chromatogr A $893: 367$

366. Roose P, Brinkman UATh (1998) Analyst 123:2167
367. Peña F, Cárdenas S, Gallego M, Valcárcel M (2004) J Chromatogr A 1052:137

368. Serrano A, Gallego M (2004) J Chromatogr A 1045:181

369. Sakata SK, Taniguchi S, Rodrigues DF, Urano ME, Wandermüren MN, Pellizari VH, Comasseto JV (2004) J Chromatogr A 1084:67

370. Otero R, Carrera G, Dulsat JF, Fábregas JL, Claramunt J (2004) J Chromatogr A 1057:193

371. Sowiński P, Wardencki W, Partyka M (2005) Anal Chim Acta 539:17

372. Stambouli A, El Bouri A, Bouayoun T, Bellimam MA (2004) Forensic Sci Int 146S:S191

373. Lucentini L, Ferretti E, Veschetti E, Sibio V, Citti G, Ottaviani M (2005) Microchem J 80:89

374. Roose P, Brinkman UATh (2000) Mar Poll Bull 40:1167

375. Roose P, Brinkman UATh (1998) J Chromatogr A 799:233

376. Roose P, Dewulf J, Brinkman UATh, van Langenhove H (2001) Water Res 35:1478

377. Huybrechts T, Dewulf J, van Langenhove H (2004) Water Res 38:3241

378. Huybrechts T, Dewulf J, van Langenhove H (2005) Environ Poll 133:255

379. Martínez E, Lacorte S, Llobet I, Viana P, Barceló D (2002) J Chromatogr A 959:181

380. Campillo N, Viñas P, López-García I, Aguinaga N, Hernández-Córdoba M (2004) Talanta 64:584

381. Campillo N, Viñas P, López-García I, Aguinaga $\mathrm{N}$, Hernández-Córdoba $\mathrm{M}$ (2004) J Chromatogr A 1035:1

382. Zoccolillo L, Amendola L, Cafaro C, Insogna S (2005) J Chromatogr A 1077:181

383. Mamede MEO, Pastore GM (2006) Food Chem 96:586

384. Tanabe A, Tsuchida Y, Ibaraki T, Kawata K, Yasuhara A, Shibamoto T (2005) J Chromatogr A 1066:159

385. Johns DO, Dills RL, Morgan MS (2005) J Chromatogr B 817:255

386. Tananaki Ch, Zotou A, Thrasyvoulou A (2005) J Chromatogr A 1083:146

387. Campillo N, Aguinaga N, Viñas P, López-García I, Hernández-Córdoba M (2004) J Chromatogr A 1061:85

388. Madrera RR, García NP, García Hevia A, Valles BS (2005) J Chromatogr A 1069:245

389. Fabietti F, Ambruzzi A, Delize M, Sprechini MR (2004) Environ Int 30:397

390. Adahchour M, Beens J, Brinkman UATh (2008) J Chromatogr A 1186:67

391. Hyötyläinen T, Riekkola M-L (2007) Trends Anal Chem 26:788

392. Smith RM (2003) J Chromatogr A 1000:3

393. Kristensson M (2005) $\mathrm{PhD}$ Thesis, Chap. 1.3, Free University, Amsterdam 